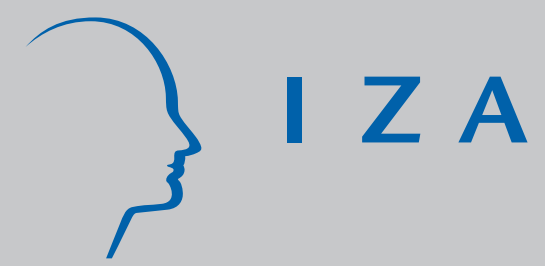

IZA DP No. 8412

Grades and Rank: Impacts of Non-Financial Incentives on Test Performance

Nina Jalava

Juanna Schrøter Joensen

Elin Pellas

August 2014

Forschungsinstitut zur Zukunft der Arbeit Institute for the Study of Labor 


\title{
Grades and Rank: Impacts of Non-Financial Incentives on Test Performance
}

\author{
Nina Jalava \\ Stockholm School of Economics \\ Juanna Schrøter Joensen \\ Stockholm School of Economics \\ and IZA \\ Elin Pellas \\ Stockholm School of Economics \\ Discussion Paper No. 8412 \\ August 2014 \\ IZA \\ P.O. Box 7240 \\ 53072 Bonn \\ Germany \\ Phone: +49-228-3894-0 \\ Fax: +49-228-3894-180 \\ E-mail: iza@iza.org
}

Any opinions expressed here are those of the author(s) and not those of IZA. Research published in this series may include views on policy, but the institute itself takes no institutional policy positions. The IZA research network is committed to the IZA Guiding Principles of Research Integrity.

The Institute for the Study of Labor (IZA) in Bonn is a local and virtual international research center and a place of communication between science, politics and business. IZA is an independent nonprofit organization supported by Deutsche Post Foundation. The center is associated with the University of Bonn and offers a stimulating research environment through its international network, workshops and conferences, data service, project support, research visits and doctoral program. IZA engages in (i) original and internationally competitive research in all fields of labor economics, (ii) development of policy concepts, and (iii) dissemination of research results and concepts to the interested public.

IZA Discussion Papers often represent preliminary work and are circulated to encourage discussion. Citation of such a paper should account for its provisional character. A revised version may be available directly from the author. 


\begin{abstract}
Grades and Rank: Impacts of Non-Financial Incentives on Test Performance ${ }^{1}$

How does effort respond to being graded and ranked? This paper examines the effects of non-financial incentives on test performance. We conduct a randomized field experiment on more than a thousand sixth graders in Swedish primary schools. Extrinsic non-financial incentives play an important role in motivating highly skilled students to exert more effort. We find significant differences in test scores between the intrinsically motivated control group and three of four extrinsically motivated treatment groups. The only treatment not increasing test performance is criterion-based grading on an A-F scale, which is the typical grading method. Test performance is significantly higher if employing rank-based grading or giving students a symbolic reward. The motivational strengths of the non- financial incentives differ across the test score distribution, across the skill distribution, with peer familiarity, and with respect to gender. Boys are only motivated by rank-based incentives, while girls are also motivated by receiving a symbolic reward. Rank-based grading and symbolic rewards tend to crowd out intrinsic motivation for students with low skills, while girls also respond less to rank-based incentives if tested with less familiar peers.
\end{abstract}

JEL Classification: $\quad$ 120, 121, D03, C93

Keywords: test-taking, performance incentives, effort, extrinsic and intrinsic motivation, randomized experiment

Corresponding author:

Juanna Schrøter Joensen

Department of Economics

Stockholm School of Economics

Sveavägen 65

Box 6501

SE 11383 Stockholm

Sweden

E-mail: Juanna.Joensen@hhs.se

\footnotetext{
${ }^{1}$ We would like to express our gratitude to the teachers and students who made this project possible through participating in the experiment - thanks for your time and collaboration. This paper also benefited from discussions with José Araújo, Ghazala Azmat, Tore Ellingsen, David Figlio, Jonathan Guryan, Krista Jonvør Schrøter Joensen, and participants at the workshop on Self-Control, SelfRegulation and Education in Aarhus. The usual disclaimer applies.
} 


\section{Introduction}

Student performance is tightly linked to student motivation and effort. Improving student performance is a key educational policy issue to which much time and resources are devoted. Student quality is typically assessed by the performance on various tests, yet little is known about student motivation and effort in test situations. A better understanding of how students respond to different test setups and different incentives can benefit the equity and efficiency of the educational system, as test performance only reflects true student quality if incentives are appropriately aligned. Low student test effort among some students could thus create substantial biases in the measure of student quality often underlying high-powered incentive schemes such as school accountability systems, the distribution of school resources, as well as teacher value added and performance pay.

Grading students is used as a screening device in school admission procedures. Grading may ensure effective communication of student performance between schools and families, so students may be more efficiently tracked and students who require additional assistance are identified and can receive necessary support. But what are the short-term consequences of grading on student motivation and effort? How does student effort respond to being graded - particularly on a test that is low-stake for the students but can carry high stakes for the teachers and schools administrating the test? What if we introduce alternative ways of incentivizing students?

In this paper, we analyze the effects of grading and non-financial extrinsic incentives on student effort on a math test. A field experiment is conducted on 1,045 sixth grade students to evaluate how short term effort can be affected by students receiving different information on the assessment of the test. We focus exclusively on evaluating non-financial means of incentivizing students, since these are relatively uncontroversial and widespread in many grading schemes and educational settings. Additionally, primary school students are found to respond strongly to immediate non-financial incentives (Levitt et al., 2012). It is, however, not known which non-financial incentives are most effective at raising student effort. The incentives we analyze are: (1) students receiving criterion-based grades A-F, 
(2) students receiving grade A if they are among the top three performing students in their class, (3) students receiving a certificate if they exceed the criterion-based score for A-B, and (4) students receiving a prize if they are among the top three performing students in their class. We randomize within the classroom and provide students with information regarding the nature of the test immediately before they start. However, the true purpose of the test is revealed only afterwards. Student treatment assignment is private information. As the students have no possibility to prepare for the test, we are able to isolate the role of effort from other factors affecting test performance. Tests are conducted in the students' natural learning environment to resemble the low-stake tests students are taking at several schooling stages; e.g. widespread national school accountability tests and international tests like the Programme for International Student Assessment (PISA) and the Trends in International Mathematics and Science Study (TIMSS). As these tests may be high-stake for schools and teachers, it is important that students exert effort in order for the test to reflect student ability. We also compare these different non-financial incentive designs in different school settings - spanning low and high performing schools, as well as schools with diverse student socioeconomic backgrounds. To the best of our knowledge, this is the first paper to directly evaluate and compare the incentive effects of the standard criterion-based grades A-F, as well as the incentive effects of introducing rank-based grading through tournaments within the classroom.

We find that the impacts vary substantially by student skill level. ${ }^{2}$ For highly skilled students, the intrinsically motivated students in the control group provide as much test effort as those graded according to the typical A-F grading scale; i.e. treatment (1). Test performance is, however, significantly higher if employing rank based grading or giving students symbolic rewards; i.e. treatments (2)-(4). We further find that motivational strengths of the non-financial incentives differ across the test score distribution and with respect to gender. Boys only increase their performance when facing rank-based grading. Girls respond as strongly to rank-based grading, but they also respond strongly to being

\footnotetext{
${ }^{2}$ Note that skill level denotes student placement on the learning trajectory, while ability denotes student placement in the underlying math ability distribution at any given point on the learning trajectory. Highly skilled students are thus those who have been exposed to more math teaching, while lower skilled students have learned less math.
} 
rewarded a certificate. The average treatment effects are between a third and half a standard deviation. The non-financial incentives primarily work by making the students in the two middle quartiles of the ability distribution exert more effort on the test. For students with lower skill levels, however, there is no significant effect of non-financial incentives. We observe the tendency that rank-based grading and symbolic rewards crowd out intrinsic motivation, as the extrinsic incentives significantly decrease test scores for the students in the bottom decile of the ability distribution where more students do not exert any effort on the test. This effect is somewhat mitigated if students have been with the same peer group for at least a school year.

By approaching the issue of student motivation and performance from a behavioral economics perspective, we are able to achieve a better understanding of student motivation and effort in test situations and understand how students react to different incentives. Our results call into question the current structure of the educational system in motivating highly skilled students in test situations and suggest that alternative non-financial incentives may increase student effort and lead to better educational outcomes. Another aspect to consider is familiarity with peers and their skills, as students tend to respond differently when they are tested at an earlier stage of their learning trajectory and with a new peer group. This has considerable policy implications, as it suggests that it is pivotal to take peer familiarity, the student skill level, and the student ability distribution into account when implementing incentives and evaluating their effectiveness. Otherwise, distributing resources based on test scores may lead to inefficient allocation of resources as some students exert low effort and test scores do not reflect true student ability and quality.

The remainder of this paper is organized as follows: Section 2 relates our paper to previous literature. Section 3 sets up the theoretical framework and testable predictions. Section 4 lays out the experimental design and implementation. Sections 5 and 6 present the experimental data and the empirical results. Finally, sections 7 and 8 provide a discussion and conclusion. 


\section{Background}

The distinction between intrinsic and extrinsic motivation is fundamental in an educational setting. Intrinsic motivation refers to motivation coming from within the students themselves and is driven by an interest in, or enjoyment of, the task itself. Extrinsic motivation relies on external factors as a driving force for motivating the students. Many studies on motivating students extrinsically have used financial means as a method of motivating; paying students has been shown to result in better performance (Bettinger and Slonim, 2007; Eisenkopf, 2011; Fryer, 2011; Bettinger, 2012; Levitt et al., 2012). Opponents worry that the introduction of extrinsic incentives can have a detrimental effect on students' future performance, as extrinsic motivation may crowd out intrinsic motivation. Especially for young students, tangible rewards seem to have a stronger detrimental effect on intrinsic motivation than for college students (Deci et al., 1999). However, neither Levitt et al. (2012) nor Bettinger and Slonim (2007) find evidence that extrinsic incentives are detrimental to primary school students' intrinsic motivation and test performance.

Extrinsic motivation can come in many different forms. While a majority of research has focused on the implementation of financial rewards, there is evidence that the effect of non-financial rewards can be considerable. Kosfeld and Neckermann (2011) find that nonfinancial rewards such as awards or trophies can have significant motivational power in the workplace, since awards yield non-material benefits in the form of social recognition, status, and improved self-esteem (Weiss and Fershtman, 1998; Ellingsen and Johannesson, 2007). Besley and Ghatak (2008) find that status incentives increase effort while reducing the optimal level of financial incentives. Levitt et al. (2012) directly compare the effects of financial and non-financial rewards on short-term student effort and performance. They find that giving primary school students a trophy leads to as large an increase in test performance as financial rewards in the range of USD 10-20. However, how do the effects of different non-financial incentives on test effort compare?

Ranking students by their performance is another tool that can be used as a source 
of motivation, as rank in itself may work as a major motivator. Tran and Zeckhauser (2012) confirm that the desire to rank highly has a measurable impact on behavior, while Delfgaauw et al. (2013) find a high symbolic value of winning a tournament and a measurable increase in retail store sales when tournament incentives are in place. Rank can be used by students to impress friends and family and to earn respect and admiration, which can be seen as tangible benefits. Students may also be directly psychologically rewarded by higher rank without the need for any tangible benefits. Students who receive rank publicly outperform those who receive their rank privately, but even when ranking information cannot be reliably communicated Tran and Zeckhauser (2012) find an effect on performance. Rank as a motivator in school can often be seen in the form of normreferenced grading, where students are assigned grades relative to the performance of other students. Azmat and Iriberri (2010) show that high school students receiving relative rank feedback increase short-term performance, while Murphy and Weinhardt (2013) also show an increase in secondary school performance by having a higher primary school rank. However, it is still an open question whether rank-based grading incentives in the form of a tournament affect student test effort.

Wise and DeMars (2005) discuss a number of potential assessment practices for managing the problems posed by low student motivation leading to lower test performance. The issue of students not exerting full effort on a test is of critical importance to assessment practitioners, as the results will tend to underestimate the students' true ability. Wise and DeMars (2005) show that motivation is an essential factor in test performance and that higher motivation is associated with higher test scores. Motivation is therefore an important factor in eliciting test results that accurately reflect a student's true ability and knowledge.

Students tend to exert low effort on standardized tests in the absence of immediate incentives (Attali et al., 2011; Levitt et al., 2012). These standardized tests are often of little importance to the students (i.e. low-stake tests) but may have important consequences for the teachers and schools (e.g. in the form of allocation of resources) and are as such high-stake tests for the teachers and the schools. Attali et al. (2011) show that 
males exhibit a larger difference in performance between low and high-stake tests than females, and also find that students with a higher socioeconomic status showed larger differences in performance. Levitt et al. (2012) find that the effects of introducing extrinsic motivators are larger for boys than for girls; i.e. boys are more responsive to short-term incentives than girls. This suggests that girls may be more intrinsically motivated, and therefore also be at a higher risk of crowding out. In their experiment of around 6,500 primary and high school students, Levitt et al. (2012) examine various types of motivators; including financial and non-financial incentives, immediate rewards and rewards handed out with a delay, as well as rewards framed as losses. They find that incentives framed as losses - giving the reward before the test and taking it back if test scores are not improved - have a stronger effect than other incentives, and that non-financial incentives are effective on primary school students but have little effect on older students. They also find that delayed rewards have no motivational power. This has important implications for the way the educational system is currently set up, with almost all feedback coming with a delay. Our study complements Levitt et al. (2012) as they only evaluate one nonfinancial incentive - a trophy for improved test performance - whereas we compare the impacts of four non-financial incentives representing different ways of grading and different immediate rewards. Our estimated average treatment effects range from being as large or larger (0.33 - 0.45 standard deviations) for highly skilled students to smaller than theirs for low-skilled students. This could both be due to the nature of the incentives, the element of competition relative to one's peers inherent in two of our treatments, and as highlighted by the theoretical framework in the following section and in Section 6 which part of the students' learning trajectory the test is administered at. ${ }^{3}$

In a related paper, Baumert and Demmrich (2001) aim at increasing around 500 German ninth grade students' stake on a shorter version of the PISA test through both financial and non-financial incentives. Their three non-financial incentives entail getting information on the importance of the test, later performance feedback from their math

\footnotetext{
${ }^{3}$ Their tests are administered in the fall, winter, and spring, and their outcome is test score improvement relative to baseline test score one or two trimesters earlier. Our outcome is the test score, benchmarked by the control group test score at the same test occasion. This way we avoid issues of noisy test scores and regression to the mean (Kane and Staiger, 2002; Chay et al., 2005).
} 
teacher, and making the test count towards their math course grade. They do not find any significant average treatment effects. This could be because rewards are experienced with a delay (Levitt et al., 2012), but our results suggest that this could also be because the students were unfamiliar with the test tasks or because their treatment is based on a criterion-based grading scale.

Lastly, our paper is also related to the literature on educational and grading standards (Becker and Rosen, 1992; Costrell, 1994; Betts, 1998; Betts and Grogger, 2003; Figlio and Lucas, 2004) and the timing of grading (Sjögren, 2010; Facchinello, 2014) focusing on the longer-term impacts of grading (standards) on educational choices and labor market performance. We contribute to this literature by isolating the short-term test effort effect and providing internally valid estimates of the differential impacts of criterion- and reference-based grading methods on test performance.

This background motivates and formulates our research question: How can students be incentivized to exert higher effort on tests without crowding out intrinsic motivation? We contribute to the literature by evaluating different non-financial methods of incentivizing primary school students, comprising different grading methods and symbolic rewards. Even if students are being tested and graded increasingly often, there is a prominent gap in research on student test-taking motivation. We analyze how test scores of extrinsically incentivized students differ from those of intrinsically motivated students, both on average and across the distribution. We focus exclusively on non-financial incentives. We also analyze how the incentive effects differ with respect to skill level, gender, and peers. To the best of our knowledge, this is the first paper to (i) directly evaluate test effort induced by standard A-F criterion-based grading, (ii) evaluate test effort responses to rank-based grading through tournaments, as well as (iii) directly compare these grading methods.

\section{Theoretical Framework}

Our experimental results can be interpreted through the lens of a simple version of Becker's Woytinsky lecture model (Becker, 1967). Students are endowed with ability 
(reflecting actual math knowledge) and have to decide how much effort to put into the low-stake test. Test scores are determined by ability, $a_{i}$, effort, $e_{i}$, and a random term, $\epsilon_{i}$, capturing how sharp and lucky the student is when taking the test:

$$
T S_{i}=\gamma_{0}+\gamma_{1} a_{i}+\gamma_{2} e_{i}+\epsilon_{i}
$$

Test scores are increasing in ability and effort, hence $\gamma_{1}>0$ and $\gamma_{2}>0$. Ability is fixed in the test situation, since the teachers are not informed about the exact nature of the test and the students are not informed about the test taking place until the outset of the class in which it is conducted. Students have no participation decision, as all of them have to sit at their desk during the ten minutes of the test duration. This enables us to isolate the impacts of extrinsic incentives on test performance through effort.

Students care about the effort they have to put into the test, as it may be inherently costly to exert effort. Let $c(e)$ denote the cost of effort. We assume the cost function is twice continuously differentiable, increasing, and convex: $c^{\prime}(e) \geq 0$ and $c^{\prime \prime}(e) \geq 0$, implying that increasing marginal effort is even more costly when already exerting a high effort. We set $c(0)=0, c^{\prime}(0)=0$, and $c^{\prime \prime}(0)=0$. Students also care about the reward they get from the test, $R$. To provide a simple example of how extrinsic incentives work in this model, we assume this reward is only achieved if the test score exceeds a predetermined cut-off, $T S_{i} \geq \overline{T S} .^{4}$ Let $F_{\epsilon}$ denote the cumulative distribution function (CDF) and $f_{\epsilon}$ the probability density function (pdf) of $\epsilon$. Students choose effort to maximize utility:

$$
\max _{e_{i}}\left\{\left(1-F_{\epsilon}\left(\overline{T S}-\gamma_{0}-\gamma_{1} a_{i}-\gamma_{2} e_{i}\right)\right) R-c\left(e_{i}\right)\right\}
$$

subject to $e_{i} \geq 0$. Optimal effort, $e_{i}^{*}$, equates marginal benefits with marginal costs and is characterized by:

$$
e_{i}^{*}\left[f_{\epsilon}\left(\overline{T S}-\gamma_{0}-\gamma_{1} a_{i}-\gamma_{2} e_{i}^{*}\right) \gamma_{2} R-c^{\prime}\left(e_{i}^{*}\right)\right]=0,
$$

\footnotetext{
${ }^{4}$ Allowing students to care about their test scores would not change the insights from this simple model. Caring about learning and test performance will be captured in the cost function in this static test setting.
} 


$$
c^{\prime}\left(e_{i}^{*}\right) \geq f_{\epsilon}\left(\overline{T S}-\gamma_{0}-\gamma_{1} a_{i}-\gamma_{2} e_{i}^{*}\right) \gamma_{2} R
$$

and $e_{i}^{*} \geq 0$. The marginal benefit here comes exclusively from the probability of receiving the reward for achieving a test score higher than $\overline{T S}$, while the marginal cost comes from increasing effort. If the marginal benefit is too low or the marginal cost is too high, then the student will optimally exert no effort on the test, $e_{i}^{*}=0$.

A reduction in intrinsic motivation can be interpreted as an increase in the cost of effort. If student effort cost is increased, students will exert less effort on the test and more students will exert no effort.

A more valuable reward (increased $R$ ) means that it will be worth it to increase effort for some students, while a less valuable reward (decreased $R$ ) similarly will decrease effort for some students. This is easy to illustrate: Ability is fixed in the test setting, but students choose how much effort to exert. How does optimal effort depend on ability? What happens if we introduce (or increase) rewards for high performance? Assume for simplicity that both the random term and ability are normally distributed. Firstly, students with very high ability, $a_{i} \geq \bar{a}$, will not be affected by the increased reward as they still do not have to change their optimal effort in order to attain the reward. Their optimal effort will still be positive though, $e_{i}^{*}>0$. Secondly, students at the margin, $\underline{a} \leq a_{i} \leq \bar{a}$, will increase their effort in response to the increased reward, $e_{i}^{*}>0$. Lastly, low ability students, $a_{i} \leq \underline{a}$, with too low ability to have a positive probability of attaining the reward will choose not to exert any effort on the test, $e_{i}^{*}=0$. This is illustrated in Figure 1.

\subsection{Reward Threshold and Skills}

A more interesting situation in our experimental setting is what happens if we increase the cut-off for attaining the reward. Increasing competitiveness can be seen as making the reward harder to attain; increase $\overline{\overline{T S}}>\overline{T S}$. This means that there will still be some students with very high ability, $a_{i} \geq \overline{\bar{a}}$, for which optimal effort stays the same, $e_{i}^{* *}=e_{i}^{*}>0$, while students with ability, $\bar{a} \leq a_{i} \leq \overline{\bar{a}}$, will have to exert more effort in order to attain the reward, $e_{i}^{* *}>e_{i}^{*}>0$, students with ability, $\underline{\underline{a}} \leq a_{i} \leq \bar{a}$, exert 
the same positive effort as before, and students with ability below $\underline{\underline{a}}$ will exert minimal effort, $e_{i}^{* *}=0$. Some of these also exerted minimal effort before the increase, but some of them (those with $\underline{a} \leq a_{i} \leq \underline{\underline{a}}$ ) exerted a higher effort. Overall, we thus see that a higher threshold $(\overline{\overline{T S}} \geq \overline{T S})$ will make some high ability students (those with $\bar{a} \leq a_{i} \leq \overline{\bar{a}}$ ) increase their effort, while it will decrease the effort of some lower ability students. This is illustrated in Figure 2. Whether we estimate a positive or negative average effect of this increase in reward threshold depends on how many students are in the two grey shaded areas, L and H. If more students are in the part of the ability distribution marked with $\mathrm{L}$, then we will estimate a negative average effect. If more students are in the part of the ability distribution marked with $\mathrm{H}$, then we will estimate a positive average effect. We can thus get an estimate of distributional effects by analyzing how extrinsic incentives affect student test scores across the distribution. This prediction is tested throughout Section 6.

As this model illustrates how the effects of extrinsic incentives vary with student ability, it also shows how the same test incentives can have different overall effects depending on the skill level of the students as learning more math increases math ability. If $\overline{T S}$ is set too high, then the reward will not necessarily induce more students to exert effort and we will instead see more students optimally exerting no effort. As this is equivalent to shifting the ability distribution downwards, the same predictions emerge if the average skill level is lower (e.g. shifted from $f_{a_{H}}$ to $f_{a_{L}}$ in Figure 2) or the test is made more difficult. This model thus predicts different impacts of the same incentives depending on whether the test is given towards the end of the school-year (when students should have acquired all the skills necessary to successfully solve all test items) or at the beginning of the school-year (when students have not yet been taught how to solve all test items). At the end of the school-year (first wave) the students have a higher skill level and the model predicts a higher average increase in effort, thus also a higher increase in test scores as more students get encouraged to increase their effort when facing the non-financial incentives. At the beginning of the school year (second wave) the students have a lower skill level and, if it is too low, the model predicts that more students may get discouraged 
compared to how many get encouraged. If this is the case, we may actually estimate an average decrease in test scores. The model thus illustrates that the size and direction of incentive effects is closely linked to the student skill level. This prediction is tested in Section 6.1 exploiting the fact that we test students at different points in their learning trajectory.

\subsection{Rank-Based Rewards and Peer Familiarity}

A simple extension of the model also illustrates how the incentive effects of rank-based grading depend on peer familiarity. The illustration above assumes an exogenously set criterion-based (or absolute) threshold similar to our treatments 1 and 3. The model is easily adapted to a rank-based (or relative) grading scheme, where the threshold will be endogenously determined as it depends on the ability and effort of peers. Even if the solution becomes more involved, all the basic predictions go through. ${ }^{5}$ We simply illustrate this assuming there are only two students in the class, $i$ and $j$, and the reward is only received by the highest ranked student. Student $i$ thus only receives the reward if performing better than student $j$, i.e. if $T S_{i} \geq T S_{j}$, and seeks to choose effort to maximize utility given by:

$$
\max _{e_{i}}\left\{\left(1-F_{2 \epsilon}\left(\gamma_{1}\left(a_{j}-a_{i}\right)+\gamma_{2}\left(e_{j}-e_{i}\right)\right)\right) R-c\left(e_{i}\right)\right\}
$$

subject to $e_{i} \geq 0$. Student $j$ solves the mirror image of this maximization problem. First, note that the rank-based grading problem in (5) is equivalent to the criterion-based grading problem in (2), but with the exogenous threshold, $\overline{T S}$, replaced by $\gamma_{1} a_{j}+\gamma_{2} e_{j}$. In this sense the new threshold for receiving the reward is endogenous, as it depends on the other student's ability and effort choice. Each student's effort choice thus becomes a best response to what the other student will do. Second, note that the constant $\gamma_{0}$ cancels out when only students' relative performance on the test matters. Third, note that uncertainty is higher with rank-based grading as $F_{\epsilon}$ in $(2)$ is replaced by $F_{2 \epsilon}$ which

\footnotetext{
${ }^{5}$ This setup is similar to the rank-order tournament model introduced by Lazear and Rosen (1981)
} 
is the CDF of $\epsilon_{i}-\epsilon_{j}$. Assuming that the random terms are independently and identically normally distributed with mean 0 and variance $\sigma^{2}$, the difference between the random terms will also be normally distributed with mean 0 and variance $2 \sigma^{2}$. The increased uncertainty simply means that increasing effort with rank-based grading does not increase the probability of receiving the reward by as much as increasing effort with criterion-based grading. Otherwise, all the basic insights from the solution (3) above go through. The only caveats are that as uncertainty increases, the reward threshold becomes endogenous, $\gamma_{1} a_{j}+\gamma_{2} e_{j}$, and information about one's peers' ability therefore becomes important with rank-based grading similar to our treatments 2 and 4. Just to give a brief overview: If students have the same ability, $a_{i}=a_{j}$, and also face the same effort cost, then the noncooperative solution implies that both choose the same optimal effort, $\tilde{e}_{i}=\tilde{e}_{j}$. Rankbased grading with identical ability students amounts to a zero sum game, where both ex-ante choose to exert equally much test effort and the ex-post outcome is like flipping a fair coin. If ability is heterogeneous, however, the student with higher ability has a higher probability of being the highest ranked. This is equivalent to the case with an exogenous threshold, $\overline{T S}$, where the higher ability students do not have to increase effort to be above the threshold and receive the reward. There will again be some students with very low ability relative to their peers who will have a zero probability to be highest ranked, even if exerting maximal effort, and will therefore exert minimal effort, $\tilde{e}_{i}=0$. This prediction that the expectation of peer ability is important for effort responses to rank-based grading is tested in Section 6.2 by exploiting the fact that some students have more information about the peers they are competing with than others. We hypothesize that those who have spent at least a school year in the same classroom as their peers will have a more precise estimate of their peers' ability, thus they face less uncertainty about the endogenous threshold and their effort will respond more strongly to rank-based grading incentives. 


\section{Empirical Strategy}

In this section we explain the experimental design and its implementation, the school environment, and the construction of treatment variables.

\subsection{Experimental Design}

We conducted a randomized field experiment to investigate the motivational power of nonfinancial incentives on primary school students. Students in the experiment were assigned to one out of five groups; either to an unincentivized control group or to an incentivized treatment group. By randomly allocating the control and four different treatments within each class, we are able to examine the effect of one incentivizing factor at a time, and minimize the impact of endogenous variables such as family, school, and class-specific factors. Students were offered no choice in whether to participate or not, and therefore we eliminate the potential sample selection bias that could arise with voluntary participation and self-selection. The randomization process means that we obtain groups that are statistically equivalent to each other, and we can thereby simply compare the difference between the means of the treatment groups and the control group to obtain internally valid estimates of the average causal effect of treatment (ATE).

Although the experimental approach circumvents the problem of selection bias and offers the virtue of internal validity, it does bring some potential issues regarding environmental dependence and replicability. We can not guarantee that our results would hold if the experiment were to be repeated in a different context. As our experimental design poses a threat to external validity, its results should best be interpreted as what can happen but not necessarily what will happen in an external environment where other variables are free to operate without being tightly controlled.

To ensure the robustness of our results, we also present estimates where we control for factors differing at the time of the test, gender, peer familiarity, class size, and schoolspecific factors. These are factors that may causally affect the outcome variable. To assess heterogeneity of treatment effects and external validity we also present estimates 
separately by gender, skill level, and peer familiarity.

\subsection{Implementation and School Environment}

The experiment was conducted on Swedish primary school students. We chose to include sixth graders because it is the last year of primary school in Sweden. Primary school is made up of grades one through six, with secondary school following for grades seven through nine. These grades all comprise compulsory schooling. Another reason for choosing sixth graders is the recent (in 2012) reintroduction of grading for sixth graders in Sweden. ${ }^{6}$ Previously, students received grades only once they reached eighth grade of secondary school. Now a comprehensive Swedish national exam is administered to all sixth grade students in order to assure uniform and fair grading. The test is administered by the Swedish National Agency for Education (Skolverket) and provides a basis for evaluating the extent to which knowledge requirements are met at the teacher level, the principal level, the school level, and the national level. The test is also meant to assure that the curriculum is fostering the desired knowledge requirements and learning outcomes. Students are typically 12 years old when entering sixth grade and most become teenagers during this school year. Sixth grade is thus considered a critical stage in the student transition from primary to secondary school.

The experiment was carried out on 1,045 sixth grade students in a total of 47 classes in 17 schools in the Stockholm municipality. Each school in the City of Stockholm's directory of compulsory schools was given a number, and with the aid of an online randomizer, we randomly selected the set of schools to contact. Teachers were contacted by telephone and asked to participate in our experiment. The sessions were usually carried out one to two weeks after the phone call was made. Out of 22 contacted schools in total, 10 accepted in the first wave and all schools accepted in the second wave. The only expressed reason for not participating was the heavy student workload, however we assess that this would have been more or less equivalent irrespective of school. We do not suspect that the teachers' choice of participating should have led to a biased sample, as all participating and

\footnotetext{
${ }^{6}$ Swedish sixth graders have not been graded since 1982. Sjögren (2010) and Facchinello (2014) analyze the impacts of the gradual abolishment of grades for younger students.
} 
non-participating schools showed a similar wide variety of school-specific characteristics. Furthermore, teachers received limited information on the specifics of the experiment. We therefore see the choice of accepting or declining as random, or at the very least not correlated with the nature of the experiment. Schools accepting the study are represented both on the high-performing and low-performing ends of the spectrum, and are diverse with respect to geographic location and socioeconomic factors.

The first wave of the experiment took place in April 2013 and the second wave of the experiment took place at the end of August and beginning of September 2013. The experiment was carried out during scheduled lecture hours and consisted of a standardized mathematical test containing four tasks giving a maximum of 22 points in total. The tasks matched the level of difficulty of tasks in the Swedish national tests for sixth grade. Furthermore, they were designed with support from educated primary school teachers not present at any of the schools where the experiment was conducted. They were formulated in such a way as to allow efficient and impartial grading. The students in the two waves were presented with identical tests and we verify that there was no grade retention. Thus it was primarily student preparation relative to the fixed test difficulty that changed between the two waves and no student took the test twice.

All sessions were introduced and conducted by us while in the presence of the teacher, thus encouraging students to perceive the experiment as formal. This was done to establish commitment to the task and to encourage students to take the test seriously. Special care was taken to ensure that the experiment was presented in an equal, or at least in a very similar, way for all classes. The aim was for the experiment to be perceived equally by all participating students. Some students may have viewed the test as more important than others and as such applied more effort, but overall, no systematic deviations should exist between the groups.

In each class, we randomly assigned students to control and treatment groups by handing out tests with differing information concerning the assessment of their performance. We did this in a randomized fashion. To prevent any kind of preparation, teachers had received limited information regarding the formalities of the test. Just before the test 
started, we stressed the importance of solving the test individually, in silence, and of carefully reading all the information provided. Students were given ten minutes to solve the test. Questions regarding how to think about the problems were responded to with the same, limited information. We asked students to remain seated with the test in front of them until the ten minutes had passed, thus avoiding any potential benefit that could arise from finishing the test early.

When the time had passed, we immediately collected and corrected the tests. Subsequent to the assessment, we returned to the classroom and qualifying students received their rewards. The class was also told the purpose of the test and our experiment, and students were able to take a look at their test score.

\subsection{Treatment Variables}

The treatment variables we evaluate reflect our interest in analyzing extrinsic incentives in the educational setting. All treatments are non-financial and we also analyze the effect of norm and criterion-based grading.

Table 1 displays a summary of the four treatments. All students received the same test, but at the top of the test, students received different information depending on their group assignment. Subjects in the control group received no information regarding the assessment of the test. The only information they received was the total amount of points obtainable - information which was also given to all the four treatment groups. Subjects in treatment group 1 were further informed that their performance would be graded on the scale A-F. They were also given the scale of points corresponding to each grade. Subjects in treatment group 2 were informed that the top three performing students in the class would receive the grade A. Subjects in treatment group 3 were informed that obtaining a score of 18 or above would result in receiving a certificate. Subjects in treatment group 4 were informed that the top three performing students would receive a prize. Table 2 displays the literal test assessment information given to the students. Students are solely informed about their private treatment status and know nothing about the other treatments. 
Table 1: Control group and Treatment groups with corresponding Incentives

\begin{tabular}{lcccccc}
\hline \hline Group & Grade A-F & Grade A & Certificate & Prize & Criterion & Norm / Top 3 \\
\hline Control & & & & & & \\
Treatment 1 & $\times$ & & & & $\times$ & \\
Treatment 2 & & $\times$ & & & & $\times$ \\
Treatment 3 & & & $\times$ & & $\times$ & \\
Treatment 4 & & & & $\times$ & & $\times$ \\
\hline
\end{tabular}

The treatments for group 1 and group 3 relate to the theory of criterion-referenced grading, which involves determining a grade by comparing a student's achievement with clearly stated criteria for learning outcomes for a particular skill level. The groups differ with respect to assessment as group 1 receives grading and group 3 receives a certificate. We are interested in comparing the effects of grades as incentives to those of a symbolic reward such as a certificate. In group 3, a test score of 18 or above is the required level of achievement in order to receive a certificate. We chose 18 points as the cut-off threshold as this is determined to be attainable by most students through exerting higher effort and corresponds to receiving at least a B in group 1. We also compare criterion-based grading to norm-referenced grading, in which a student's grade is based on their relative ranking within a particular group of students. Norm-referenced grading involves fitting a ranked list of students' scores to a pre-determined distribution for rewarding grades. This type of grading can be seen in treatment groups 2 and 4, where it is stated that only the top three performing students will be rewarded. Norm-referenced grading can be used as a motivation tool as it speaks to the students' desire to be ranked highly. It has been shown that students who receive information on their relative rank outperform those who do not (Azmat and Iriberri, 2010; Tran and Zeckhauser, 2012). Comparing treatment groups 2 and 4, we can assess whether the nature of the reward - the non-material grade A versus the material prize - matters when employing norm-referenced grading based on students' relative rank within their class.

We choose these treatments because of our interest in comparing the differing effects of intrinsic incentives and the traditional incentive of grades without ranking to those of alternative incentives such as certificates, prizes, and grades with ranking. The choice of 
Table 2: Information regarding Test Assessment

\section{Control group}

On this test you can obtain a total of 22 points.

\section{Treatment group 1}

On this test you can obtain a total of 22 points.

If you obtain 21-22 points you will receive grade A.

If you obtain 18-20 points you will receive grade B.

If you obtain 15-17 points you will receive grade C.

If you obtain 12-14 points you will receive grade D.

If you obtain 10-11 points you will receive grade E.

If you obtain 0-9 points you will receive grade $\mathrm{F}$.

\section{Treatment group 2}

On this test you can obtain a total of 22 points.

If you are among the three with the highest score in the class you will receive grade A.

\section{Treatment group 3}

On this test you can obtain a total of 22 points.

If you obtain 18 points or more you will receive a certificate.

\section{Treatment group 4}

On this test you can obtain a total of 22 points.

If you are among the three with the highest score in the class you will receive a prize.

a certificate as reward reflects an interest in analyzing non-material status rewards, as

Kosfeld and Neckermann (2011) and Levitt et al. (2012) found these types of rewards to have a significant impact and motivational power. The prize (a simple refillable pencil) is the only material reward and is therefore used to compare materialistic incentives to non-materialistic incentives. The nature of the prize was only revealed after completion of the test, thus avoiding potential issues with differences in student preferences.

\section{Data}

The experiment was carried out on a total of 1,104 students, but due to implementation difficulties in one of the schools, we have chosen to exclude the data collected in that particular school from our dataset. The experiment was unsupervised in one of three classes and students had been given prior, misleading information about the test and its implications before our arrival at the school. Including these observations could thus lead to biased estimates, however, we have confirmed that including them does not change our conclusions. Our dataset therefore consists of a total of 1,045 observations (378 from the 
first wave and 667 from the second wave) from 47 classes and 17 schools. Of the 1,045 students, 493 are boys and 552 are girls. The gender distribution across the groups can be seen in Table 3. The number of students in each group spans from 205 to 212.

As a result of randomization within each class, we obtained a balanced number of students across treatment and control groups. Randomization also implies that the groups are balanced with regard to other factors such as gender, class size, and school-specific factors such as socioeconomic background. This is corroborated by Hotelling's $T^{2}$ tests and in Tables 4 to 6 . We have chosen to include a set of control variables in our dataset to increase the precision of our estimates and to certify that our findings are robust. The only individual control variable is an indicator for gender. The class-level control variables include class size, wave, learning weeks, and peer familiarity. First, class size could have an indirect effect on student learning and skill level through teacher-student time and attention. ${ }^{7}$ Class size further determines how many students are competing for the top three positions in treatments 2 and 4. Second, Section 3.1 shows that the student skill level plays an important role. This is proxied by wave and learning weeks; i.e. how many weeks the student has been learning math in sixth grade. Third, Section 3.2 shows that peer familiarity also plays an important role in student accuracy of assessing peer ability and the probability of winning the tournaments in T2 and T4. This is proxied by an indicator of whether the student is in a classroom with mostly new peers. ${ }^{8}$ Lastly, we also include four school-level controls: a measure of average GPA at ninth grade graduation (end of compulsory schooling) to proxy school quality, the percentage of foreign-born students present at the school, and the percentage of students born in Sweden with both parents being foreign-born, and a measure of average parental education level. Gender is naturally measured at the individual level, while the class-level variables are collected via the field experiment. All information on the last four control variables were obtained at

\footnotetext{
${ }^{7}$ There is a large literature testifying the importance of class size. Closest to our setting and using Swedish data, Fredriksson et al. (2013) show that a smaller class size in fourth to sixth grade increases cognitive and non-cognitive skills at the end of sixth grade, as well as longer term education and labor market outcomes.

${ }^{8}$ We have also estimated the treatment effects including detailed controls for factors varying at the time of the test (temperature, rainfall, hour-of-the-day and day-of-the-week specific effects) to further certify the robustness of our results; see the accompanying online Appendix.
} 
the school level from the analysis tool Skolverkets Arbetsverktyg för Lokala SambandsAnalyser (SALSA), which is administered by the Swedish National Agency for Education and based on statistics gathered from Statistics Sweden's school register. Data was available only for schools with grades 1-9. Three schools in our sample (two in the first wave and one in the second wave) did not fulfill this criteria, hence we single them out in all our specifications including school-level controls.

Table 5 reports means of outcome and control variables for the control group, and the differences in means between the control group and each treatment group, for the first wave of the experiment. The only differences in means that are of statistical significance are those for test scores for treatment groups 2-4. When comparing means of test scores in treatment groups against the control group, we see that all treatment groups show a positive difference in mean test scores. This indicates that students in the incentivized treatment groups performed better than students in the unincentivized control group, on average. Included control variables are statistically equal in means, indicating that students are as good as randomly assigned to groups. The random assignment to control and treatment groups is true also for the second wave of the experiment. This can be seen in Table 6. However, unlike in the first wave of the experiment, none of the applied treatments show significant differences in means of test score.

Table 3 reports the group mean test scores obtained in each of the control and treatment groups. The average test score obtained in the experiment was 13.77 (both waves), 14.91 (first wave) and 12.98 (second wave). We observe differences in gender with respect to average test scores; 13.32 for boys and 14.34 for girls. Thus girls performed better than boys, on average. The highest average test score for boys was obtained in treatment group 2 (grade A) with a score of 13.73 , and for girls in treatment group 4 (prize) with a score of 15.00. The lowest average test score for both boys and girls can be found in the control group with scores of 13.02 and 13.91, respectively. The differences in average test scores between the different groups for all students and with respect to gender can be seen in Figure 3, Figure 4, and Table 3. The scores obtained range from the minimum of 0 points to the maximum of 22 points and the test score distribution is negatively 
skewed, which means that the students perceived the test as relatively easy - especially in the first wave; see Figure 6.

Figures 5 to 7 graphically illustrate the test score distributions for each group, both for all students and for boys and girls separately. We note that with treatments in place, the test score distributions are negatively skewed towards higher points. The test score distribution for the control group is more symmetric (skewness=-0.11). For boys, the largest negative skew (-0.66) is present for treatment group 2 (grade A), and for girls the largest skew (-0.80) is seen for treatment group 4 (prize). Overall, $9 \%$ of students score the maximum of 22 points. ${ }^{9}$ We also note that, in line with the predictions of the model in Section 4, more students in the incentivized treatment groups provide minimal effort and perform in the bottom of the test score distribution - particularly boys and students in the second wave.

\section{Results}

Having established that our control and treatment groups are balanced is pivotal, as it implies that students are randomly assigned to the five groups and we will obtain internally valid and unbiased estimates of the causal effect of treatment.

To draw robust inference, we estimate cluster-robust standard errors on the class (and school) level. Even if students are randomly assigned to control and treatment groups, the error terms may still contain class (or school) level correlations. This may obviously be an issue when adding school level controls (Moulton, 1990), but errors may even be correlated at the class level when using rank-based grading as students' optimal effort depends on the expected ability and effort of the classmates they are competing with for being among the top three test performers. Since we have a relatively low number of clusters, the standard Eicker-Huber-White cluster-robust standard error estimates may be

\footnotetext{
${ }^{9}$ We recognize the potential of underpredicting the impacts of non-financial incentives for the best performing students. To be conservative, we could interpret the positive effects we estimate as lower bounds of the true effects for the best students. This is a typical feature of test score distributions, but Koedel and Betts (2010) show that test-score-ceiling effects only result in significant biases for much more skewed distributions with a skewness of more than twenty times the maximum we observe.
} 
downward biased. ${ }^{10}$ The fact that our clusters are of similar size should, however, reduce the potential bias due to the small number of clusters. According to Rogers (1987) we should not expect this potential bias to be large in our sample, since none of the classes are larger than 5 percent of the total sample. This implies that the standard errors will not be too far off because each term will be off by less than 1 in 400 . This implies that the standard cluster-robust standard error estimator with only 19-28 clusters of similar size in the first-second wave should suffer minimal bias. We expect this bias to be extremely close to zero in the total sample with 47 classes, but slightly higher when also clustering at the school level with only $7-17$ schools, where 7 of 17 schools in the total sample comprise less than 5 percent of the sample. Cameron et al. (2008) report that a wild bootstrap cluster-robust estimator performs well when the number of clusters is smaller than 50 . We confirm that the OLS and standard cluster-robust error estimates are very similar to the adjustment for school and class level common shocks suggested by Cameron et al. (2011) as well as their wild bootstrap (Cameron et al., 2008). In no cases do inference and our conclusions change. In all tables we thus simply report the standard cluster-robust standard errors.

Tables 7 and 8 present ATE estimates of the four non-financial incentives on standardized test scores. Table 7 reveals that we find positive, but insignificant ATE of all four treatments. Table 8 reveals that this is true for both boys and girls.

We can also examine the treatment effects across the test score distribution. Randomization within each classroom assures that - in the absence of treatment - all groups of students would be equally likely to be observed in each of the percentiles of the test score distribution. Hence, movements up (or down) in the test score distribution can be attributed to the increased (or decreased) effort caused by the extrinsic incentive (treatment) as both the ability and skill level are fixed in the test situation. Table 9 reveals that there is a significant increase in the probability of scoring above the median for treatments 3 and 4 (certificate and prize) and on the probability of scoring above the top quartile for treatments 1 and 3 (grade A-F and certificate). Treatments 3 and 4 increase

\footnotetext{
${ }^{10}$ Wooldridge (2003) provides a more comprehensive discussion of these issues.
} 
the probability of scoring above the median by $7-8$ percentage points and treatments 1 and 3 increase the probability of scoring above the top quartile by 7-8 percentage points. This is consistent with the predictions of the model in Section 4 that effort will increase most for students at the margin for which the threshold for a performance reward is within reach if they put more effort into the test. These students who increase their effort when incentivized by rank-based grading and rewards are in the upper-middle part of the ability distribution in our full sample of sixth graders. Table 9 further shows that adding all individual, class, and school level controls does not change these conclusions. ${ }^{11}$ It also reveals that the reason girls' average test scores are higher on average is that they have a lower probability to score in the lower half of the distribution. Finally, we also estimate the distributional impacts by gender. Table 10 shows that only treatment 2 (grade A) significantly increases the probability of scoring above the median by 10 percentage points for boys. Table 11 shows that for girls, treatment 4 (prize) increases the probability of scoring above the lower quartile by 9 percentage points and treatment 3 (certificate) increases the probability of scoring above the upper quartile by 11-14 percentage points, while it also decreases the probability of scoring above the lowest decile by 5 percentage points. This is also consistent with the theory in Section 4 and indicates that the girls around the upper quartile of the test score distribution are those increasing their effort with the outlook of a certificate for high performance, while the girls around the lowest decile are those getting demotivated by the too high threshold being out of reach. Overall, it seems like boys get most motivated by competing for the grade $\mathrm{A}$, while girls get most motivated by competing for a prize or receiving a certificate for high performance.

\subsection{Heterogeneous Treatment Effects by Skill level}

We exploit that the preparation for the test is different for students in the two waves. Students in the first wave are tested in April 2013, which is towards the end of the schoolyear and around the time they will be taking the national test. The students should

\footnotetext{
${ }^{11}$ We verify that this is also true when we restrict our attention only to the students at schools with complete information on school-specific variables in the first two specifications. We further verify that estimating a probit model instead of the linear probability model leads to the same conclusions.
} 
therefore be in their comfort zone according to one of the leading theories of optimal learning (Vygotsky, 1978) and be able to solve all the test tasks on their own if they provide enough effort. The students in the second wave are tested in August-September 2013, which is at the beginning of sixth grade. As the test is designed to be a broad test of the math skills acquired during their first six school years, some of the test tasks may be too difficult for the students in the second wave to solve unassisted. ${ }^{12}$ On an optimal learning trajectory (Vygotsky, 1978) these students should therefore be in their zone of proximal development or if the tasks are way too hard even in their frustration zone. The incentives may therefore unintentionally reduce their effort. Through the lens of the model in Section 4, we interpret this as the students in the first wave being more skilled than those in the second wave. In Figure 2 the distribution of ability in the first wave is represented by $f_{a_{H}}$, while $f_{a_{L}}$ represents the ability distribution of the second wave students. The model predicts a lower increase in effort (or even more students exerting no effort) in the second wave, as more students have a lower ability, $\underline{a} \leq a_{i} \leq \underline{a}$, while the model predicts a larger increase in effort by incentivized students in the first wave as more students have a higher ability, $\bar{a} \leq a_{i} \leq \overline{\bar{a}}$.

Table 12 shows that we cannot reject this prediction, as the ATE is significant for three of the four treatments among first wave students - with the exception of treatment group 1 (grade A-F). Treatment group 4 (prize) tends to have the largest ATE, followed by treatment group 2 (grade A), and treatment group 3 (certificate). Receiving the information that the performance on the test may lead to being rewarded with a prize leads to almost half a standard deviation higher test score on average than when only intrinsically motivated. Receiving a certificate for scoring above the cut-off for receiving at least a $\mathrm{B}$ results in an average increase in test scores of about a third of a standard deviation. This indicates that rank-based grading increases performance most, however, the ATE of treatments 2,3 , and 4 are not statistically different; i.e. we cannot reject the null hypothesis $\delta_{2}=\delta_{3}=\delta_{4}$. Being assigned to treatment group 1 (grade A-F) shows no significant difference in average test scores. For the second wave, the ranking is re-

\footnotetext{
${ }^{12}$ After seeing the test, some of the teachers also pointed out that they had not yet taught the students how to solve some of the tasks.
} 
versed, but not statistically significant. These results remain robust to including control variables.

Table 13 presents ATEs separately by gender for the first wave. It reveals that boys tend to be motivated only by rank-based grading singling out the top three test scorers in the class: treatments 2 and 4 (grade A, prize). The size of these increases are about half a standard deviation. We do not find statistically different responses to treatments by gender, apart from the fact that only girls are induced to exert more effort by treatment 3 (certificate). Girls and boys are equally motivated by the two rank-based grading treatments and the effects are in the range of a third to half a standard deviation. ${ }^{13}$

We further analyze the distributional effects in the each wave. Table 14 reveals that among the students in the first wave, the probability of scoring above the median is significantly increased by treatments $2-4$ (grade $\mathrm{A}$, certificate, prize). $P\left(T S_{i} \geq P 50_{T S}\right)$ is increased by 19-21 percentage points. Treatment 2 (grade A) also increases the probability of scoring above $P 25_{T S}$ and $P 75_{T S}$ by 19-21 percentage points, while treatment 3 (certificate) seems to have more motivational power at the upper quartile, and treatment 4 has more motivational power at the lower quartile. Examining these distributional effects separately by gender, Table 15 presents the results for boys and Table 16 presents the results for girls. For boys, treatment 2 (grade A) has a large effect higher up in the distribution as it increases the probability of scoring above $P 25_{T S}$ by 17 , and above $P 50_{T S}$ and $P 75_{T S}$ by $25-26$ percentage points. The other rank-based grading treatment 4 (prize) has an effect lower in the distribution as it increases the probability of scoring above $P 10_{T S}$ and $P 25_{T S}$ by $12-29$ percentage points, while treatment 3 (certificate) increases the probability of scoring above $P 10_{T S}$ by 15 percentage points. For girls, treatment 2 (grade A) has a similar effect at the lower quartile and median, although the motivational power is only as strong at the lower quartile. Treatments 4 (prize) has a significant effect higher up in the distribution, as does treatment 3 (certificate) by increasing girls' probability of scoring above the median and the top quartile by 28-30 percentage points. Treatment

\footnotetext{
${ }^{13}$ We have also estimated class-specific fixed effects specifications as an additional test of whether the class-level randomization was successful. These estimates are displayed in Table A.16 in the online Appendix and corroborate the robustness of our results to adding class FE - both overall and in the individual waves.
} 
1 (grade A-F) also significantly raises girls' probability of scoring above the median by 24-26 percentage points and above $P 90_{T S}$ by 9 percentage points.

Table 17 reveals that among the students in the second wave, the probability of scoring above the tenth percentile, $P\left(T S_{i} \geq P 10_{T S}\right)$, is lowered by $3-5$ percentage points when facing the non-financial incentives. This is consistent with the model prediction that more students will optimally exert zero effort when the bar is set too high. Finally, we corroborate that these conclusions are also robust to adding class and school-level controls.

All in all, we find that while non-financial incentives increase test performance more for students in the middle-upper part of the distribution among the highly skilled students, the same incentives also decrease performance in the bottom of the distribution of lowskilled students.

Finally, we test the impact of student placement on the learning trajectory more directly. Is it really differences in student skill levels that drive the differences in treatment responses between the first and the second wave? To answer this question, we employ a more finely measured proxy for student skill level: learning weeks, denoting the number of weeks the student has been learning math in sixth grade at the time of the test. The results from adding interactions between learning weeks and the four treatment indicators are presented in Table 18. We first note that adding learning weeks as a control does not change any of our conclusions, but strongly diminishes the correlation between wave and baseline test scores. This would be expected if wave mainly picks up the differences in weeks the students have been learning math in sixth grade. More importantly, interacting learning weeks with the four treatment indicators reveals that students respond more strongly to T2-T4 when having been exposed to more weeks of sixth grade math classes. This corroborates that the main factor determining the different impacts of treatment in the two waves is student skill level at the time of the test. 


\subsection{Heterogeneous Treatment Effects by Peer Familiarity}

The model in Section 3.2 shows that expectations about peer ability are important for effort responses to rank-based grading incentives. We now turn to testing this model prediction. We exploit the fact that some students have more information about the peers they are competing with than others. We hypothesize that those who have spent at least a school year in the same classroom as their peers will have a more precise estimate of their peers' ability; they thus face less uncertainty about the endogenous threshold and their effort will respond more strongly to rank-based grading incentives. Table 19 presents a direct test of this hypothesis, by separately presenting ATEs for students who have been taught at least a school year in the classroom with the same peers and whether the ATEs are different for those who just started with new peers within the last six weeks. Our estimates support this hypothesis, as test score responses to treatments 2 and 4 (grade A, prize) are significantly lower for those who are with new peers. Test scores are on average increased by $0.35-0.37$ standard deviations less by treatment 2 (grade A) and by 0.48 standard deviations less by treatment 4 (prize) if tested in a new peer group. ${ }^{14}$ We also note that treatment 4 (prize) significantly increases test scores by 0.22 standard deviations if in a familiar peer group. The last four columns of Table 19 reveal that this is due to girls responding very strongly and raising their test scores by about a third of a standard deviation if receiving a prize for being among the top three performers. Table 19 also shows that only girls respond significantly less to the rank-based grading incentives when tested with unfamiliar peers.

Table 20 presents the distributional effects of non-financial incentives for the students who have been with the same peers for at least a school year. We find that incentives increase effort in the middle of the distribution. Treatment 3 (certificate) increases the probability to score above both $P 50_{T S}$ and $P 75_{T S}$ by 8-11 percentage points, while the two

\footnotetext{
${ }^{14}$ Responses also tend to be lower for treatment 3 (certificate), but only significantly lower when adding school-level controls. This is not predicted by the model in Section 3, since expectations about peer ability should not be important for the individual reward on a criterion-based grading scale. This could be because of some psychological factors related to uncertainty, self-confidence, self-evaluation of math ability, or because students dislike being singled out to receive a certificate in front of their new peers.
} 
rank-based treatments 2 and 4 (grade A, prize) increase performance lower in the ability distribution. Table 21 shows that the incentives motivate lower in the distribution for boys, where treatment 2 (grade A) increases the probability of scoring above $P 10_{T S}$ and by 11 percentage points and treatment 3 (certificate) increases the probability of scoring above $P 10_{T S}$ by 10 percentage points. Table 22 reveals that treatment 4 (prize) has a large and significant effect throughout the test score distribution for girls, while treatment 3 (certificate) has a similarly large effect in the middle-upper part of the distribution by increasing the probability of scoring above $P 50_{T S}$ and $P 75_{T S}$ by $13-19$ percentage points.

Overall, we find strong empirical support for the model prediction that increased uncertainty about peer ability - and consequently own winning probability - decreases the motivational effect of tournament incentives. This motivational decrease is particularly strong for girls. Our field experiment is not directly designed to distinguish between competing theories of this observation. This could be done by introducing gender-specific preference (Croson and Gneezy, 2009) and cost parameters in the model in Section 3. For example, girls' effort response under competition would be lowered when facing more uncertainty about peers' ability if girls expect their actual winning probabilities to be lower than boys with the same math ability. This could occur if girls are less overconfident (Alpert and Raiffa, 1982; Svenson, 1981), and could be a credible explanation as many studies find boys to be more overconfident (Niederle and Vesterlund, 2010). Specifying and estimating such a structural model to directly quantify the gender-specific differences in parameters and their implications for behavior would be an interesting avenue for future research.

\section{Discussion}

The results from our field experiment show that non-financial extrinsic incentives have a motivational effect on highly skilled students' performance in a test situation. Ranking students by distinguishing the top three performers has particularly large motivational power. However, the motivational power of evaluated incentives differs with respect to 
gender. Boys only increase their effort if offered to compete, whereas girls also increase their effort if offered a certificate for criterion-based grades A-B. Girls' responses to rankbased grading incentives are also significantly lower if they are in a class with new peers. This indicates that girls' responses to a competitive environment are particularly sensitive to their knowledge about the ability of the peers they are competing with.

Why would we expect gender differences in the responses to the rank-based test assessments? Boys are most responsive to being ranked with respect to grades, whereas girls react most strongly to the incentive of receiving a prize for high rank. Receiving a prize may offer a more public form of competition, and most studies find that boys exhibit more competitive behavior (Gneezy et al., 2003; Gneezy and Rustichini, 2004; Croson and Gneezy, 2009; Niederle and Vesterlund, 2010). ${ }^{15}$ However, we find no significant difference in the performance response to competition among these sixth grade students. ${ }^{16}$ This is consistent with Lavy (2012) who estimates no gender difference in teacher effort under performance pay even if the female teachers are more pessimistic about the performance pay scheme, and with Joensen and Nielsen (2014) who find that girls are less likely to choose competitive advanced math classes in high school - even if the expected financial reward is at least as high as for boys. It may thus be that the competitive environment lowers girls' utility (e.g. because they find it more unpleasant) even if they increase their performance as much (or more) under the rank-based grading. ${ }^{17}$

Why do only girls respond to the symbolic reward? This could be because girls attach relatively more importance to reflected appraisals, whereas boys attach relatively

\footnotetext{
${ }^{15}$ Note that all these studies use financial incentives. We cannot be certain of how the incentives were perceived by the students. Thus we cannot conclude that prize was the most worthy of competition. Therefore, boys may still have displayed the most competitive behavior, but have valued grade A higher than prize. As prize is the only materialistic reward, girls' strong reaction to this incentive may indicate that they are more materialistic than boys.

${ }^{16}$ Some studies even find the opposite to be true. Cárdenas et al. (2012) find that the competitive performance increase in math is higher for girls than for boys in Sweden. However, they find that girls are less likely to choose to compete on the math task.

${ }^{17}$ There does not seem to be a consensus on the nature and emergence of gender differences in competitiveness. Gneezy et al. (2009) show that culture matters as men (women) are more competitive in a patriarchal (matrilineal) society, while Andersen et al. (2010) suggest that girls become less competitive around puberty in a patriarchal society and Booth and Nolen (2012) find that social learning matters as girls from single-sex schools are more competitive at age 15 than girls from coed schools in the UK. Contrary to this Sutter and Rützler (2010) find that boys are already more competitive around age three in Austria, whereas Dreber et al. (2011) find no evidence of differences in competitiveness among Swedish children aged 7 to 10 .
} 
more importance to social comparisons (Schwalbe and Staples, 1991). ${ }^{18}$ Both rank-based incentives and receiving a symbolic reward offer sources of reflected appraisals, while rank-based incentives offer a more direct form of competition and social comparison. This could explain why we find a considerable impact on girls' performance as soon as rank-based incentives or a symbolic reward is in place, but for boys this impact is only prevalent when facing competition. It is possible that boys do not view the symbolic reward (and criterion-based grades more generally) as a strong enough social comparison. If girls are more motivated by reflected appraisals they will, however, be motivated both by the top three competition and by a symbolic reward. Josephs et al. (1992) also stresses that males are more likely to individuate themselves from others in areas of importance and value, whereas separation from others is not as important for females. If so, boys would be more motivated by the possibility of successfully separating themselves from others through individuating attainments by being top of their class. This could reflect our results as boys tend to be motivated by wanting to stand out in competition, while girls are motivated even though the reward is symbolic and many classmates also may receive it by meeting the criteria.

Could social comparisons be important in other ways? We present additional evidence indicating that boys (girls) tend to be more sensitive to the performance of other boys (girls) in their class. ${ }^{19}$ We estimate (i) a significantly higher baseline performance and (ii) a significantly lower response to all treatments if the same-gender average performance in the class is higher, while there is no significant differential response to the other-gender average performance in the class. These results suggest that gender is a salient feature of identity and students tend to compare themselves to their same-gender classmates; i.e. boys (girls) are more likely to have other boys (girls) as their reference group and make within-gender social comparisons. These results also suggest that it is harder to increase your social reward through higher test effort if your reference-peers are higher ability. The lower treatment responses could be due to lower self-esteem if having more upward social

\footnotetext{
${ }^{18}$ Reflected appraisals (Cooley, 1902) refer to how others react to us - their image of us and how we reflect it - and social comparisons (Festinger, 1954) refer to using others as references for our selfevaluations, self-enhancements, and self-improvements.

${ }^{19}$ See Tables A.17-A.19 in the accompanying Online Appendix for these results.
} 
comparison possibilities in the relevant gender-specific reference group (Dijkstra et al., 2008). These social comparisons do not seem particularly sensitive to peer familiarity. In future research, it would be interesting to test these hypotheses on a sample with larger control groups, as well as to open the black box of how students make social comparisons, how it affects their performance, and how it affects their responses to extrinsic incentives.

Given the differences in placement in the test score distribution and the fact that responses to extrinsic incentives vary considerably over the skill and ability distribution, we cannot draw strong conclusions on the economic significance of these gender differences without introducing more structure. Boys have a higher variance of test scores compared to girls, since boys are much more likely to score in the bottom of the distribution. There is also a gender level difference in which girls outperform boys with an average of 0.87 standardized points. This tells us either that girls have higher intrinsic motivation, apply more effort in the test situation, or are simply better at solving the mathematical tasks presented in the experiment. There is a growing literature addressing the issue that boys are lagging behind in schools and having worse average educational achievement because of low motivation, low self-discipline, or low non-cognitive skills in general (Jacob, 2002; Duckworth and Seligman, 2006; Fortin et al., 2013; Cornwell et al., 2013). ${ }^{20}$ This could have longer-term detrimental effects as an early skill deficit lowers later educational attainment and the returns to education (Cunha et al., 2006; Cunha and Heckman, 2007; Oreopoulos and Salvanes, 2011). Our results suggest that one way of incentivizing boys to be more engaged and put forth more effort in school would be to include more competition into the assessment of their tests. This could be equally beneficial for both highly skilled boys' and girls' math achievement.

Our results also highlight that the diverging results in the literature on responses to, and emergence of, competitiveness may not only be due to differences in the gender stereotypicality of the task (Dreber et al., 2011) and the implementation environments, but also due to failing to appropriately take the skill levels relative to task difficulty and

\footnotetext{
${ }^{20}$ This could be because boys' non-cognitive skills are more sensitive to parental inputs as they, for example, become relatively more disadvantaged if growing up in a broken home (Bertrand and Pan, 2013).
} 
peer familiarity into account. Particularly, girls' responses to competition seem to be very sensitive to how well they know their peers. Our results therefore call for more research to pin down how skills and peers affect responses to competition and other extrinsic incentives.

\section{Conclusions}

The educational system is built upon a sequence of tests to measure student performance. The results of these tests often lay the foundation for the distribution of school resources and spur considerable public debates, but how do test incentives affect student motivation and effort? For tests to be a useful measure of students' knowledge and quality, they need to accurately reflect students' skill levels. This can only be the case if students are motivated to perform well when taking tests and if they exert enough effort in the test situation.

Measures of student quality, achievement gaps, teacher value added, and school quality will be biased if some groups of students are not motivated to exert effort on achievement tests and large scale national standardized tests carrying low stakes for the students, but potentially high stakes for teachers and schools. Policy decisions based on such biased measures could be seriously misguided and have unintended consequences. Two examples of high-powered and widespread incentive systems based on student test scores are school accountability systems and performance pay based on teacher value added. First, Kane and Staiger (2002) lay out the promises and pitfalls for using school accountability systems based on imprecise school-level test score measures, while Figlio and Winicki (2005) provide an example of unintended consequences of school accountability as some schools feed their students with more calories just before the test in order to boost their test performance. Second, Hanushek and Rivkin (2010) and Neal (2011) highlight several reasons why using teacher value-added measures as a basis for performance pay, employment, promotion, and assignment decisions may be problematic: e.g. they capture very short-term rather than longer-term learning gains (Rothstein, 2010; Jacob et al., 
2010). ${ }^{21}$ Measures of school quality could even have important consequences for sorting of students across schools if these are widely publicized (Rivkin et al., 2005; Rothstein, 2010). Our results further highlight that these measures are highly dependent on student preparation for the test, peer familiarity, and the implicit incentives in the grading of the test. It could therefore be easy for teachers and principals to manipulate such measures by simply giving a symbolic reward or singling out the top performers on the day of the test. Future research will hopefully reveal whether these non-financial test incentives have longer-term effects.

Our results also have implications for grading design and the organization of schools, as they show there is cause to question the current incentives being used to motivate highly skilled students. We show that grading highly skilled students on an A-F scale according to a pre-specified set of criteria does not motivate students to increase test effort. To grade with criteria - without a corresponding distribution - is the most commonly used method of student assessment in primary schools. ${ }^{22}$ Norm-referenced assessment methods would be more effective in increasing highly skilled students' test effort. However, introducing tournaments within the classroom will potentially lower test effort of students with lower skill levels. Thus norm-referenced grading can have unintended consequences if applied in a learning environment where students are not fully mastering the learning requirements. This demotivating effect for low skilled students should, however, not be large for students who are well prepared for their final exam or (inter)national tests. This suggests the importance of choosing the appropriate grading method for the test to accurately reflect the knowledge level it is intended to measure on the students' learning trajectory. If teacher pay depends on students' test scores, they may be induced to teachto-the-test by shifting their attention away from those who are lagging behind to those who are more skilled (Lazear, 2006). This is exactly what happened when Chicago Public Schools changed their proficiency requirements and teachers shifted their attention to those close to this requirement (Neal and Schanzenbach, 2010). Our results suggest that

\footnotetext{
${ }^{21}$ Lavy (2009) shows that teacher performance pay can sometimes lead to improved student performance through better teaching methods, which may potentially lead to positive longer-term effects.

${ }^{22}$ Note that even if this is also the typical grading method in Swedish schools, it is still novel - like the other evaluated grading methods - to the sixth grade students participating in the experiment.
} 
norm-referenced grading could lead to similar polarization in a heterogeneous learning environment.

Our results also suggest some interesting avenues for future research: Is is better to use criterion-based grading with more or fewer grades? How important are the exact cut-offs in criterion-based grading? How important is the degree of competitiveness in rank-based grading? Does the nature of non-financial rewards matter? By further analyzing other non-financial incentives, one could find even more efficient methods for increasing student effort and performance. In this paper, we isolate the effort effect in the test situation, while we plan to also evaluate other incentive effects and the importance of sorting when evaluating longer-term impacts. ${ }^{23}$ Among the four non-financial incentives we evaluate, we find those involving norm-referenced assessment to be the most effective in increasing test effort of highly skilled students, but not for students with too low skill level. Such rank-based grading is often prevalent at later educational stages. Our results indicate that an earlier implementation could have positive effects on student effort and performance, thus could lead to more efficient tracking and sorting across skill levels. A deeper analysis of these issues and the longer-term effects of grading and reward schemes could be a fruitful avenue for future research.

\footnotetext{
${ }^{23}$ Leuven et al. (2011) show that such distinctions may be crucial when comparing different financial tournament incentives for university students.
} 


\section{References}

Alpert, M. and H. Raiffa (1982). A progress report on the training of probability assessors. In D. Kahneman, P. Slovic, and A. Tversky (Eds.), Judgment Under Uncertainty: Heuristics and Biases, pp. 294-305. Cambridge University Press.

Andersen, S., S. Ertac, U. Gneezy, J. A. List, and S. Maximiano (2010). Gender, competitiveness and socialization at a young age: evidence from a matrilineal and a patriarchal society. Review of Economics and Statistics.

Attali, Y., Z. Neeman, and A. Schlosser (2011). Rise to the challenge or not give a damn: differential performance in high vs. low stakes tests. IZA Discussion Paper No. 5693.

Azmat, G. and N. Iriberri (2010). The importance of relative performance feedback information: Evidence from a natural experiment using high school students. Journal of Public Economics 94(7), 435-452.

Baumert, J. and A. Demmrich (2001). Test motivation in the assessment of student skills: The effects of incentives on motivation and performance. European Journal of Psychology of Education 16(3), 441-462.

Becker, G. S. (1967). Human capital and the personal distribution of income: An analytical approach, Volume 1. Woytinsky lecture. Institute of Public Administration Ann Arbor, MI.

Becker, W. E. and S. Rosen (1992). The learning effect of assessment and evaluation in high school. Economics of Education Review 11(2), 107-118.

Bertrand, M. and J. Pan (2013). The trouble with boys: Social influences and the gender gap in disruptive behavior. American Economic Journal: Applied Economics 5(1), $32-64$.

Besley, T. and M. Ghatak (2008). Status incentives. American Economic Review $98(2)$, $206-211$. 
Bettinger, E. and R. Slonim (2007). Patience among children. Journal of Public Economics $91(1), 343-363$.

Bettinger, E. P. (2012). Paying to learn: The effect of financial incentives on elementary school test scores. Review of Economics and Statistics 94(3), 686-698.

Betts, J. R. (1998). The impact of educational standards on the level and distribution of earnings. American Economic Review, 266-275.

Betts, J. R. and J. Grogger (2003). The impact of grading standards on student achievement, educational attainment, and entry-level earnings. Economics of Education Review 22(4), 343-352.

Booth, A. and P. Nolen (2012). Choosing to compete: How different are girls and boys? Journal of Economic Behavior \& Organization 81(2), 542-555.

Cameron, A. C., J. B. Gelbach, and D. L. Miller (2008). Bootstrap-based improvements for inference with clustered errors. The Review of Economics and Statistics 90(3), $414-427$.

Cameron, A. C., J. B. Gelbach, and D. L. Miller (2011). Robust inference with multiway clustering. Journal of Business \& Economic Statistics 29(2).

Cárdenas, J.-C., A. Dreber, E. Von Essen, and E. Ranehill (2012). Gender differences in competitiveness and risk taking: Comparing children in colombia and sweden. Journal of Economic Behavior \& Organization 83(1), 11-23.

Chay, K. Y., P. J. McEwan, and M. Urquiola (2005). The central role of noise in evaluating interventions that use test scores to rank schools. American Economic Review, 12371258.

Cooley, C. H. (1902). Human Nature and the Social Order. New York: Schocken.

Cornwell, C., D. B. Mustard, and J. Van Parys (2013). Noncognitive skills and the gender disparities in test scores and teacher assessments: Evidence from primary school. Journal of Human Resources 48(1), 236-264. 
Costrell, R. M. (1994). A simple model of educational standards. The American Economic Review, 956-971.

Croson, R. and U. Gneezy (2009). Gender differences in preferences. Journal of Economic Literature, 448-474.

Cunha, F. and J. Heckman (2007). The technology of skill formation. American Economic Review 97(2), 31-47.

Cunha, F., J. J. Heckman, L. Lochner, and D. V. Masterov (2006). Interpreting the evidence on life cycle skill formation. Handbook of the Economics of Education 1, $697-812$.

Deci, E. L., R. Koestner, and R. M. Ryan (1999). A meta-analytic review of experiments examining the effects of extrinsic rewards on intrinsic motivation. Psychological Bulletin 125(6), 627.

Delfgaauw, J., R. Dur, J. Sol, and W. Verbeke (2013). Tournament incentives in the field: Gender differences in the workplace. Journal of Labor Economics 31(2), 305-326.

Dijkstra, P., H. Kuyper, G. van der Werf, A. P. Buunk, and Y. G. van der Zee (2008). Social comparison in the classroom: A review. Review of Educational Research 78(4), $828-879$.

Dreber, A., E. Von Essen, and E. Ranehill (2011). Outrunning the gender gap - boys and girls compete equally. Experimental Economics 14(4), 567-582.

Duckworth, A. L. and M. E. Seligman (2006). Self-discipline gives girls the edge: Gender in self-discipline, grades, and achievement test scores. Journal of Educational Psychology 98(1), 198.

Eisenkopf, G. (2011). Paying for better test scores. Education Economics 19(4), 329-339.

Ellingsen, T. and M. Johannesson (2007). Paying respect. The Journal of Economic Perspectives $21(4), 135-150$. 
Facchinello, L. (2014). The impact of grading on academic choices: Mechanisms and social implications. Manuscript, Stockholm School of Economics.

Festinger, L. (1954). A theory of social comparison processes. Human relations 7(2), $117-140$.

Figlio, D. N. and M. E. Lucas (2004). Do high grading standards affect student performance? Journal of Public Economics 88(9), 1815-1834.

Figlio, D. N. and J. Winicki (2005). Food for thought: the effects of school accountability plans on school nutrition. Journal of Public Economics 89(2), 381-394.

Fortin, N. M., P. Oreopoulos, and S. Phipps (2013). Leaving boys behind: Gender disparities in high academic achievement. NBER Working Paper (19331).

Fredriksson, P., B. Öckert, and H. Oosterbeek (2013). Long-term effects of class size. The Quarterly Journal of Economics 128(1), 249-285.

Fryer, R. G. (2011). Financial incentives and student achievement: Evidence from randomized trials. The Quarterly Journal of Economics 126(4), 1755-1798.

Gneezy, U., K. L. Leonard, and J. A. List (2009). Gender differences in competition: Evidence from a matrilineal and a patriarchal society. Econometrica 77(5), 1637-1664.

Gneezy, U., M. Niederle, and A. Rustichini (2003). Performance in competitive environments: Gender differences. The Quarterly Journal of Economics 118(3), 1049-1074.

Gneezy, U. and A. Rustichini (2004). Gender and competition at a young age. The American Economic Review 94(2), 377-381.

Hanushek, E. A. and S. G. Rivkin (2010). Generalizations about using value-added measures of teacher quality. The American Economic Review 100(2), 267-271.

Jacob, B. A. (2002). Where the boys aren't: non-cognitive skills, returns to school and the gender gap in higher education. Economics of Education Review 21 (6), 589-598. 
Jacob, B. A., L. Lefgren, and D. P. Sims (2010). The persistence of teacher-induced learning. Journal of Human Resources 45(4), 915-943.

Joensen, J. S. and H. S. Nielsen (2014). Math and gender: Heterogeneity in causes and consequences of math. forthcoming in the Economic Journal.

Josephs, R. A., H. R. Markus, and R. W. Tafarodi (1992). Gender and self-esteem. Journal of personality and social psychology 63(3), 391.

Kane, T. J. and D. O. Staiger (2002). The promise and pitfalls of using imprecise school accountability measures. The Journal of Economic Perspectives 16(4), 91-114.

Koedel, C. and J. Betts (2010). Value added to what? how a ceiling in the testing instrument influences value-added estimation. Education 5(1), 54-81.

Kosfeld, M. and S. Neckermann (2011). Getting more work for nothing? symbolic awards and worker performance. American Economic Journal: Microeconomics 3(3), 86-99.

Lavy, V. (2009). Performance pay and teachers' effort, productivity, and grading ethics. American Economic Review 99(5), 1979-2011.

Lavy, V. (2012). Gender differences in market competitiveness in a real workplace: Evidence from performance-based pay tournaments among teachers. The Economic Journal.

Lazear, E. P. (2006). Speeding, terrorism, and teaching to the test. The Quarterly Journal of Economics, 1029-1061.

Lazear, E. P. and S. Rosen (1981). Rank-order tournaments as optimum labor contracts. The Journal of Political Economy, 841-864.

Leuven, E., H. Oosterbeek, J. Sonnemans, and B. Van der Klaauw (2011). Incentives versus sorting in tournaments: Evidence from a field experiment. Journal of Labor Economics 29(3), 637-658. 
Levitt, S. D., J. A. List, S. Neckermann, and S. Sadoff (2012). The behavioralist goes to school: Leveraging behavioral economics to improve educational performance. NBER Working Paper (18165).

Moulton, B. R. (1990). An illustration of a pitfall in estimating the effects of aggregate variables on micro units. The Review of Economics and Statistics, 334-338.

Murphy, R. and F. Weinhardt (2013). Top of class: the importance of ordinal rank position. CEP Discussion Paper No 1241.

Neal, D. (2011). The design of performance pay in education. Handbook of the Economics of Education 4, 495-550.

Neal, D. and D. W. Schanzenbach (2010). Left behind by design: Proficiency counts and test-based accountability. The Review of Economics and Statistics 92(2), 263-283.

Niederle, M. and L. Vesterlund (2010). Explaining the gender gap in math test scores: The role of competition. The Journal of Economic Perspectives 24(2), 129-144.

Oreopoulos, P. and K. G. Salvanes (2011). Priceless: The nonpecuniary benefits of schooling. The Journal of Economic Perspectives 25(1), 159-184.

Rivkin, S. G., E. A. Hanushek, and J. F. Kain (2005). Teachers, schools, and academic achievement. Econometrica 73(2), 417-458.

Rogers, W. (1987). Regression standard errors in clustered samples. Stata Technical Bulletin 3(13).

Rothstein, J. (2010). Teacher quality in educational production: Tracking, decay, and student achievement. The Quarterly Journal of Economics 125(1), 175-214.

Schwalbe, M. L. and C. L. Staples (1991). Gender differences in sources of self-esteem. Social Psychology Quarterly, 158-168.

Sjögren, A. (2010). Graded children: Evidence of longrun consequences of school grades from a nationwide reform. Technical report, Working paper//IFAU-Institute for Labour Market Policy Evaluation. 
Sutter, M. and D. Rützler (2010). Gender differences in competition emerge early in life. IZA Discussion Paper No. 5015.

Svenson, O. (1981). Are we all less risky and more skillful than our fellow drivers? Acta Psychologica 47(2), 143-148.

Tran, A. and R. Zeckhauser (2012). Rank as an inherent incentive: Evidence from a field experiment. Journal of Public Economics 96(9), 645-650.

Vygotsky, L. L. S. (1978). Mind in society: The development of higher psychological processes. Harvard University Press.

Weiss, Y. and C. Fershtman (1998). Social status and economic performance: A survey. European Economic Review 42(3-5), 801-820.

Wise, S. L. and C. E. DeMars (2005). Low examinee effort in low-stakes assessment: Problems and potential solutions. Educational Assessment 10(1), 1-17.

Wooldridge, J. M. (2003). Cluster-sample methods in applied econometrics. The American Economic Review 93(2), 133-138. 


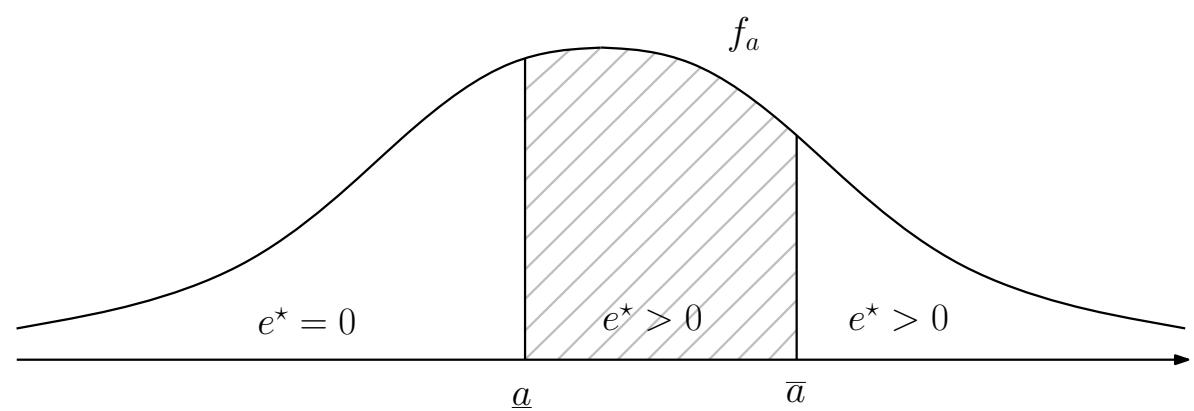

Figure 1: Optimal test effort over the ability distribution. $f_{a}$ denotes the pdf of the ability distribution and $e^{*}$ denotes optimal effort when the reward is given for all tests scores above $\overline{T S}$.

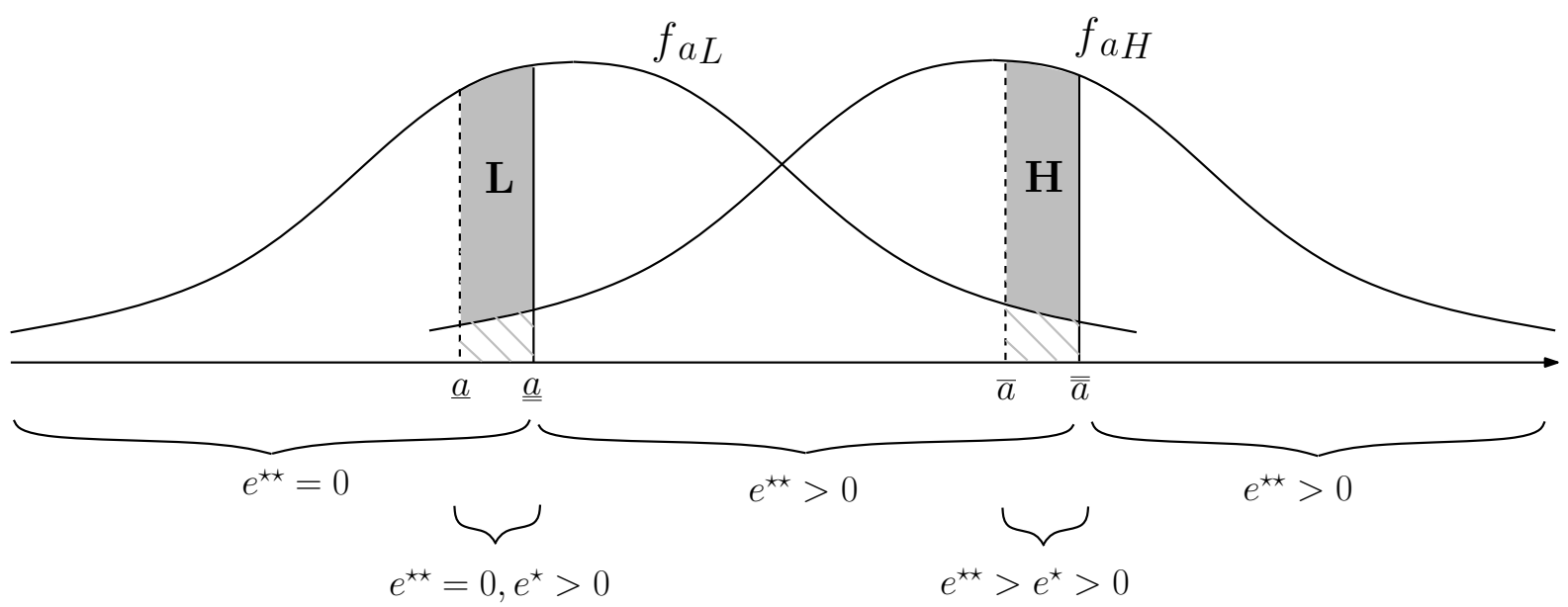

Figure 2: Optimal test effort, $e^{*}$, when the reward threshold is $\overline{T S}$, and optimal effort, $e^{* *}$, for the higher reward threshold $\overline{\overline{T S}}>\overline{T S}$ over the ability distribution for a population of highly skilled students, $f_{a_{H}}$, and a population of students with lower skills, $f_{a_{L}}$. 

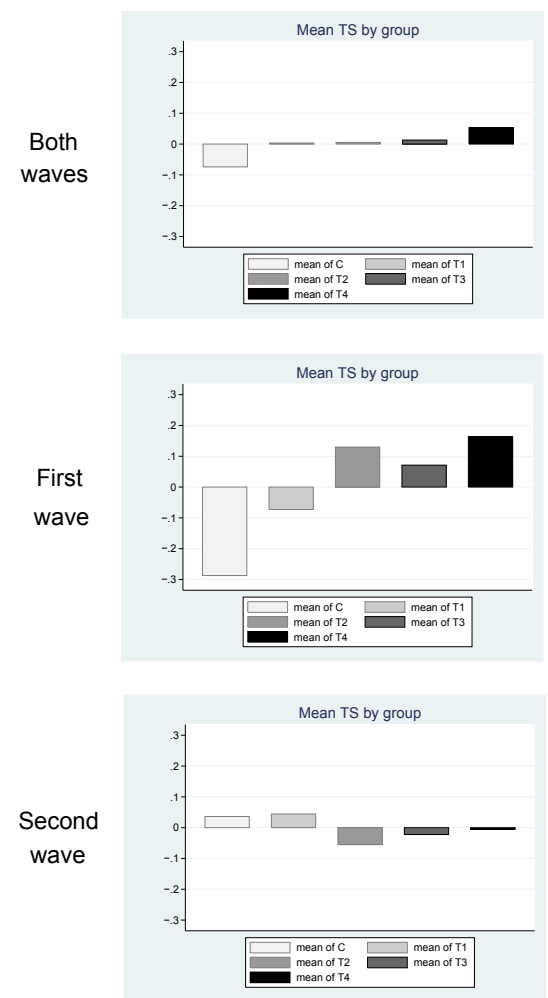

Boys
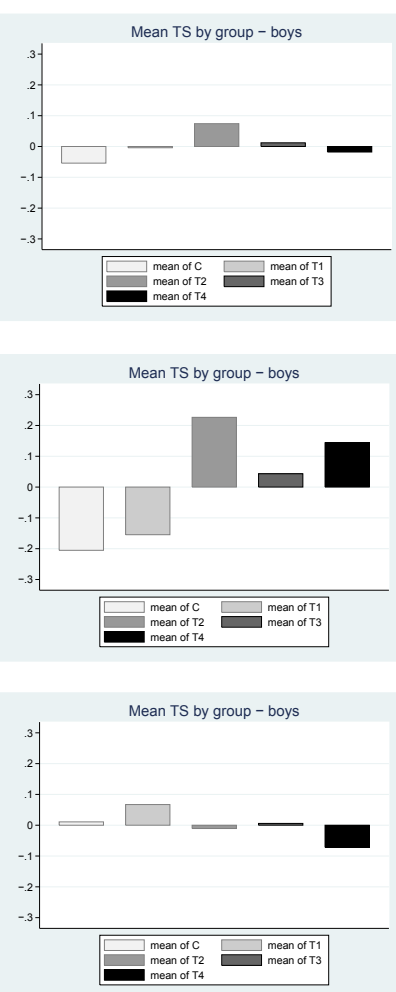

Girls
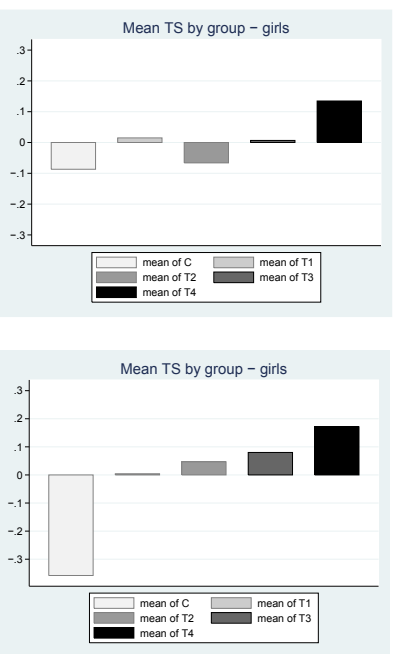

Mean TS by group - girls

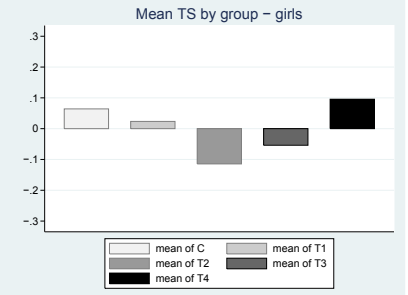

Figure 3: Mean Test Scores (standardized within subsample) across groups

All
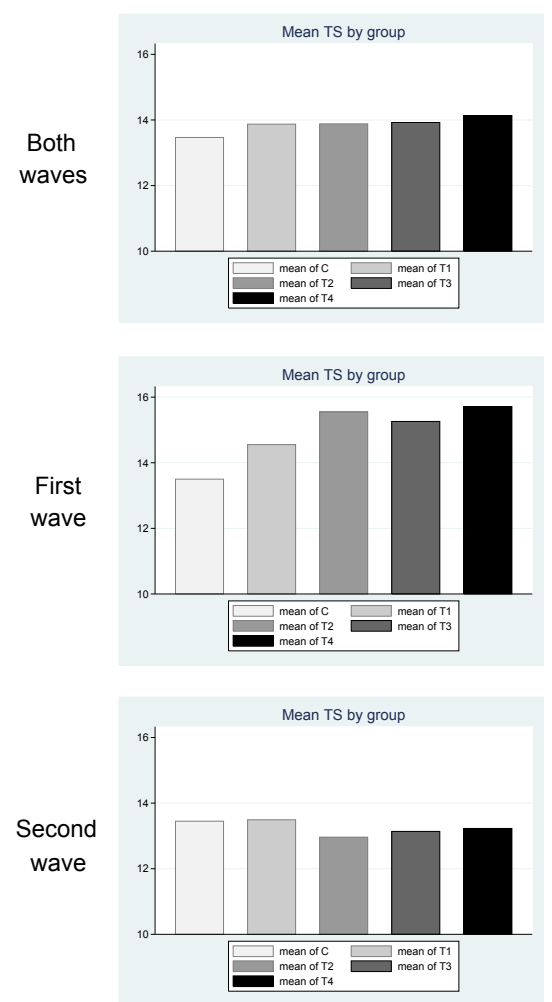

Boys
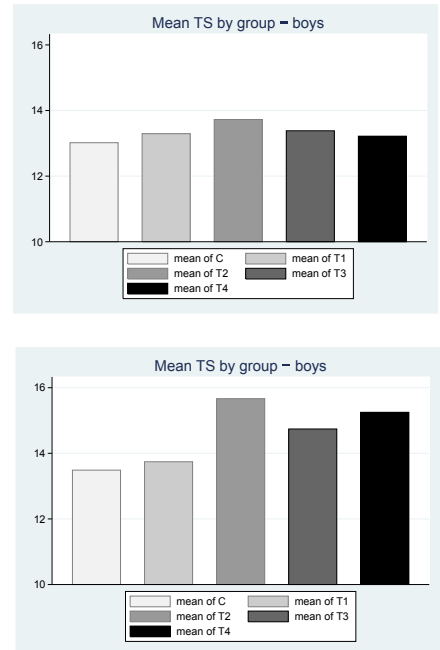

Mean TS by group - boys

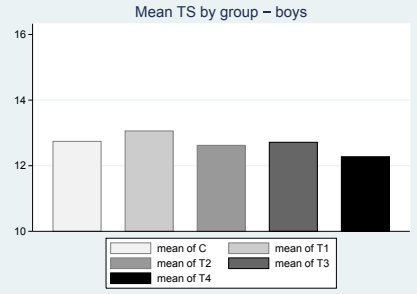

Girls
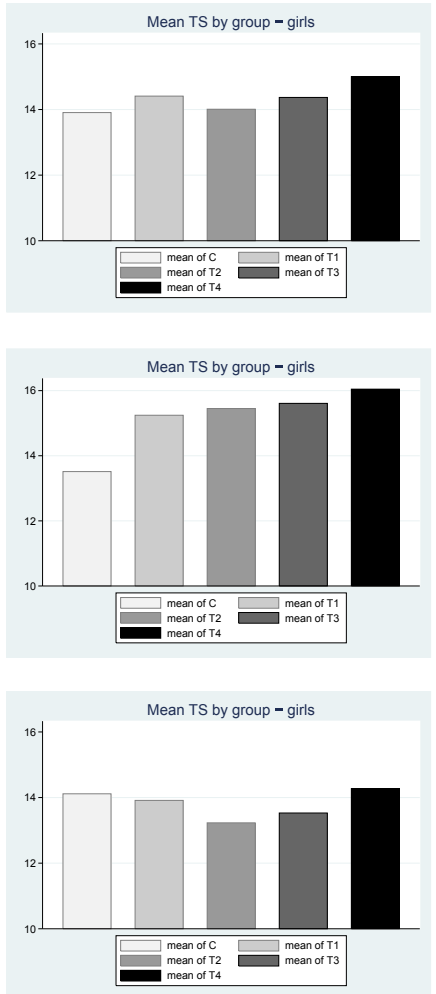

Figure 4: Mean Test Scores (points) across groups 

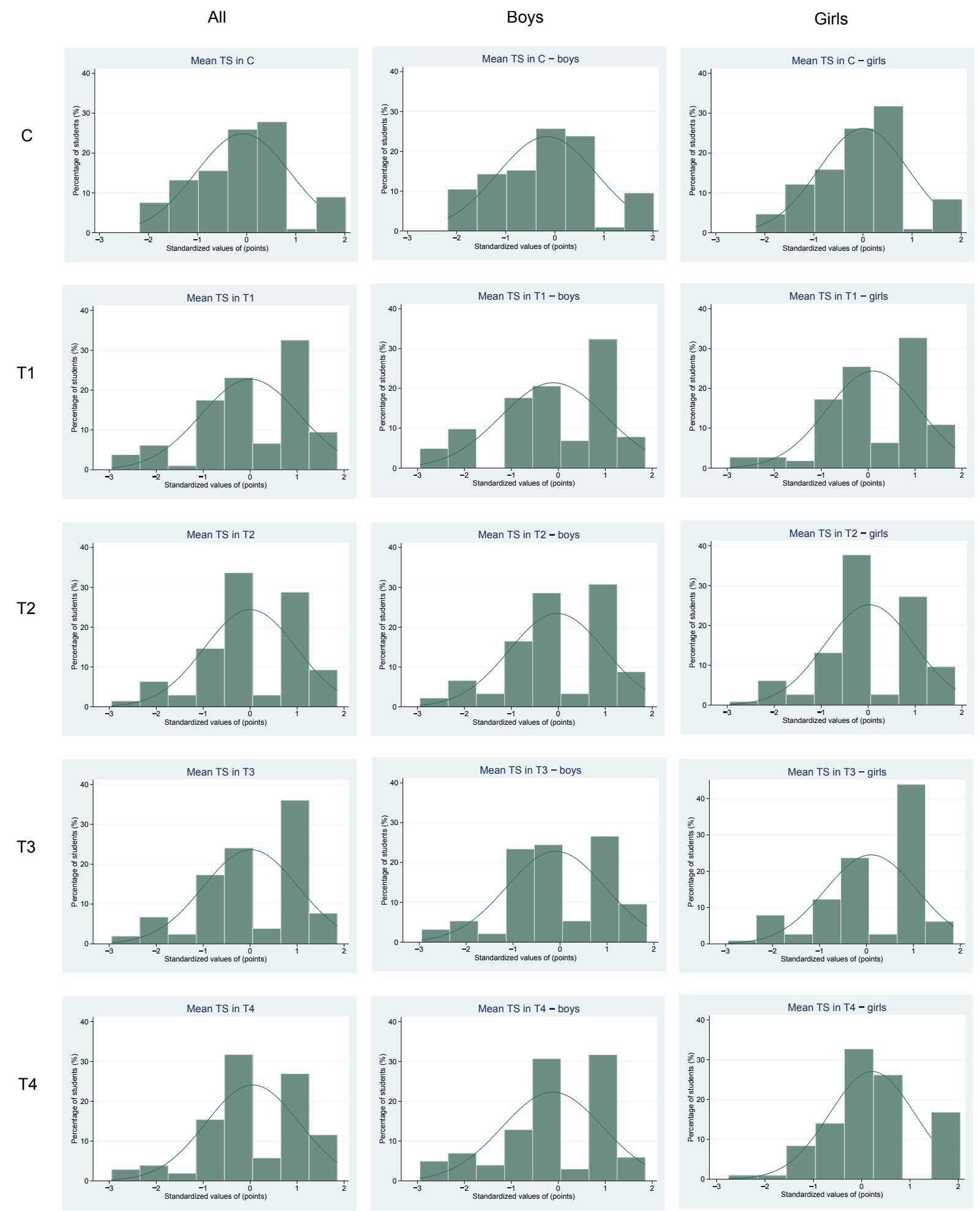

Figure 5: Test Score (standardized) distributions, both waves 

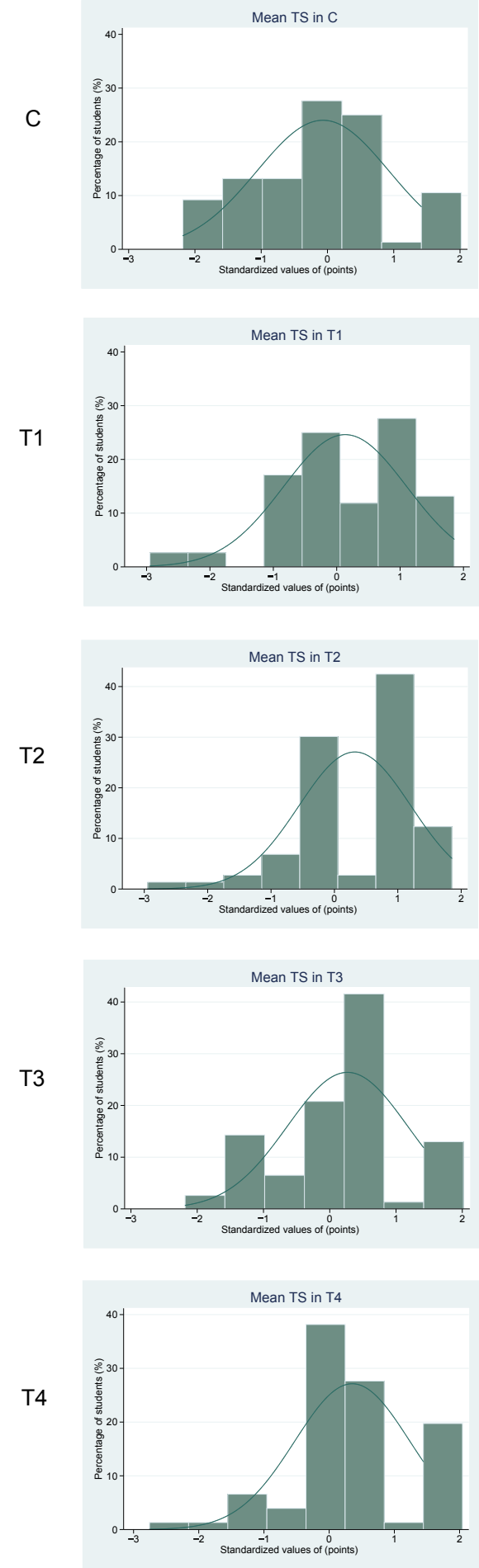

Boys
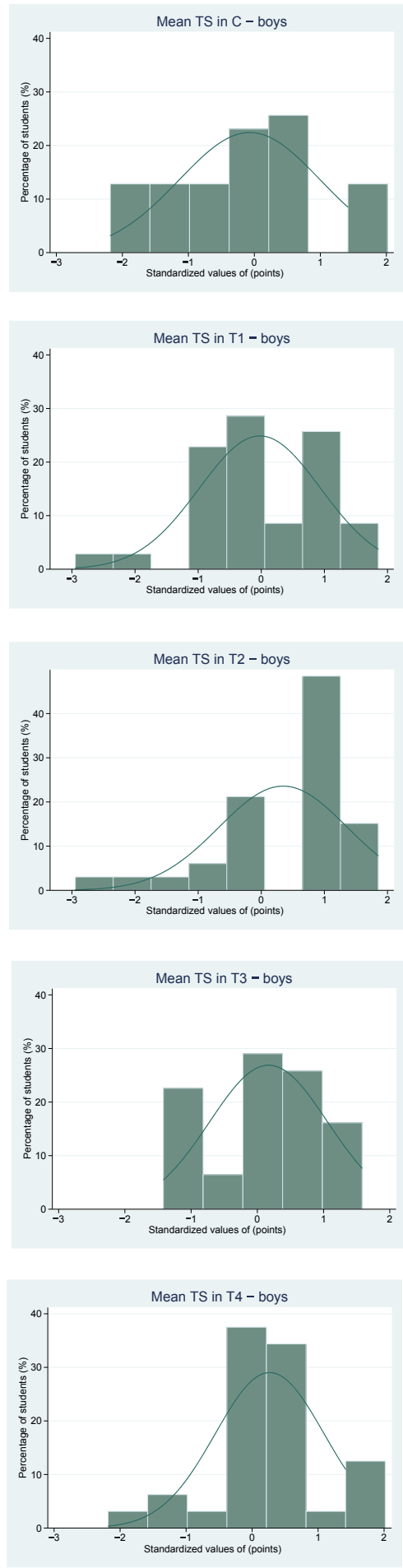

Girls
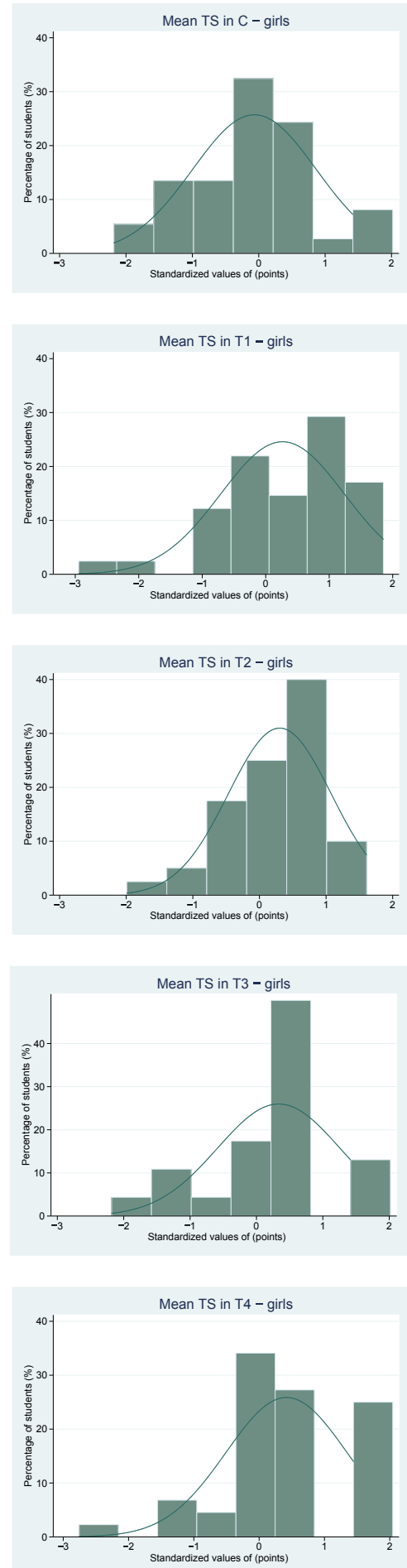

Figure 6: Test Score (standardized) distributions, first wave 
All
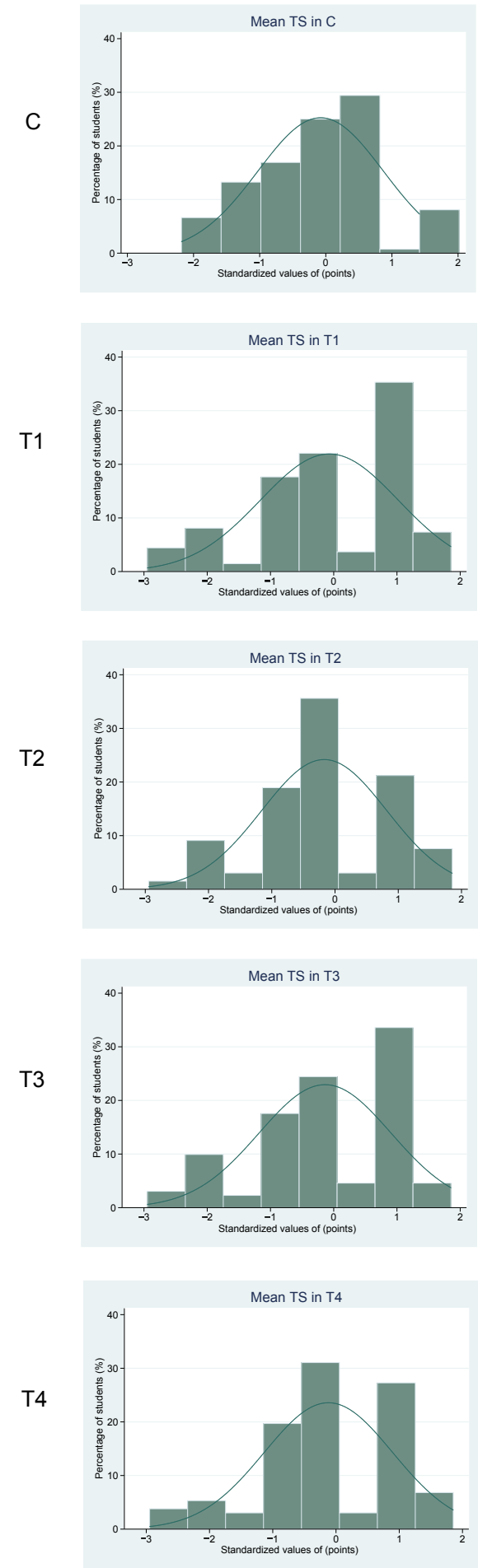

Boys
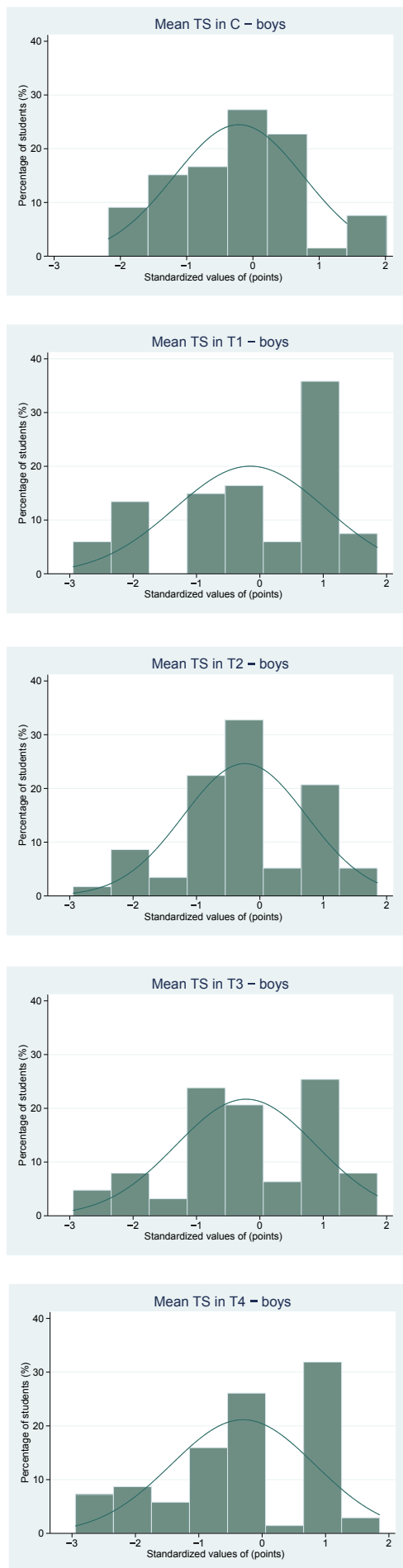

Girls
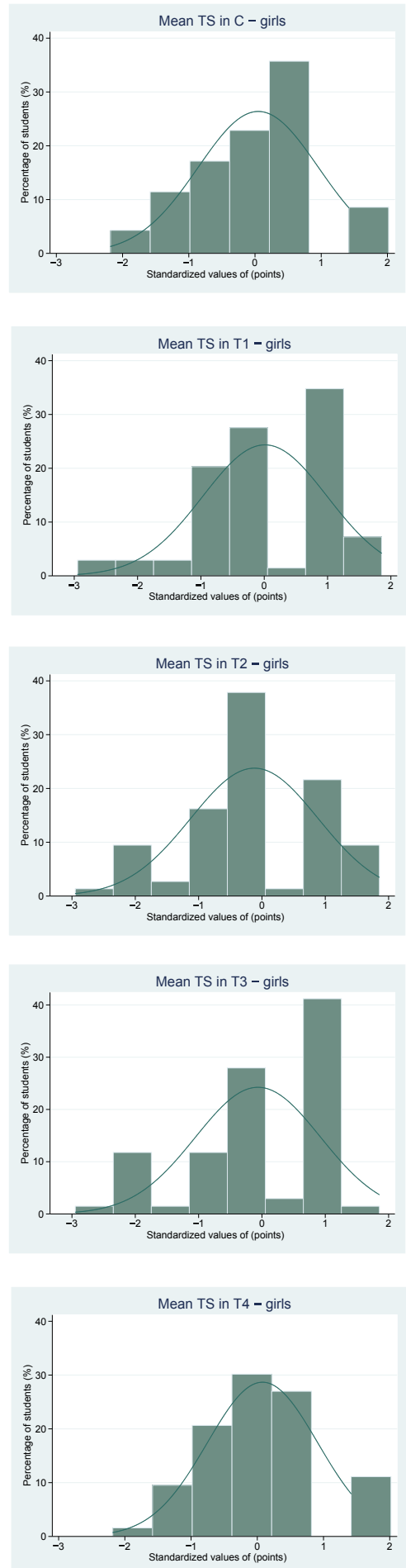

Figure 7: Test Score (standardized) distribution, second wave 
Table 3: Average Test Scores across Control and Treatment groups.

\begin{tabular}{|c|c|c|c|c|c|}
\hline & Control & $\mathrm{T} 1$ & $\mathrm{~T} 2$ & $\mathrm{~T} 3$ & $\mathrm{~T} 4$ \\
\hline \multicolumn{6}{|l|}{ Full sample, both waves } \\
\hline $\mathrm{N}$ individuals & 212 & 212 & 205 & 208 & 208 \\
\hline \multirow[t]{2}{*}{ Test Score (standardized) } & -0.074 & 0.003 & 0.005 & 0.013 & 0.053 \\
\hline & $(0.066)$ & $(0.072)$ & $(0.068)$ & $(0.070)$ & $(0.069)$ \\
\hline Test Score (points) & $\begin{array}{l}13.467 \\
(0.346)\end{array}$ & $\begin{array}{l}13.873 \\
(0.379)\end{array}$ & $\begin{array}{l}13.883 \\
(0.358)\end{array}$ & $\begin{array}{l}13.923 \\
(0.367)\end{array}$ & $\begin{array}{l}14.135 \\
(0.361)\end{array}$ \\
\hline \multicolumn{6}{|l|}{ Boys } \\
\hline $\mathrm{N}$ individuals & 105 & 102 & 91 & 94 & 101 \\
\hline Test Score (standardized) & $\begin{array}{c}-0.160 \\
(0.010)\end{array}$ & $\begin{array}{c}-0.107 \\
(0.111)\end{array}$ & $\begin{array}{c}-0.025 \\
(0.107)\end{array}$ & $\begin{array}{c}-0.090 \\
(0.108)\end{array}$ & $\begin{array}{l}-0.122 \\
(0.107)\end{array}$ \\
\hline Test Score (points) & $\begin{array}{l}13.019 \\
(0.516)\end{array}$ & $\begin{array}{l}13.294 \\
(0.579)\end{array}$ & $\begin{array}{l}13.725 \\
(0.561)\end{array}$ & $\begin{array}{l}13.383 \\
(0.567)\end{array}$ & $\begin{array}{l}13.218 \\
(0.559)\end{array}$ \\
\hline \multicolumn{6}{|l|}{ Girls } \\
\hline \multirow{2}{*}{$\begin{array}{l}\mathrm{N} \text { individuals } \\
\text { Test Score (standardized) }\end{array}$} & 107 & 110 & 114 & 114 & 107 \\
\hline & $\begin{array}{c}0.010 \\
(0.088)\end{array}$ & $\begin{array}{c}0.106 \\
(0.094)\end{array}$ & $\begin{array}{c}0.029 \\
(0.089)\end{array}$ & $\begin{array}{c}0.098 \\
(0.092)\end{array}$ & $\begin{array}{c}0.219 \\
(0.086)\end{array}$ \\
\hline Test Score (points) & $\begin{array}{l}13.907 \\
(0.462)\end{array}$ & $\begin{array}{l}14.409 \\
(0.491)\end{array}$ & $\begin{array}{l}14.009 \\
(0.466)\end{array}$ & $\begin{array}{l}14.368 \\
(0.479)\end{array}$ & $\begin{array}{l}15.000 \\
(0.448)\end{array}$ \\
\hline \multicolumn{6}{|l|}{ Full sample, first wave } \\
\hline \multirow{2}{*}{ Test Score (standardized) } & 76 & 76 & 73 & 77 & 76 \\
\hline & $\begin{array}{c}-0.287 \\
(0.122)\end{array}$ & $\begin{array}{c}-0.072 \\
(0.119)\end{array}$ & $\begin{array}{c}0.130 \\
(0.110)\end{array}$ & $\begin{array}{c}0.071 \\
(0.110)\end{array}$ & $\begin{array}{c}0.163 \\
(0.108)\end{array}$ \\
\hline Test Score (points) & $\begin{array}{l}13.500 \\
(0.599)\end{array}$ & $\begin{array}{l}14.553 \\
(0.584)\end{array}$ & $\begin{array}{l}15.548 \\
(0.542)\end{array}$ & $\begin{array}{l}15.260 \\
(0.541)\end{array}$ & $\begin{array}{l}15.711 \\
(0.530)\end{array}$ \\
\hline \multicolumn{6}{|l|}{ Boys } \\
\hline $\mathrm{N}$ individuals & 39 & 35 & 33 & 31 & 32 \\
\hline Test Score (standardized) & $\begin{array}{c}-0.290 \\
(0.182)\end{array}$ & $\begin{array}{c}-0.238 \\
(0.173)\end{array}$ & $\begin{array}{c}0.154 \\
(0.188)\end{array}$ & $\begin{array}{c}-0.034 \\
(0.171)\end{array}$ & $\begin{array}{c}0.069 \\
(0.155)\end{array}$ \\
\hline Test Score (points) & $\begin{array}{l}13.487 \\
(0.895)\end{array}$ & $\begin{array}{l}13.743 \\
(0.851)\end{array}$ & $\begin{array}{l}15.667 \\
(0.925)\end{array}$ & $\begin{array}{l}14.742 \\
(0.837)\end{array}$ & $\begin{array}{l}15.250 \\
(0.763)\end{array}$ \\
\hline \multicolumn{6}{|l|}{ Girls } \\
\hline $\mathrm{N}$ individuals & 37 & 41 & 40 & 46 & 44 \\
\hline Test Score (standardized) & $\begin{array}{c}-0.284 \\
(0.163)\end{array}$ & $\begin{array}{c}0.068 \\
(0.162)\end{array}$ & $\begin{array}{c}0.110 \\
(0.130)\end{array}$ & $\begin{array}{c}0.142 \\
(0.145)\end{array}$ & $\begin{array}{c}0.231 \\
(0.149)\end{array}$ \\
\hline Test Score (points) & $\begin{array}{l}13.514 \\
(0.801)\end{array}$ & $\begin{array}{l}15.244 \\
(0.796)\end{array}$ & $\begin{array}{l}15.450 \\
(0.639)\end{array}$ & $\begin{array}{l}15.609 \\
(0.711)\end{array}$ & $\begin{array}{l}16.045 \\
(0.731)\end{array}$ \\
\hline \multicolumn{6}{|l|}{ Full sample, second wave } \\
\hline $\mathrm{N}$ individuals & 136 & 136 & 132 & 131 & 132 \\
\hline Test Score (standardized) & $\begin{array}{c}0.036 \\
(0.080)\end{array}$ & $\begin{array}{c}0.044 \\
(0.092)\end{array}$ & $\begin{array}{c}-0.055 \\
(0.085)\end{array}$ & $\begin{array}{c}-0.022 \\
(0.090)\end{array}$ & $\begin{array}{l}-0.005 \\
(0.087)\end{array}$ \\
\hline Test Score (points) & $\begin{array}{l}13.449 \\
(0.426)\end{array}$ & $\begin{array}{l}13.493 \\
(0.490)\end{array}$ & $\begin{array}{l}12.962 \\
(0.451)\end{array}$ & $\begin{array}{l}13.137 \\
(0.477)\end{array}$ & $\begin{array}{l}13.227 \\
(0.463)\end{array}$ \\
\hline \multicolumn{6}{|l|}{ Boys } \\
\hline $\mathrm{N}$ individuals & 66 & 67 & 58 & 63 & 69 \\
\hline Test Score (standardized) & $\begin{array}{c}-0.097 \\
(0.118)\end{array}$ & $\begin{array}{c}-0.037 \\
(0.144)\end{array}$ & $\begin{array}{c}-0.119 \\
(0.126)\end{array}$ & $\begin{array}{c}-0.102 \\
(0.137)\end{array}$ & $\begin{array}{l}-0.184 \\
(0.134)\end{array}$ \\
\hline Test Score (points) & $\begin{array}{l}12.742 \\
(0.630)\end{array}$ & $\begin{array}{l}13.060 \\
(0.765)\end{array}$ & $\begin{array}{l}12.621 \\
(0.668)\end{array}$ & $\begin{array}{l}12.714 \\
(0.728)\end{array}$ & $\begin{array}{l}12.275 \\
(0.713)\end{array}$ \\
\hline \multicolumn{6}{|l|}{ Girls } \\
\hline $\mathrm{N}$ individuals & 70 & 69 & 74 & 68 & 63 \\
\hline Test Score (standardized) & $\begin{array}{c}0.161 \\
(0.107)\end{array}$ & $\begin{array}{c}0.123 \\
(0.116)\end{array}$ & $\begin{array}{c}-0.005 \\
(0.115)\end{array}$ & $\begin{array}{c}0.051 \\
(0.118)\end{array}$ & $\begin{array}{c}0.190 \\
(0.103)\end{array}$ \\
\hline Test Score (points) & $\begin{array}{l}14.114 \\
(0.568)\end{array}$ & $\begin{array}{l}13.913 \\
(0.620)\end{array}$ & $\begin{array}{l}13.230 \\
(0.613)\end{array}$ & $\begin{array}{l}13.529 \\
(0.627)\end{array}$ & $\begin{array}{l}14.270 \\
(0.551)\end{array}$ \\
\hline
\end{tabular}

Note: The table displays descriptive statistics of test scores and the number of students in each of the treatment groups and the control group. Both average points scored on the test and standardized test scores (with mean 0 and standard deviation 1). The first column represents the control group and columns T1 to T4 represent the four treatment groups; (T1) criterion-based grade A-F, (T2) rank-based grade A, (T3) criterion-based certificate, and (T4) rank-based prize. The full sample includes the first wave conducted towards the end of sixth grade in April 2013 and the second wave conducted at the beginning of sixth grade in August-September 2013. All statistics are displayed separately by gender and wave. Standard errors are displayed in parentheses. 
Table 4: Differences in Means.

\begin{tabular}{|c|c|c|c|c|c|}
\hline & Control & $\mathrm{T} 1-\mathrm{C}$ & $\mathrm{T} 2-\mathrm{C}$ & $\mathrm{T} 3-\mathrm{C}$ & $\mathrm{T} 4-\mathrm{C}$ \\
\hline \multicolumn{6}{|l|}{ Full sample } \\
\hline Test Score (points) & $\begin{array}{l}13.467 \\
(0.346)\end{array}$ & $\begin{array}{c}0.406 \\
(0.513)\end{array}$ & $\begin{array}{c}0.416 \\
(0.498)\end{array}$ & $\begin{array}{c}0.456 \\
(0.505)\end{array}$ & $\begin{array}{c}0.668 \\
(0.500)\end{array}$ \\
\hline Test Score (standardized) & $\begin{array}{c}-0.074 \\
(0.066)\end{array}$ & $\begin{array}{c}0.077 \\
(0.098)\end{array}$ & $\begin{array}{c}0.079 \\
(0.095)\end{array}$ & $\begin{array}{c}0.087 \\
(0.096)\end{array}$ & $\begin{array}{c}0.128 \\
(0.095)\end{array}$ \\
\hline Learning Weeks & $\begin{array}{l}13.825 \\
(1.071)\end{array}$ & $\begin{array}{c}0.005 \\
(1.515)\end{array}$ & $\begin{array}{l}-0.113 \\
(1.528)\end{array}$ & $\begin{array}{c}0.405 \\
(1.527)\end{array}$ & $\begin{array}{c}0.208 \\
(1.526)\end{array}$ \\
\hline New Peers & $\begin{array}{c}0.222 \\
(0.029)\end{array}$ & $\begin{array}{l}-0.019 \\
(0.040)\end{array}$ & $\begin{array}{l}-0.041 \\
(0.039)\end{array}$ & $\begin{array}{l}-0.034 \\
(0.039)\end{array}$ & $\begin{array}{l}-0.034 \\
(0.039)\end{array}$ \\
\hline Class Size & $\begin{array}{l}23.170 \\
(0.330)\end{array}$ & $\begin{array}{l}-0.038 \\
(0.466)\end{array}$ & $\begin{array}{c}0.089 \\
(0.474)\end{array}$ & $\begin{array}{c}0.258 \\
(0.470)\end{array}$ & $\begin{array}{l}0.272 \\
(0.470\end{array}$ \\
\hline Female & $\begin{array}{c}0.505 \\
(0.034)\end{array}$ & $\begin{array}{c}0.014 \\
(0.049)\end{array}$ & $\begin{array}{c}0.051 \\
(0.049)\end{array}$ & $\begin{array}{c}0.043 \\
(0.049)\end{array}$ & $\begin{array}{c}0.010 \\
(0.049)\end{array}$ \\
\hline GPA & $\begin{array}{c}233.247 \\
(1.81)\end{array}$ & $\begin{array}{l}-0.288 \\
(2.564)\end{array}$ & $\begin{array}{l}-0.827 \\
(2.575)\end{array}$ & $\begin{array}{l}-0.562 \\
(2.592)\end{array}$ & $\begin{array}{c}0.104 \\
(2.622)\end{array}$ \\
\hline Foreign-Born & $\begin{array}{c}0.114 \\
(0.009)\end{array}$ & $\begin{array}{c}0.003 \\
(0.013)\end{array}$ & $\begin{array}{c}0.002 \\
(0.013)\end{array}$ & $\begin{array}{c}0.002 \\
(0.013)\end{array}$ & $\begin{array}{c}0.002 \\
(0.013)\end{array}$ \\
\hline Foreign Parents & $\begin{array}{c}0.114 \\
(0.007)\end{array}$ & $\begin{array}{c}0.002 \\
(0.010)\end{array}$ & $\begin{array}{c}0.009 \\
(0.010)\end{array}$ & $\begin{array}{c}0.006 \\
(0.010)\end{array}$ & $\begin{array}{c}0.001 \\
(0.010)\end{array}$ \\
\hline Parent Education & $\begin{array}{c}2.387 \\
(0.015)\end{array}$ & $\begin{array}{l}-0.002 \\
(0.021)\end{array}$ & $\begin{array}{l}-0.011 \\
(0.021)\end{array}$ & $\begin{array}{l}-0.011 \\
(0.021)\end{array}$ & $\begin{array}{l}-0.003 \\
(0.021)\end{array}$ \\
\hline No 7-9 Grade & $\begin{array}{c}0.085 \\
(0.019)\end{array}$ & $\begin{array}{l}-0.009 \\
(0.026)\end{array}$ & $\begin{array}{l}-0.002 \\
(0.027)\end{array}$ & $\begin{array}{l}-0.003 \\
(0.027)\end{array}$ & $\begin{array}{l}-0.011 \\
(0.028)\end{array}$ \\
\hline \multicolumn{6}{|l|}{ Boys } \\
\hline Test Score (points) & $\begin{array}{l}13.019 \\
(0.516)\end{array}$ & $\begin{array}{c}0.275 \\
(0.775)\end{array}$ & $\begin{array}{c}0.706 \\
(0.761)\end{array}$ & $\begin{array}{c}0.364 \\
(0.765)\end{array}$ & $\begin{array}{c}0.199 \\
(0.760\end{array}$ \\
\hline Test Score (standardized) & $\begin{array}{l}-0.160 \\
(0.099)\end{array}$ & $\begin{array}{c}0.053 \\
(0.148)\end{array}$ & $\begin{array}{c}0.135 \\
(0.145)\end{array}$ & $\begin{array}{c}0.070 \\
(0.146)\end{array}$ & $\begin{array}{c}0.038 \\
(0.145)\end{array}$ \\
\hline Learning Weeks & $\begin{array}{l}14.333 \\
(1.521)\end{array}$ & $\begin{array}{l}-1.029 \\
(2.159)\end{array}$ & $\begin{array}{l}-0.377 \\
(2.234)\end{array}$ & $\begin{array}{l}-1.397 \\
(2.197)\end{array}$ & $\begin{array}{l}-1.908 \\
(2.150)\end{array}$ \\
\hline New Peers & $\begin{array}{c}0.219 \\
(0.041)\end{array}$ & $\begin{array}{l}-0.003 \\
(0.058)\end{array}$ & $\begin{array}{l}-0.043 \\
(0.057)\end{array}$ & $\begin{array}{l}-0.006 \\
(0.059)\end{array}$ & $\begin{array}{l}-0.011 \\
(0.057)\end{array}$ \\
\hline Class Size & $\begin{array}{l}22.505 \\
(0.443)\end{array}$ & $\begin{array}{l}0.456 \\
(0.640)\end{array}$ & $\begin{array}{c}0.484 \\
(0.678)\end{array}$ & $\begin{array}{l}0.868 \\
(0.650)\end{array}$ & $\begin{array}{l}1.317^{* *} \\
(0.646)\end{array}$ \\
\hline GPA & $\begin{array}{c}227.907 \\
(2.593)\end{array}$ & $\begin{array}{c}4.469 \\
(3.587)\end{array}$ & $\begin{array}{l}-1.102 \\
(3.835)\end{array}$ & $\begin{array}{l}6.284^{*} \\
(3.651)\end{array}$ & $\begin{array}{c}4.766 \\
(3.653)\end{array}$ \\
\hline Foreign-Born & $\begin{array}{c}0.140 \\
(0.014)\end{array}$ & $\begin{array}{l}-0.026 \\
(0.019)\end{array}$ & $\begin{array}{l}-0.006 \\
(0.022)\end{array}$ & $\begin{array}{l}-0.032^{*} \\
(0.019)\end{array}$ & $\begin{array}{c}-0.024 \\
(0.020)\end{array}$ \\
\hline Foreign Parents & $\begin{array}{c}0.130 \\
(0.009)\end{array}$ & $\begin{array}{l}-0.014 \\
(0.013)\end{array}$ & $\begin{array}{c}0.000 \\
(0.014)\end{array}$ & $\begin{array}{l}-0.006 \\
(0.014)\end{array}$ & $\begin{array}{l}-0.002 \\
(0.014)\end{array}$ \\
\hline Parent Education & $\begin{array}{c}2.340 \\
(0.021)\end{array}$ & $\begin{array}{c}0.044 \\
(0.029)\end{array}$ & $\begin{array}{l}-0.014 \\
(0.031)\end{array}$ & $\begin{array}{l}0.051^{*} \\
(0.029)\end{array}$ & $\begin{array}{c}0.034 \\
(0.029)\end{array}$ \\
\hline No 7-9 Grade & $\begin{array}{c}0.076 \\
(0.026)\end{array}$ & $\begin{array}{c}0.012 \\
(0.038)\end{array}$ & $\begin{array}{c}0.023 \\
(0.040)\end{array}$ & $\begin{array}{l}-0.023 \\
(0.035)\end{array}$ & $\begin{array}{l}-0.017 \\
(0.035)\end{array}$ \\
\hline \multicolumn{6}{|l|}{ Girls } \\
\hline Test Score (points) & $\begin{array}{l}13.907 \\
(0.462)\end{array}$ & $\begin{array}{c}0.503 \\
(0.675)\end{array}$ & $\begin{array}{c}0.102 \\
(0.657)\end{array}$ & $\begin{array}{c}0.462 \\
(0.667)\end{array}$ & $\begin{array}{l}1.093^{*} \\
(0.644)\end{array}$ \\
\hline Test Score (standardized) & $\begin{array}{l}0.010 \\
(0.088)\end{array}$ & $\begin{array}{c}0.096 \\
(0.129)\end{array}$ & $\begin{array}{c}0.020 \\
(0.125)\end{array}$ & $\begin{array}{l}0.088 \\
(0.127)\end{array}$ & $\begin{array}{l}0.209^{*} \\
(0.123)\end{array}$ \\
\hline Learning Weeks & $\begin{array}{l}13.327 \\
(1.513)\end{array}$ & $\begin{array}{c}0.991 \\
(2.133)\end{array}$ & $\begin{array}{c}0.190 \\
(2.107)\end{array}$ & $\begin{array}{c}1.971 \\
(2.130)\end{array}$ & $\begin{array}{c}2.224 \\
(2.162)\end{array}$ \\
\hline New Peers & $\begin{array}{c}0.224 \\
(0.041)\end{array}$ & $\begin{array}{l}-0.033 \\
(0.055)\end{array}$ & $\begin{array}{l}-0.040 \\
(0.054)\end{array}$ & $\begin{array}{l}-0.058 \\
(0.053)\end{array}$ & $\begin{array}{l}-0.056 \\
(0.054)\end{array}$ \\
\hline Class Size & $\begin{array}{l}23.822 \\
(0.483)\end{array}$ & $\begin{array}{l}-0.532 \\
(0.672)\end{array}$ & $\begin{array}{l}-0.349 \\
(0.661)\end{array}$ & $\begin{array}{l}-0.349 \\
(0.672)\end{array}$ & $\begin{array}{l}-0.738 \\
(0.678)\end{array}$ \\
\hline GPA & $\begin{array}{c}238.588 \\
(2.420)\end{array}$ & $\begin{array}{l}-5.102 \\
(3.603)\end{array}$ & $\begin{array}{l}-1.823 \\
(3.358)\end{array}$ & $\begin{array}{c}-7.215^{* *} \\
(3.613)\end{array}$ & $\begin{array}{l}-4.545 \\
(3.698)\end{array}$ \\
\hline Foreign-Born & $\begin{array}{c}0.088 \\
(0.011)\end{array}$ & $\begin{array}{l}0.032^{*} \\
(0.018)\end{array}$ & $\begin{array}{c}0.013 \\
(0.015)\end{array}$ & $\begin{array}{l}0.035^{*} \\
(0.018)\end{array}$ & $\begin{array}{c}0.029 \\
(0.018)\end{array}$ \\
\hline Foreign Parents & $\begin{array}{c}0.099 \\
(0.010)\end{array}$ & $\begin{array}{c}0.017 \\
(0.014)\end{array}$ & $\begin{array}{c}0.019 \\
(0.014)\end{array}$ & $\begin{array}{c}0.018 \\
(0.013)\end{array}$ & $\begin{array}{c}0.004 \\
(0.013)\end{array}$ \\
\hline Parent Education & $\begin{array}{c}2.434 \\
(0.020)\end{array}$ & $\begin{array}{l}-0.049^{*} \\
(0.029)\end{array}$ & $\begin{array}{l}-0.018 \\
(0.027)\end{array}$ & $\begin{array}{c}-0.070^{* *} \\
(0.029)\end{array}$ & $\begin{array}{l}-0.040 \\
(0.030)\end{array}$ \\
\hline No 7-9 Grade & $\begin{array}{c}0.093 \\
(0.028)\end{array}$ & $\begin{array}{l}-0.030 \\
(0.037)\end{array}$ & $\begin{array}{l}-0.023 \\
(0.037)\end{array}$ & $\begin{array}{c}0.012 \\
(0.040)\end{array}$ & $\begin{array}{c}0.037 \\
(0.043)\end{array}$ \\
\hline
\end{tabular}

Note: The table displays descriptive statistics for the outcome and control variables separately over treatment and control groups. The first column presents the control group mean for each variable: the outcome variable (points scored on the test and its standardized counterpart with mean 0 and standard deviation 1), learning weeks, new peers, class size, gender, and five school-level variables (average GPA of ninth graders, fraction of students born abroad, fraction of students for which both parents were born abroad, average level of parental education, and schools without grades 7-9). Columns T1-C to T4-C represent the differences in means between treatment groups and the control group. The four treatments are: (T1) criterion-based grade A-F, (T2) rank-based grade A, (T3) criterion-based certificate, and (T4) rank-based prize. Tests are conducted on the full sample; including the first wave conducted towards the end of sixth grade in April 2013 and the second wave conducted at the beginning of sixth grade in August-September 2013. Standard errors are displayed in parentheses. Asterisks indicate a significant difference of means, where $(* * *, p<0.01),(* *, p<0.05)$ and $(*, p<0.1)$. 
Table 5: Differences in Means, first wave.

\begin{tabular}{|c|c|c|c|c|c|}
\hline & Control & $\mathrm{T} 1-\mathrm{C}$ & $\mathrm{T} 2-\mathrm{C}$ & $\mathrm{T} 3-\mathrm{C}$ & $\mathrm{T} 4-\mathrm{C}$ \\
\hline \multicolumn{6}{|l|}{ Full sample } \\
\hline Test Score (points) & $\begin{array}{l}13.500 \\
(0.599)\end{array}$ & $\begin{array}{c}1.053 \\
(0.836)\end{array}$ & $\begin{array}{c}2.048^{* *} \\
(0.809)\end{array}$ & $\begin{array}{c}1.760^{* *} \\
(0.806)\end{array}$ & $\begin{array}{c}2.211^{* * *} \\
(0.799)\end{array}$ \\
\hline Test Score (standardized) & $\begin{array}{l}-0.287 \\
(0.122)\end{array}$ & $\begin{array}{c}0.214 \\
(0.170)\end{array}$ & $\begin{array}{c}0.417^{* *} \\
(0.165)\end{array}$ & $\begin{array}{c}0.358^{* *} \\
(0.164)\end{array}$ & $\begin{array}{c}0.450 * * * \\
(0.163)\end{array}$ \\
\hline Learning Weeks & $\begin{array}{l}34.566 \\
(0.078)\end{array}$ & $\begin{array}{c}0.013 \\
(0.110)\end{array}$ & $\begin{array}{c}0.010 \\
(0.112)\end{array}$ & $\begin{array}{c}0.446 \\
(0.109)\end{array}$ & $\begin{array}{c}0.013 \\
(0.109)\end{array}$ \\
\hline Class Size & $\begin{array}{l}20.789 \\
(0.564)\end{array}$ & $\begin{array}{c}0.211 \\
(0.789)\end{array}$ & $\begin{array}{c}-0.132 \\
(0.800)\end{array}$ & $\begin{array}{c}0.353 \\
(0.798)\end{array}$ & $\begin{array}{c}0.316 \\
(0.818)\end{array}$ \\
\hline Female & $\begin{array}{c}0.487 \\
(0.057)\end{array}$ & $\begin{array}{c}0.053 \\
(0.082)\end{array}$ & $\begin{array}{c}0.061 \\
(0.082)\end{array}$ & $\begin{array}{c}0.111 \\
(0.081)\end{array}$ & $\begin{array}{c}0.092 \\
(0.081)\end{array}$ \\
\hline GPA & $\begin{array}{c}232.349 \\
(4.250)\end{array}$ & $\begin{array}{c}0.120 \\
(6.020)\end{array}$ & $\begin{array}{l}-1.383 \\
(6.104)\end{array}$ & $\begin{array}{l}-1.318 \\
(6.038)\end{array}$ & $\begin{array}{c}0.909 \\
(6.152)\end{array}$ \\
\hline Foreign-Born & $\begin{array}{c}0.147 \\
(0.019)\end{array}$ & $\begin{array}{c}0.005 \\
(0.028)\end{array}$ & $\begin{array}{c}0.007 \\
(0.028)\end{array}$ & $\begin{array}{c}0.012 \\
(0.028)\end{array}$ & $\begin{array}{c}0.006 \\
(0.028)\end{array}$ \\
\hline Foreign Parents & $\begin{array}{c}0.149 \\
(0.014)\end{array}$ & $\begin{array}{c}0.000 \\
(0.020)\end{array}$ & $\begin{array}{c}0.006 \\
(0.021)\end{array}$ & $\begin{array}{c}0.002 \\
(0.020)\end{array}$ & $\begin{array}{l}-0.005 \\
(0.020)\end{array}$ \\
\hline Parent Education & $\begin{array}{c}2.357 \\
(0.032)\end{array}$ & $\begin{array}{l}-0.001 \\
(0.046)\end{array}$ & $\begin{array}{l}-0.013 \\
(0.046)\end{array}$ & $\begin{array}{l}-0.015 \\
(0.046)\end{array}$ & $\begin{array}{c}0.000 \\
(0.046)\end{array}$ \\
\hline No 7-9 Grade & $\begin{array}{c}0.171 \\
(0.041)\end{array}$ & $\begin{array}{c}-0.013 \\
(0.061)\end{array}$ & $\begin{array}{c}0.021 \\
(0.064)\end{array}$ & $\begin{array}{l}-0.015 \\
(0.061)\end{array}$ & $\begin{array}{c}0.013 \\
(0.062)\end{array}$ \\
\hline \multicolumn{6}{|l|}{ Boys } \\
\hline Test Score (points) & $\begin{array}{l}13.487 \\
(0.895)\end{array}$ & $\begin{array}{c}0.256 \\
(1.243)\end{array}$ & $\begin{array}{c}2.179^{*} \\
(1.293)\end{array}$ & $\begin{array}{c}1.255 \\
(1.252)\end{array}$ & $\begin{array}{c}1.763 \\
(1.207)\end{array}$ \\
\hline Test Score (standardized) & $\begin{array}{l}-0.290 \\
(0.182)\end{array}$ & $\begin{array}{c}0.052 \\
(0.253)\end{array}$ & $\begin{array}{l}0.444^{*} \\
(0.263)\end{array}$ & $\begin{array}{c}0.256 \\
(0.255)\end{array}$ & $\begin{array}{c}0.359 \\
(0.246)\end{array}$ \\
\hline Learning Weeks & $\begin{array}{l}34.462 \\
(0.103)\end{array}$ & $\begin{array}{c}0.081 \\
(0.151)\end{array}$ & $\begin{array}{c}0.023 \\
(0.155)\end{array}$ & $\begin{array}{c}0.151 \\
(0.168)\end{array}$ & $\begin{array}{c}0.195 \\
(0.170)\end{array}$ \\
\hline Class Size & $\begin{array}{l}20.410 \\
(0.739)\end{array}$ & $\begin{array}{c}-0.467 \\
(1.017)\end{array}$ & $\begin{array}{c}-0.744 \\
(1.056)\end{array}$ & $\begin{array}{c}0.977 \\
(1.121)\end{array}$ & $\begin{array}{c}0.465 \\
(1.134)\end{array}$ \\
\hline GPA & $\begin{array}{c}230.970 \\
(6.023)\end{array}$ & $\begin{array}{l}-5.785 \\
(8.826)\end{array}$ & $\begin{array}{l}-7.530 \\
(8.902)\end{array}$ & $\begin{array}{c}2.066 \\
(8.716)\end{array}$ & $\begin{array}{l}-1.720 \\
(8.625)\end{array}$ \\
\hline Foreign-Born & $\begin{array}{c}0.158 \\
(0.028)\end{array}$ & $\begin{array}{c}0.019 \\
(0.042)\end{array}$ & $\begin{array}{c}0.008 \\
(0.043)\end{array}$ & $\begin{array}{c}-0.018 \\
(0.040)\end{array}$ & $\begin{array}{l}-0.004 \\
(0.040)\end{array}$ \\
\hline Foreign Parents & $\begin{array}{c}0.143 \\
(0.019)\end{array}$ & $\begin{array}{c}0.016 \\
(0.028)\end{array}$ & $\begin{array}{c}0.015 \\
(0.029)\end{array}$ & $\begin{array}{c}0.018 \\
(0.030)\end{array}$ & $\begin{array}{c}0.036 \\
(0.030)\end{array}$ \\
\hline Parent Education & $\begin{array}{c}2.345 \\
(0.045)\end{array}$ & $\begin{array}{l}-0.043 \\
(0.067)\end{array}$ & $\begin{array}{l}-0.056 \\
(0.066)\end{array}$ & $\begin{array}{c}0.007 \\
(0.065)\end{array}$ & $\begin{array}{l}-0.026 \\
(0.064)\end{array}$ \\
\hline No 7-9 Grade & $\begin{array}{c}0.154 \\
(0.059)\end{array}$ & $\begin{array}{c}0.075 \\
(0.092)\end{array}$ & $\begin{array}{c}0.089 \\
(0.094)\end{array}$ & $\begin{array}{l}-0.057 \\
(0.081)\end{array}$ & $\begin{array}{c}-0.029 \\
(0.084)\end{array}$ \\
\hline \multicolumn{6}{|l|}{ Girls } \\
\hline Test Score (points) & $\begin{array}{l}13.514 \\
(0.801)\end{array}$ & $\begin{array}{c}1.730 \\
(1.132)\end{array}$ & $\begin{array}{l}1.936^{*} \\
(1.018)\end{array}$ & $\begin{array}{l}2.095^{*} \\
(1.070)\end{array}$ & $\begin{array}{c}2.532^{* *} \\
(1.084)\end{array}$ \\
\hline Test Score (standardized) & $\begin{array}{l}-0.284 \\
(0.163)\end{array}$ & $\begin{array}{c}0.352 \\
(0.231)\end{array}$ & $\begin{array}{l}0.394^{*} \\
(0.207)\end{array}$ & $\begin{array}{l}0.427^{*} \\
(0.218)\end{array}$ & $\begin{array}{c}0.516^{* *} \\
(0.221)\end{array}$ \\
\hline Learning Weeks & $\begin{array}{c}34.641 \\
(0.079)\end{array}$ & $\begin{array}{c}-0.066 \\
(0.160)\end{array}$ & $\begin{array}{l}-0.026 \\
(0.161)\end{array}$ & $\begin{array}{l}-0.067 \\
(0.145)\end{array}$ & $\begin{array}{c}-0.153 \\
(0.140)\end{array}$ \\
\hline Class Size & $\begin{array}{l}21.189 \\
(0.864)\end{array}$ & $\begin{array}{c}0.713 \\
(1.189)\end{array}$ & $\begin{array}{c}0.286 \\
(1.178)\end{array}$ & $\begin{array}{c}-0.211 \\
(1.147)\end{array}$ & $\begin{array}{c}0.084 \\
(1.186)\end{array}$ \\
\hline GPA & $\begin{array}{c}233.867 \\
(6.075)\end{array}$ & $\begin{array}{c}3.917 \\
(8.295)\end{array}$ & $\begin{array}{c}2.633 \\
(8.448)\end{array}$ & $\begin{array}{l}-4.353 \\
(8.552)\end{array}$ & $\begin{array}{c}2.692 \\
(8.887)\end{array}$ \\
\hline Foreign-Born & $\begin{array}{c}0.134 \\
(0.027)\end{array}$ & $\begin{array}{l}-0.002 \\
(0.037)\end{array}$ & $\begin{array}{c}0.010 \\
(0.037)\end{array}$ & $\begin{array}{c}0.040 \\
(0.039)\end{array}$ & $\begin{array}{c}0.017 \\
(0.040)\end{array}$ \\
\hline Foreign Parents & $\begin{array}{c}0.156 \\
(0.023)\end{array}$ & $\begin{array}{c}-0.014 \\
(0.030)\end{array}$ & $\begin{array}{c}-0.003 \\
(0.031)\end{array}$ & $\begin{array}{c}-0.012 \\
(0.028)\end{array}$ & $\begin{array}{l}-0.040 \\
(0.027)\end{array}$ \\
\hline Parent Education & $\begin{array}{c}2.370 \\
(0.047)\end{array}$ & $\begin{array}{c}0.026 \\
(0.064)\end{array}$ & $\begin{array}{c}0.014 \\
(0.065)\end{array}$ & $\begin{array}{l}-0.036 \\
(0.065)\end{array}$ & $\begin{array}{c}0.018 \\
(0.067)\end{array}$ \\
\hline No 7-9 Grade & $\begin{array}{c}0.189 \\
(0.065)\end{array}$ & $\begin{array}{c}-0.092 \\
(0.079)\end{array}$ & $\begin{array}{l}-0.039 \\
(0.086)\end{array}$ & $\begin{array}{c}0.006 \\
(0.088)\end{array}$ & $\begin{array}{c}0.038 \\
(0.092)\end{array}$ \\
\hline
\end{tabular}

Note: The table displays descriptive statistics for the outcome and control variables separately over treatment and control groups. The first column presents the control group mean for each variable: the outcome variable (points scored on the test and its standardized counterpart with mean 0 and standard deviation 1), learning weeks, class size, gender, and five schoollevel variables (average GPA of ninth graders, fraction of students born abroad, fraction of students for which both parents were born abroad, average level of parental education, and schools without grades 7-9). Columns T1-C to T4-C represent the differences in means between treatment groups and the control group. The four treatments are: (T1) criterion-based grade A-F, (T2) rank-based grade A, (T3) criterion-based certificate, and (T4) rank-based prize. Tests are conducted on the first wave conducted towards the end of sixth grade in April 2013. Standard errors are displayed in parentheses. Asterisks indicate a significant difference of means, where $(* * *, p<0.01),(* *, p<0.05)$ and $(*, p<0.1)$. 
Table 6: Differences in Means, second wave.

\begin{tabular}{|c|c|c|c|c|c|}
\hline & Control & $\mathrm{T} 1-\mathrm{C}$ & $\mathrm{T} 2-\mathrm{C}$ & $\mathrm{T} 3-\mathrm{C}$ & $\mathrm{T} 4-\mathrm{C}$ \\
\hline \multicolumn{6}{|l|}{ Full sample } \\
\hline Test Score (points) & $\begin{array}{l}13.449 \\
(0.426)\end{array}$ & $\begin{array}{c}0.044 \\
(0.649)\end{array}$ & $\begin{array}{l}-0.486 \\
(0.620)\end{array}$ & $\begin{array}{l}-0.311 \\
(0.638)\end{array}$ & $\begin{array}{l}-0.221 \\
(0.628)\end{array}$ \\
\hline Test Score (standardized) & $\begin{array}{c}0.036 \\
(0.080)\end{array}$ & $\begin{array}{c}0.008 \\
(0.122)\end{array}$ & $\begin{array}{l}-0.091 \\
(0.116)\end{array}$ & $\begin{array}{c}-0.058 \\
(0.120)\end{array}$ & $\begin{array}{l}-0.042 \\
(0.118)\end{array}$ \\
\hline Learning Weeks & $\begin{array}{l}2.235 \\
(0.125)\end{array}$ & $\begin{array}{c}0.000 \\
(0.180)\end{array}$ & $\begin{array}{l}-0.061 \\
(0.174)\end{array}$ & $\begin{array}{c}0.017 \\
(0.176)\end{array}$ & $\begin{array}{l}-0.031 \\
(0.176)\end{array}$ \\
\hline New Peers & $\begin{array}{c}0.346 \\
(0.041)\end{array}$ & $\begin{array}{l}-0.029 \\
(0.057)\end{array}$ & $\begin{array}{l}-0.065 \\
(0.057)\end{array}$ & $\begin{array}{l}-0.048 \\
(0.057)\end{array}$ & $\begin{array}{l}-0.050 \\
(0.057)\end{array}$ \\
\hline Class Size & $\begin{array}{l}24.500 \\
(0.361)\end{array}$ & $\begin{array}{l}-0.076 \\
(0.520)\end{array}$ & $\begin{array}{l}0.197 \\
(0.520)\end{array}$ & $\begin{array}{c}0.271 \\
(0.516)\end{array}$ & $\begin{array}{l}0.288 \\
(0.507)\end{array}$ \\
\hline Female & $\begin{array}{c}0.515 \\
(0.043)\end{array}$ & $\begin{array}{l}-0.007 \\
(0.061)\end{array}$ & $\begin{array}{l}0.046 \\
(0.061)\end{array}$ & $\begin{array}{c}0.004 \\
(0.061)\end{array}$ & $\begin{array}{l}-0.037 \\
(0.061)\end{array}$ \\
\hline GPA & $\begin{array}{c}233.679 \\
(1.748)\end{array}$ & $\begin{array}{l}-0.482 \\
(2.473)\end{array}$ & $\begin{array}{l}-0.594 \\
(2.492)\end{array}$ & $\begin{array}{l}-0.140 \\
(2.474)\end{array}$ & $\begin{array}{l}-0.283 \\
(2.518)\end{array}$ \\
\hline Foreign-Born & $\begin{array}{c}0.098 \\
(0.010)\end{array}$ & $\begin{array}{c}0.002 \\
(0.014)\end{array}$ & $\begin{array}{l}0.000 \\
(0.014)\end{array}$ & $\begin{array}{l}-0.005 \\
(0.014)\end{array}$ & $\begin{array}{c}0.001 \\
(0.014)\end{array}$ \\
\hline Foreign Parents & $\begin{array}{c}0.098 \\
(0.007)\end{array}$ & $\begin{array}{l}0.002 \\
(0.010)\end{array}$ & $\begin{array}{c}0.011 \\
(0.010)\end{array}$ & $\begin{array}{c}0.006 \\
(0.010)\end{array}$ & $\begin{array}{l}0.003 \\
(0.010)\end{array}$ \\
\hline Parent Education & $\begin{array}{c}2.401 \\
(0.015)\end{array}$ & $\begin{array}{l}-0.003 \\
(0.021)\end{array}$ & $\begin{array}{l}-0.010 \\
(0.022)\end{array}$ & $\begin{array}{l}-0.007 \\
(0.022)\end{array}$ & $\begin{array}{l}-0.004 \\
(0.022)\end{array}$ \\
\hline No 7-9 Grade & $\begin{array}{c}0.037 \\
(0.016)\end{array}$ & $\begin{array}{l}-0.007 \\
(0.022)\end{array}$ & $\begin{array}{l}-0.014 \\
(0.021)\end{array}$ & $\begin{array}{c}0.001 \\
(0.023)\end{array}$ & $\begin{array}{c}0.009 \\
(0.024)\end{array}$ \\
\hline \multicolumn{6}{|l|}{ Boys } \\
\hline Test Score (points) & $\begin{array}{l}12.742 \\
(0.630)\end{array}$ & $\begin{array}{c}0.317 \\
(0.992)\end{array}$ & $\begin{array}{c}-0.122 \\
(0.919)\end{array}$ & $\begin{array}{l}-0.028 \\
(0.960)\end{array}$ & $\begin{array}{l}-0.467 \\
(0.955)\end{array}$ \\
\hline Test Score (standardized) & $\begin{array}{l}-0.097 \\
(0.118)\end{array}$ & $\begin{array}{c}0.060 \\
(0.186)\end{array}$ & $\begin{array}{l}-0.023 \\
(0.173)\end{array}$ & $\begin{array}{l}-0.005 \\
(0.180)\end{array}$ & $\begin{array}{l}-0.088 \\
(0.179)\end{array}$ \\
\hline Learning Weeks & $\begin{array}{c}2.439 \\
(0.157)\end{array}$ & $\begin{array}{l}-0.230 \\
(0.241)\end{array}$ & $\begin{array}{l}-0.164 \\
(0.230)\end{array}$ & $\begin{array}{l}-0.170 \\
(0.244)\end{array}$ & $\begin{array}{l}-0.323 \\
(0.230)\end{array}$ \\
\hline New Peers & $\begin{array}{c}0.348 \\
(0.059)\end{array}$ & $\begin{array}{l}-0.020 \\
(0.083)\end{array}$ & $\begin{array}{l}-0.073 \\
(0.084)\end{array}$ & $\begin{array}{l}-0.031 \\
(0.084)\end{array}$ & $\begin{array}{l}-0.044 \\
(0.081)\end{array}$ \\
\hline Class Size & $\begin{array}{l}23.742 \\
(0.498)\end{array}$ & $\begin{array}{c}0.795 \\
(0.714)\end{array}$ & $\begin{array}{c}1.137 \\
(0.748)\end{array}$ & $\begin{array}{c}0.607 \\
(0.733)\end{array}$ & $\begin{array}{c}1.446^{* *} \\
(0.691)\end{array}$ \\
\hline GPA & $\begin{array}{c}226.328 \\
(2.430)\end{array}$ & $\begin{array}{c}8.990 \\
(3.300)\end{array}$ & $\begin{array}{l}1.953 \\
(3.794)\end{array}$ & $\begin{array}{c}8.393^{* *} \\
(3.439)\end{array}$ & $\begin{array}{c}7.776^{\text {** }} \\
(3.586)\end{array}$ \\
\hline Foreign-Born & $\begin{array}{c}0.130 \\
(0.016)\end{array}$ & $\begin{array}{c}-0.043^{* *} \\
(0.020)\end{array}$ & $\begin{array}{c}-0.011 \\
(0.025)\end{array}$ & $\begin{array}{c}-0.038^{*} \\
(0.021)\end{array}$ & $\begin{array}{l}-0.030 \\
(0.021)\end{array}$ \\
\hline Foreign Parents & $\begin{array}{c}0.123 \\
(0.010)\end{array}$ & $\begin{array}{c}-0.024^{*} \\
(0.014)\end{array}$ & $\begin{array}{l}-0.006 \\
(0.015)\end{array}$ & $\begin{array}{l}-0.017 \\
(0.015)\end{array}$ & $\begin{array}{l}-0.017 \\
(0.014)\end{array}$ \\
\hline Parent Education & $\begin{array}{c}2.337 \\
(0.021)\end{array}$ & $\begin{array}{c}0.080^{* * *} * \\
(0.029)\end{array}$ & $\begin{array}{c}0.005 \\
(0.033)\end{array}$ & $\begin{array}{c}0.071^{* *} \\
(0.030)\end{array}$ & $\begin{array}{c}0.060^{* *} \\
(0.031)\end{array}$ \\
\hline No 7-9 Grade & $\begin{array}{c}0.030 \\
(0.021)\end{array}$ & $\begin{array}{l}-0.015 \\
(0.026)\end{array}$ & $\begin{array}{l}-0.013 \\
(0.028)\end{array}$ & $\begin{array}{c}0.001 \\
(0.031)\end{array}$ & $\begin{array}{l}-0.001 \\
(0.029)\end{array}$ \\
\hline \multicolumn{6}{|l|}{ Girls } \\
\hline Test Score (points) & $\begin{array}{l}14.114 \\
(0.568)\end{array}$ & $\begin{array}{l}-0.201 \\
(0.840)\end{array}$ & $\begin{array}{l}-0.885 \\
(0.838)\end{array}$ & $\begin{array}{l}-0.585 \\
(0.845)\end{array}$ & $\begin{array}{l}0.156 \\
(0.794)\end{array}$ \\
\hline Test Score (standardized) & $\begin{array}{c}0.161 \\
(0.107)\end{array}$ & $\begin{array}{c}-0.038 \\
(0.158)\end{array}$ & $\begin{array}{l}-0.166 \\
(0.157)\end{array}$ & $\begin{array}{c}-0.110 \\
(0.159)\end{array}$ & $\begin{array}{c}0.030 \\
(0.149)\end{array}$ \\
\hline Learning Weeks & $\begin{array}{c}2.043 \\
(0.191)\end{array}$ & $\begin{array}{c}0.218 \\
(0.258)\end{array}$ & $\begin{array}{c}0.052 \\
(0.256)\end{array}$ & $\begin{array}{c}0.192 \\
(0.252)\end{array}$ & $\begin{array}{c}0.259 \\
(0.266)\end{array}$ \\
\hline New Peers & $\begin{array}{c}0.343 \\
(0.057)\end{array}$ & $\begin{array}{l}-0.039 \\
(0.080)\end{array}$ & $\begin{array}{l}-0.059 \\
(0.078)\end{array}$ & $\begin{array}{l}-0.063 \\
(0.079)\end{array}$ & $\begin{array}{l}-0.057 \\
(0.081)\end{array}$ \\
\hline Class Size & $\begin{array}{l}25.214 \\
(0.511)\end{array}$ & $\begin{array}{l}-1.098 \\
(0.747)\end{array}$ & $\begin{array}{l}-0.660 \\
(0.718)\end{array}$ & $\begin{array}{l}-0.053 \\
(0.716)\end{array}$ & $\begin{array}{l}-0.865 \\
(0.734)\end{array}$ \\
\hline GPA & $\begin{array}{c}240.702 \\
(2.204)\end{array}$ & $\begin{array}{c}-9.626^{* * *} \\
(3.464)\end{array}$ & $\begin{array}{l}-3.813 \\
(3.019)\end{array}$ & $\begin{array}{c}-8.271^{* *} \\
(3.342)\end{array}$ & $\begin{array}{c}-8.108^{* *} \\
(3.314)\end{array}$ \\
\hline Foreign-Born & $\begin{array}{c}0.068 \\
(0.010)\end{array}$ & $\begin{array}{c}0.046^{* *} \\
(0.019)\end{array}$ & $\begin{array}{c}0.014 \\
(0.014)\end{array}$ & $\begin{array}{c}0.026 \\
(0.017)\end{array}$ & $\begin{array}{l}0.030^{*} \\
(0.017)\end{array}$ \\
\hline Foreign Parents & $\begin{array}{c}0.074 \\
(0.008)\end{array}$ & $\begin{array}{c}0.027^{* *} \\
(0.012)\end{array}$ & $\begin{array}{c}0.028^{* *} \\
(0.012)\end{array}$ & $\begin{array}{c}0.028^{* *} \\
(0.012)\end{array}$ & $\begin{array}{l}0.022^{*} \\
(0.012)\end{array}$ \\
\hline Parent Education & $\begin{array}{c}2.463 \\
(0.019)\end{array}$ & $\begin{array}{c}-0.083^{* * *} \\
(0.030)\end{array}$ & $\begin{array}{l}-0.032 \\
(0.026)\end{array}$ & $\begin{array}{c}-0.082^{* * *} \\
(0.029)\end{array}$ & $\begin{array}{c}-0.065^{*} \\
(0.029)\end{array}$ \\
\hline No 7-9 Grade & $\begin{array}{c}0.043 \\
(0.024)\end{array}$ & $\begin{array}{c}0.001 \\
(0.035)\end{array}$ & $\begin{array}{l}-0.016 \\
(0.031)\end{array}$ & $\begin{array}{c}0.001 \\
(0.034)\end{array}$ & $\begin{array}{c}0.021 \\
(0.039) \\
\end{array}$ \\
\hline
\end{tabular}

Note: The table displays descriptive statistics for the outcome and control variables separately over treatment and control groups. The first column presents the control group mean for each variable: the outcome variable (points scored on the test and its standardized counterpart with mean 0 and standard deviation 1), learning weeks, new peers, class size, gender, and five school-level variables (average GPA of ninth graders, fraction of students born abroad, fraction of students for which both parents were born abroad, average level of parental education, and schools without grades 7-9). Columns T1-C to $\mathrm{T} 4-\mathrm{C}$ represent the differences in means between treatment groups and the control group. The four treatments are: (T1) criterion-based grade A-F, (T2) rank-based grade A, (T3) criterion-based certificate, and (T4) rank-based prize. Tests are conducted on the second wave conducted at the beginning of sixth grade in August-September 2013. Standard errors are displayed in parentheses. Asterisks indicate a significant difference of means, where $(* * *, p<0.01),(* *, p<0.05)$ and $(*, p<0.1)$. 
Table 7: Impact of Non-Financial Incentives on Test Scores.

\begin{tabular}{|c|c|c|c|}
\hline & (1) & $(2)$ & $(3)$ \\
\hline $\mathrm{T} 1$ & $\begin{array}{c}0.077 \\
(0.071)\end{array}$ & $\begin{array}{c}0.072 \\
(0.068)\end{array}$ & $\begin{array}{c}0.075 \\
(0.056)\end{array}$ \\
\hline $\mathrm{T} 2$ & $\begin{array}{c}0.080 \\
(0.086)\end{array}$ & $\begin{array}{c}0.064 \\
(0.088)\end{array}$ & $\begin{array}{c}0.076 \\
(0.105)\end{array}$ \\
\hline $\mathrm{T} 3$ & $\begin{array}{c}0.083 \\
(0.084)\end{array}$ & $\begin{array}{c}0.064 \\
(0.085)\end{array}$ & $\begin{array}{c}0.080 \\
(0.078)\end{array}$ \\
\hline $\mathrm{T} 4$ & $\begin{array}{c}0.125 \\
(0.090)\end{array}$ & $\begin{array}{c}0.114 \\
(0.091)\end{array}$ & $\begin{array}{c}0.124 \\
(0.089)\end{array}$ \\
\hline First Wave & $\begin{array}{c}0.315^{* *} \\
(0.119)\end{array}$ & $\begin{array}{l}-1.593 \\
(1.187)\end{array}$ & $\begin{array}{l}-0.956 \\
(2.062)\end{array}$ \\
\hline Learning Weeks & & $\begin{array}{c}0.059 \\
(0.037)\end{array}$ & $\begin{array}{c}0.037 \\
(0.068)\end{array}$ \\
\hline New Peers & & $\begin{array}{l}-0.187 \\
(0.157)\end{array}$ & $\begin{array}{l}-0.145 \\
(0.138)\end{array}$ \\
\hline Class Size & & $\begin{array}{c}0.016 \\
(0.012)\end{array}$ & $\begin{array}{c}-0.019 \\
(0.020)\end{array}$ \\
\hline Female & & $\begin{array}{c}0.177^{* * *} \\
(0.058)\end{array}$ & $\begin{array}{c}0.158^{* * *} \\
(0.053)\end{array}$ \\
\hline GPA & & & $\begin{array}{c}0.011 \\
(0.009)\end{array}$ \\
\hline Foreign-Born & & & $\begin{array}{l}-0.484 \\
(0.891)\end{array}$ \\
\hline Foreign Parents & & & $\begin{array}{l}-0.467 \\
(0.733)\end{array}$ \\
\hline Parent Education & & & $\begin{array}{l}-0.624 \\
(0.868)\end{array}$ \\
\hline No 7-9 Grade & & & $\begin{array}{c}1.009 \\
(0.917)\end{array}$ \\
\hline Constant & $\begin{array}{c}-0.187^{* *} \\
(0.080)\end{array}$ & $\begin{array}{c}-0.734^{*} \\
(0.383) \\
\end{array}$ & $\begin{array}{c}-0.851 \\
(1.333) \\
\end{array}$ \\
\hline N Individuals & 1,045 & 1,045 & 1,045 \\
\hline N Classes & 47 & 47 & 47 \\
\hline N Schools & 17 & 17 & 17 \\
\hline
\end{tabular}

Note: The table reports OLS estimates of the ATE on test performance of four non-financial incentives; (T1) criterion-based grade A-F, (T2) rank-based grade A, (T3) criterion-based certificate, and (T4) rank-based prize. The outcome variable is test scores, standardized to mean 0 and standard deviation 1. All estimations are conducted on the full sample; including the first wave conducted towards the end of sixth grade in April 2013 and the second wave conducted at the beginning of sixth grade in AugustSeptember 2013. Column (1) only includes a control for wave, column (2) also controls for learning weeks, new peers, class size, and gender, while column (3) further controls for school-level variables (average GPA of ninth graders, fraction of students born abroad, fraction of students for which both parents were born abroad, average level of parental education, and schools without grades 7-9). Cluster-robust standard errors clustered at the class (school when also including school-level controls) level are displayed in parentheses. Asterisks indicate significance, where $(* * *, p<0.01),(* *, p<0.05)$ and $(*, p<0.1)$. 
Table 8: Impact of Non-Financial Incentives on Test Scores, by gender.

\begin{tabular}{|c|c|c|c|c|c|c|}
\hline & \multicolumn{3}{|c|}{ Boys } & \multicolumn{3}{|c|}{ Girls } \\
\hline & (1) & $(2)$ & $(3)$ & (4) & $(5)$ & $(6)$ \\
\hline \multirow[t]{2}{*}{$\mathrm{T} 1$} & 0.063 & 0.053 & 0.029 & 0.089 & 0.085 & 0.120 \\
\hline & $(0.122)$ & $(0.119)$ & $(0.096)$ & $(0.116)$ & $(0.116)$ & $(0.124)$ \\
\hline \multirow[t]{2}{*}{$\mathrm{T} 2$} & 0.138 & 0.113 & 0.131 & 0.018 & 0.023 & 0.039 \\
\hline & $(0.128)$ & $(0.131)$ & $(0.137)$ & $(0.103)$ & $(0.105)$ & $(0.122)$ \\
\hline \multirow[t]{2}{*}{ T3 } & 0.084 & 0.067 & 0.038 & 0.073 & 0.066 & 0.121 \\
\hline & $(0.115)$ & $(0.116)$ & $(0.084)$ & $(0.106)$ & $(0.111)$ & $(0.104)$ \\
\hline \multirow[t]{2}{*}{$\mathrm{T} 4$} & 0.057 & 0.031 & 0.023 & 0.190 & $0.191^{*}$ & 0.214 \\
\hline & $(0.128)$ & $(0.131)$ & $(0.112)$ & $(0.112)$ & $(0.113)$ & $(0.157)$ \\
\hline \multirow[t]{2}{*}{ First Wave } & $0.353^{* * *}$ & 0.273 & 0.857 & $0.267^{* *}$ & $-3.272^{* *}$ & -2.454 \\
\hline & $(0.130)$ & $(1.483)$ & $(1.799)$ & $(0.131)$ & $(2.176)$ & $(2.229)$ \\
\hline \multirow[t]{2}{*}{ Learning Weeks } & & 0.000 & -0.023 & & $0.111^{* *}$ & 0.086 \\
\hline & & $(0.047)$ & $(0.060)$ & & $(0.043)$ & $(0.073)$ \\
\hline \multirow[t]{2}{*}{ New Peers } & & $-0.403^{* *}$ & $-0.300^{* *}$ & & 0.023 & -0.007 \\
\hline & & $(0.215)$ & $(0.136)$ & & $(0.134)$ & $(0.146)$ \\
\hline \multirow[t]{2}{*}{ Class Size } & & 0.014 & -0.023 & & 0.019 & -0.013 \\
\hline & & $(0.012)$ & $(0.019)$ & & $(0.013)$ & $(0.023)$ \\
\hline \multirow[t]{2}{*}{ GPA } & & & $0.019^{* *}$ & & & 0.003 \\
\hline & & & $(0.008)$ & & & $(0.011)$ \\
\hline \multirow[t]{2}{*}{ Foreign-Born } & & & 0.025 & & & -0.929 \\
\hline & & & $(0.824)$ & & & $(0.937)$ \\
\hline \multirow[t]{2}{*}{ Foreign Parents } & & & 0.147 & & & -0.860 \\
\hline & & & $(0.743)$ & & & $(0.754)$ \\
\hline \multirow[t]{2}{*}{ Parent Education } & & & -1.119 & & & 0.022 \\
\hline & & & $(0.791)$ & & & $(1.035)$ \\
\hline \multirow[t]{2}{*}{ No 7-9 Grade } & & & $2.021^{* *}$ & & & 0.361 \\
\hline & & & $(0.847)$ & & & $(0.999)$ \\
\hline \multirow[t]{2}{*}{ Constant } & $-0.291^{* * *}$ & -0.483 & -1.371 & -0.082 & $-0.803^{*}$ & -0.507 \\
\hline & $(0.099)$ & $(0.405)$ & $(1.271)$ & $(0.094)$ & $(0.406)$ & $(1.418)$ \\
\hline N Individuals & 493 & 493 & 493 & 552 & 552 & 552 \\
\hline N Classes & 47 & 47 & 47 & 47 & 47 & 47 \\
\hline N Schools & 17 & 17 & 17 & 17 & 17 & 17 \\
\hline
\end{tabular}

Note: The table reports OLS estimates of the ATE on test performance of four non-financial incentives; (T1) criterion-based grade A-F, (T2) rank-based grade A, (T3) criterion-based certificate, and (T4) rank-based prize. The outcome variable is test scores, standardized to mean 0 and standard deviation 1. All estimations are conducted on the full sample; including the first wave conducted towards the end of sixth grade in April 2013 and the second wave conducted at the beginning of sixth grade in AugustSeptember 2013. ATEs are displayed separately by gender; columns (1)-(3) show the ATEs for boys, while columns (4)-(6) show the ATEs for girls. Columns (1) and (4) only include a control for wave, columns (2) and (5) also control for learning weeks, new peers, and class size, while columns (3) and (6) further control for school-level variables (average GPA of ninth graders, fraction of students born abroad, fraction of students for which both parents were born abroad, average level of parental education, and schools without grades 7-9). Cluster-robust standard errors clustered at the class (school when also including school-level controls) level are displayed in parentheses. Asterisks indicate significance, where $(* * *, p<0.01),(* *, p<0.05)$ and $(*, p<0.1)$. 


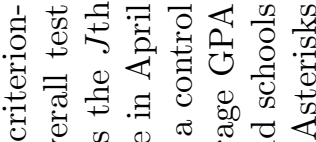

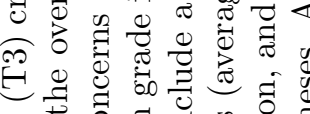

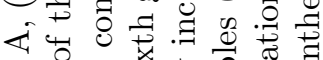

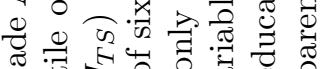

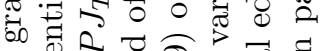

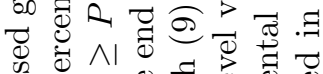

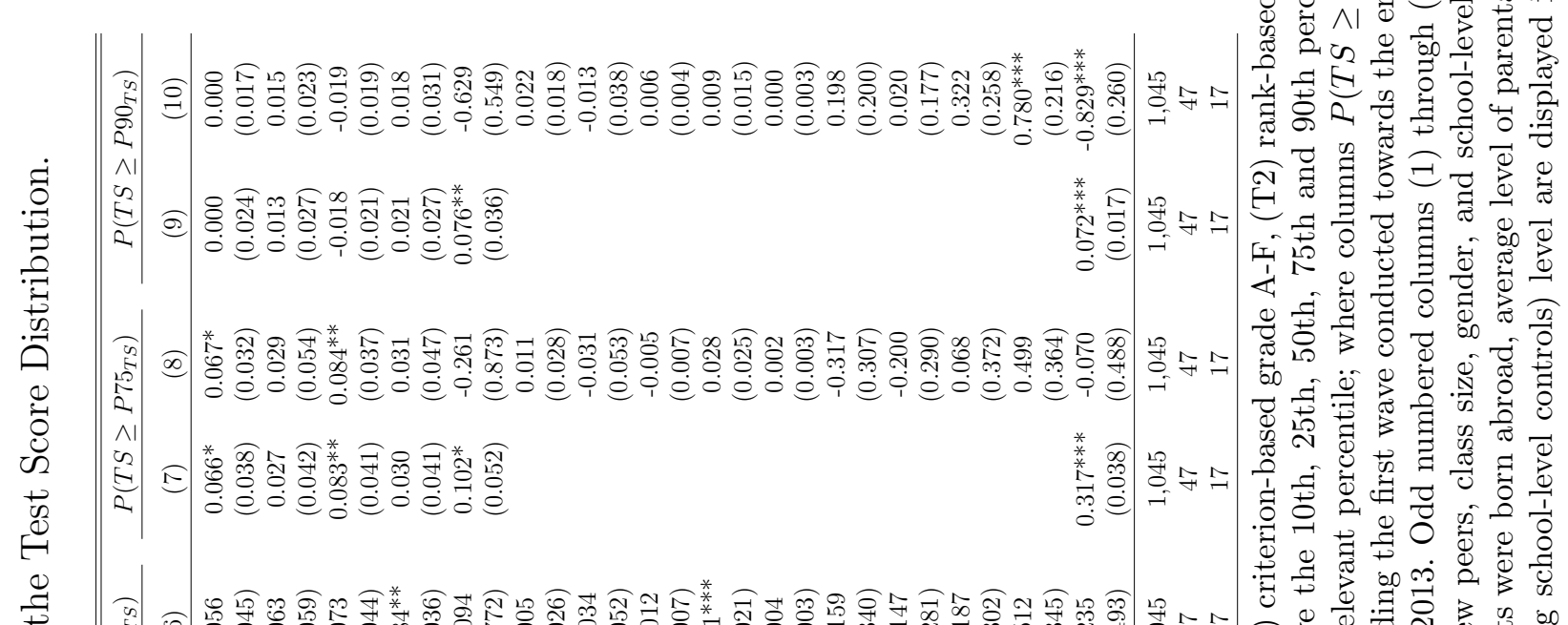

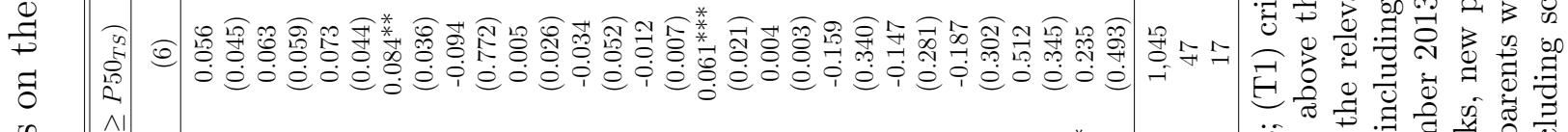

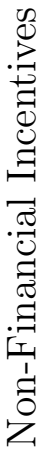

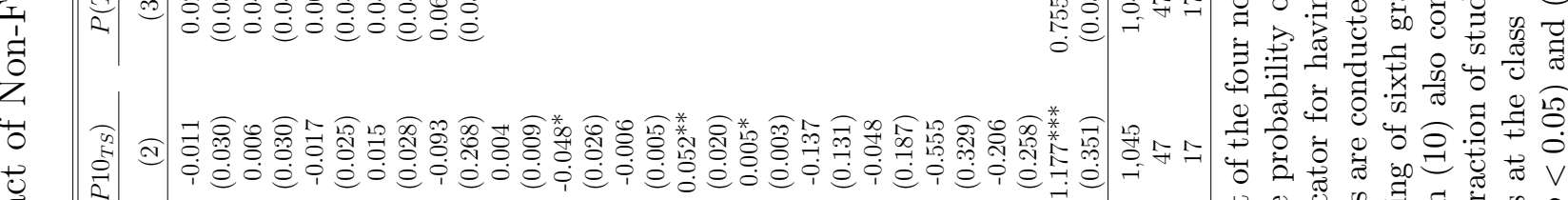

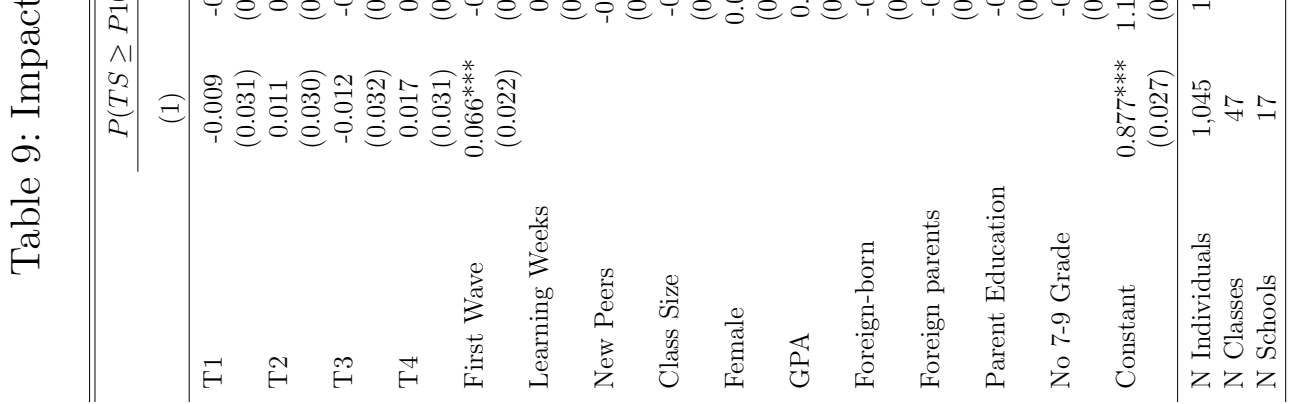

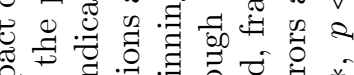

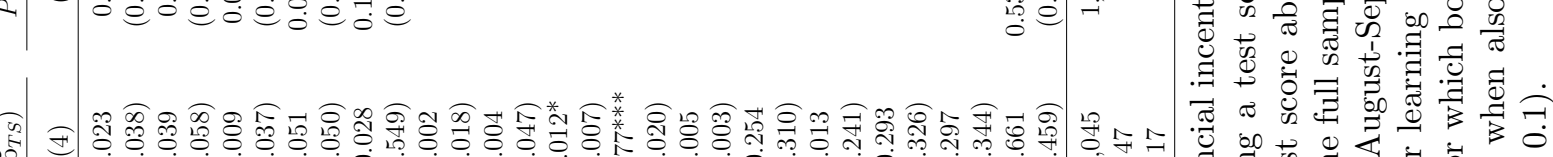

2.

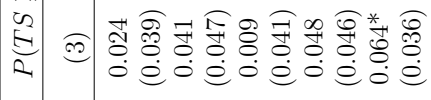

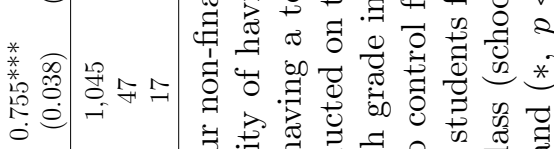

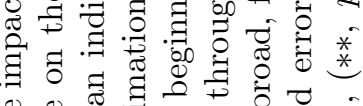

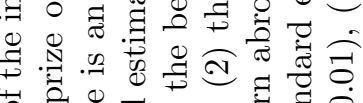

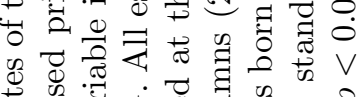

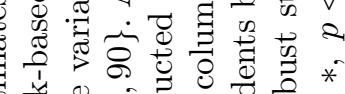

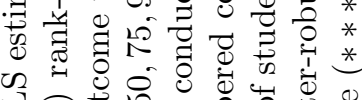

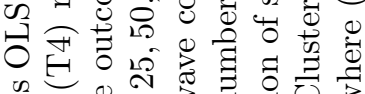

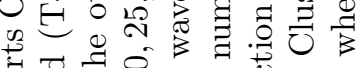

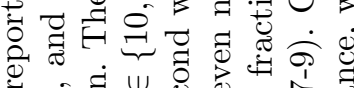

of $\begin{gathered}0 \\ \text { o }\end{gathered}$

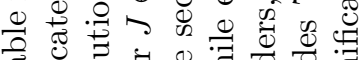

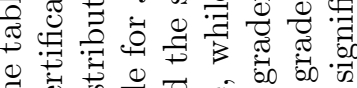

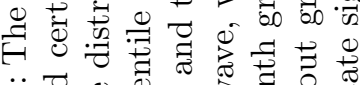

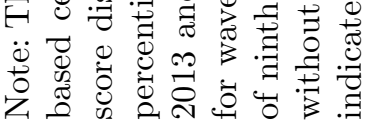




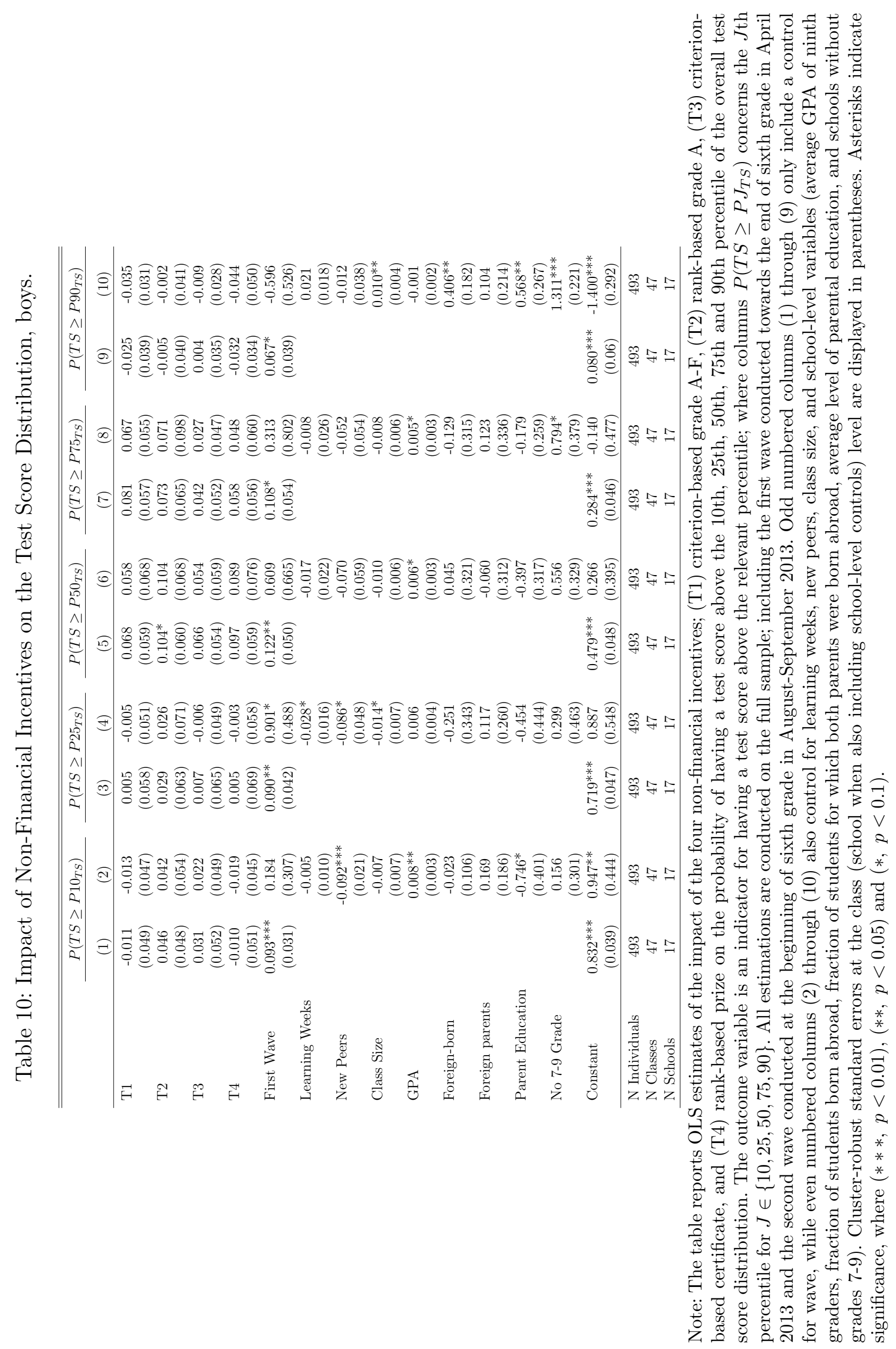




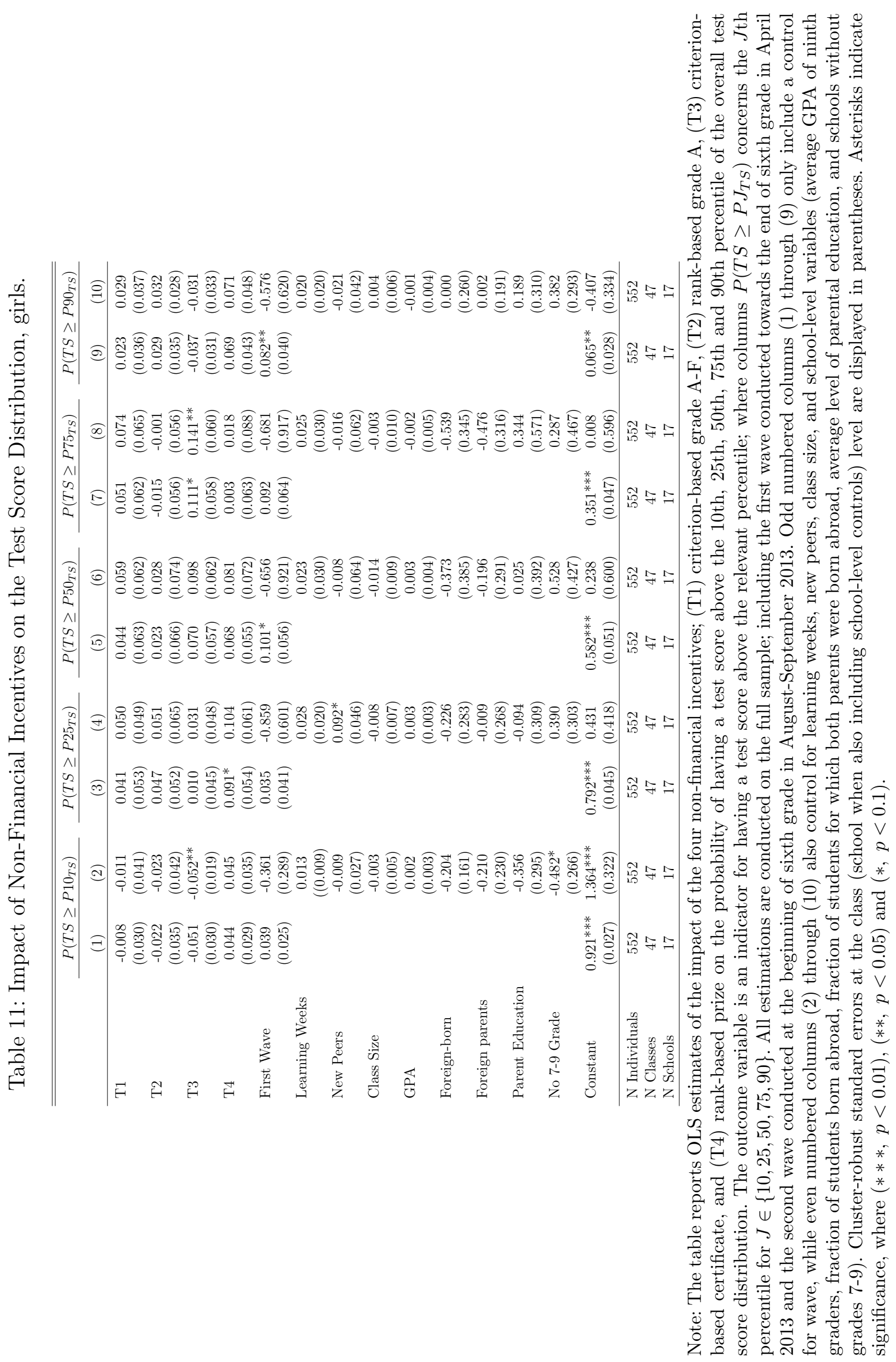


Table 12: Impact of Non-Financial Incentives on Test Scores, by wave.

\begin{tabular}{|c|c|c|c|c|c|c|}
\hline & \multicolumn{3}{|c|}{ First Wave } & \multicolumn{3}{|c|}{ Second Wave } \\
\hline & (1) & $(2)$ & $(3)$ & (4) & $(5)$ & $(6)$ \\
\hline \multirow[t]{2}{*}{$\mathrm{T} 1$} & 0.214 & 0.201 & 0.208 & 0.008 & 0.003 & 0.003 \\
\hline & $(0.142)$ & $(0.142)$ & $(0.120)$ & $(0.079)$ & $(0.073)$ & $(0.050)$ \\
\hline \multirow[t]{2}{*}{$\mathrm{T} 2$} & $0.417^{* *}$ & $0.415^{* *}$ & $0.418^{* *}$ & -0.091 & -0.113 & -0.113 \\
\hline & $(0.153)$ & $(0.154)$ & $(0.157)$ & $(0.093)$ & $(0.095)$ & $(0.097)$ \\
\hline \multirow[t]{2}{*}{$\mathrm{T} 3$} & $0.358^{* *}$ & $0.332^{* *}$ & $0.362^{*}$ & -0.059 & -0.069 & -0.070 \\
\hline & $(0.157)$ & $(0.156)$ & $(0.168)$ & $(0.093)$ & $(0.097)$ & $(0.049)$ \\
\hline \multirow[t]{2}{*}{$\mathrm{T} 4$} & $0.450^{* * *}$ & $0.430 * *$ & $0.430 * *$ & -0.042 & -0.043 & -0.029 \\
\hline & $(0.154)$ & $(0.153)$ & $(0.157)$ & $(0.103)$ & $(0.106)$ & $(0.112)$ \\
\hline \multirow[t]{2}{*}{ Learning Weeks } & & 0.112 & -0.065 & & 0.015 & -0.053 \\
\hline & & $(0.104)$ & $(0.342)$ & & $(0.043)$ & $(0.050)$ \\
\hline \multirow[t]{2}{*}{ New Peers } & & & & & -0.204 & $-0.256^{* *}$ \\
\hline & & & & & $(0.160)$ & $(0.110)$ \\
\hline \multirow[t]{2}{*}{ Class Size } & & $0.033^{*}$ & 0.024 & & -0.003 & $-0.052^{* * *}$ \\
\hline & & $(0.018)$ & $(0.043)$ & & $(0.014)$ & $(0.014)$ \\
\hline \multirow[t]{2}{*}{ Female } & & 0.085 & 0.045 & & $0.211^{* *}$ & $0.192^{* *}$ \\
\hline & & $(0.089)$ & $(0.083)$ & & $(0.078)$ & $(0.068)$ \\
\hline \multirow[t]{2}{*}{ GPA } & & & 0.002 & & & 0.010 \\
\hline & & & $(0.005)$ & & & $(0.010)$ \\
\hline \multirow[t]{2}{*}{ Foreign-Born } & & & $1.741^{* * *}$ & & & $-2.374^{*}$ \\
\hline & & & $(0.221)$ & & & $(1.154)$ \\
\hline \multirow[t]{2}{*}{ Foreign Parents } & & & 1.352 & & & -1.380 \\
\hline & & & $(2.317)$ & & & $(1.449)$ \\
\hline \multirow[t]{2}{*}{ Parent Education } & & & $2.062^{* *}$ & & & $-1.861^{*}$ \\
\hline & & & $(0.670)$ & & & $(0.967)$ \\
\hline \multirow[t]{2}{*}{ No 7-9 Grade } & & & $6.111^{* * *}$ & & & $-2.872^{*}$ \\
\hline & & & $(1.663)$ & & & $(1.472)$ \\
\hline \multirow[t]{2}{*}{ Constant } & $-0.287^{*}$ & -4.894 & -4.316 & 0.036 & 0.049 & $3.896^{* *}$ \\
\hline & $(0.151)$ & $(3.714)$ & $(9.845)$ & $(0.078)$ & $(0.452)$ & $(1.713)$ \\
\hline N Individuals & 378 & 378 & 378 & 667 & 667 & 667 \\
\hline N Classes & 19 & 19 & 19 & 28 & 28 & 28 \\
\hline N Schools & 9 & 9 & 9 & 11 & 11 & 11 \\
\hline
\end{tabular}

Note: The table reports OLS estimates of the ATE on test performance of four non-financial incentives; (T1) criterion-based grade A-F, (T2) rank-based grade A, (T3) criterion-based certificate, and (T4) rankbased prize. The outcome variable is test scores, standardized to mean 0 and standard deviation 1 . ATEs are displayed separately by wave; columns (1)-(3) show the ATEs for the first wave conducted towards the end of sixth grade in April 2013, while columns (4)-(6) show the ATEs for the second wave conducted at the beginning of sixth grade in August-September 2013. Columns (1) and (4) do not include any control variables, columns (2) and (5) control for learning weeks, new peers, class size, and gender, while columns (3) and (6) further control for school-level variables (average GPA of ninth graders, fraction of students born abroad, fraction of students for which both parents were born abroad, average level of parental education, and schools without grades 7-9). Cluster-robust standard errors clustered at the class (school when also including school-level controls) level are displayed in parentheses. Asterisks indicate significance, where $(* * *, p<0.01),(* *, p<0.05)$ and $(*, p<0.1)$. 
Table 13: Impact of Non-Financial Incentives on Test Scores, first wave, by gender.

\begin{tabular}{|c|c|c|c|c|c|c|}
\hline & \multicolumn{3}{|c|}{ Boys } & \multicolumn{3}{|c|}{$\overline{~ G i r l s ~}$} \\
\hline & $(1)$ & $(2)$ & $(3)$ & $(4)$ & $(5)$ & $(6)$ \\
\hline \multirow[t]{2}{*}{$\mathrm{T} 1$} & 0.052 & 0.044 & 0.061 & $0.352^{*}$ & 0.323 & 0.331 \\
\hline & $(0.216)$ & $(0.213)$ & $(0.136)$ & $(0.188)$ & $(0.189)$ & $(0.213)$ \\
\hline \multirow[t]{2}{*}{$\mathrm{T} 2$} & $0.444^{*}$ & $0.452^{*}$ & $0.495^{*}$ & $0.394^{*}$ & $0.383^{*}$ & 0.370 \\
\hline & $(0.228)$ & $(0.218)$ & $(0.215)$ & $(0.207)$ & $(0.208)$ & $(0.215)$ \\
\hline \multirow[t]{2}{*}{ T3 } & 0.256 & 0.209 & $0.280^{*}$ & $0.427^{* *}$ & $0.439 * *$ & $0.460^{*}$ \\
\hline & $(0.181)$ & $(0.192)$ & $(0.150)$ & $(0.178)$ & $(0.185)$ & $(0.240)$ \\
\hline \multirow[t]{2}{*}{$\mathrm{T} 4$} & $0.359^{*}$ & 0.313 & $0.402^{*}$ & $0.516^{* *}$ & $0.518^{* *}$ & $0.491^{* *}$ \\
\hline & $(0.199)$ & $(0.210)$ & $(0.213)$ & $(0.210)$ & $(0.211)$ & $(0.189)$ \\
\hline \multirow[t]{2}{*}{ Learning Week } & & 0.195 & 0.063 & & 0.040 & -0.203 \\
\hline & & $(0.116)$ & $(0.316)$ & & $(0.120)$ & $(0.390))$ \\
\hline \multirow[t]{2}{*}{ Class Size } & & 0.018 & -0.004 & & $0.045^{* *}$ & 0.055 \\
\hline & & $(0.019)$ & $(0.044)$ & & $(0.019)$ & $(0.045)$ \\
\hline \multirow[t]{2}{*}{ GPA } & & & 0.003 & & & -0.003 \\
\hline & & & $(0.002)$ & & & $(0.008)$ \\
\hline \multirow[t]{2}{*}{ Foreign-Born } & & & $2.345^{* * *}$ & & & $1.043^{* *}$ \\
\hline & & & $(0.204)$ & & & $(0.390)$ \\
\hline \multirow[t]{2}{*}{ Foreign Parents } & & & 0.765 & & & 2.149 \\
\hline & & & $(2.235)$ & & & $(2.520)$ \\
\hline \multirow[t]{2}{*}{ Parent Education } & & & $2.283^{* * *}$ & & & $2.074^{*}$ \\
\hline & & & $(0.302)$ & & & $(1.001)$ \\
\hline \multirow[t]{2}{*}{ No 7-9 Grade } & & & $7.020 * * *$ & & & $5.250^{* *}$ \\
\hline & & & $(1.365)$ & & & $(2.138)$ \\
\hline \multirow[t]{2}{*}{ Constant } & -0.290 & $-7.386^{*}$ & -9.038 & -0.284 & -2.625 & 0.704 \\
\hline & $(0.170)$ & $(4.059)$ & $(9.090)$ & $(0.185)$ & $(4.281)$ & $(11.251)$ \\
\hline N Individuals & 170 & 170 & 170 & 208 & 208 & 208 \\
\hline N Classes & 19 & 19 & 19 & 19 & 19 & 19 \\
\hline N Schools & 9 & 9 & 9 & 9 & 9 & 9 \\
\hline
\end{tabular}

Note: The table reports OLS estimates of the ATE on test performance of four non-financial incentives; (T1) criterion-based grade A-F, (T2) rank-based grade A, (T3) criterion-based certificate, and (T4) rank-based prize. The outcome variable is test scores, standardized to mean 0 and standard deviation 1. All estimations are conducted on the first wave sample gathered towards the end of sixth grade in April 2013. ATEs are displayed separately by gender; columns (1)-(3) show the ATEs for boys, while columns (4)-(6) show the ATEs for girls. Columns (1) and (4) do not include any control variables, columns (2) and (5) control for learning weeks and class size, while columns (3) and (6) further control for school-level variables (average GPA of ninth graders, fraction of students born abroad, fraction of students for which both parents were born abroad, average level of parental education, and schools without grades 7-9). Cluster-robust standard errors clustered at the class (school when also including school-level controls) level are displayed in parentheses. Asterisks indicate significance, where $(* * *, p<0.01),(* *, p<0.05)$ and $(*, p<0.1)$. 


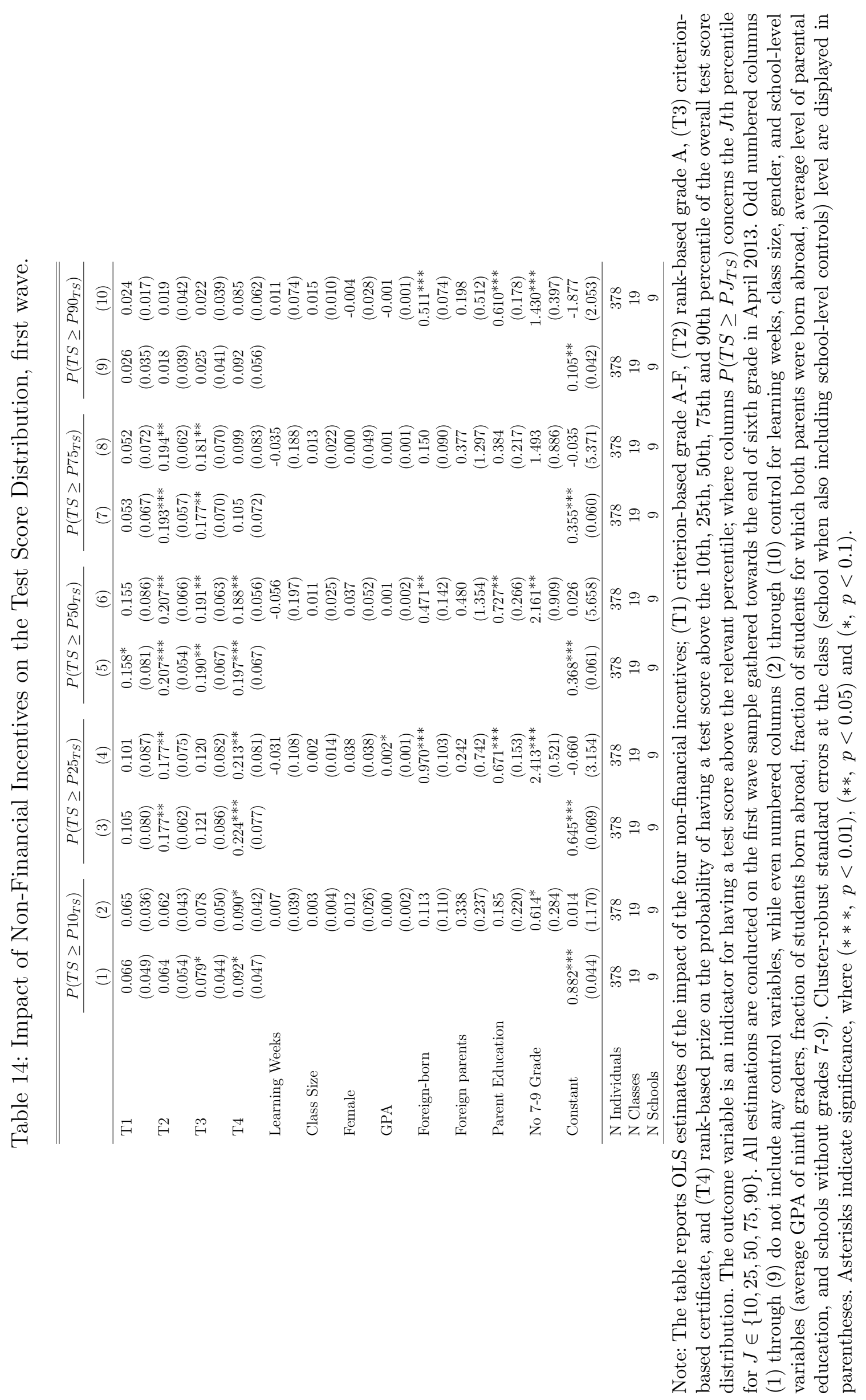




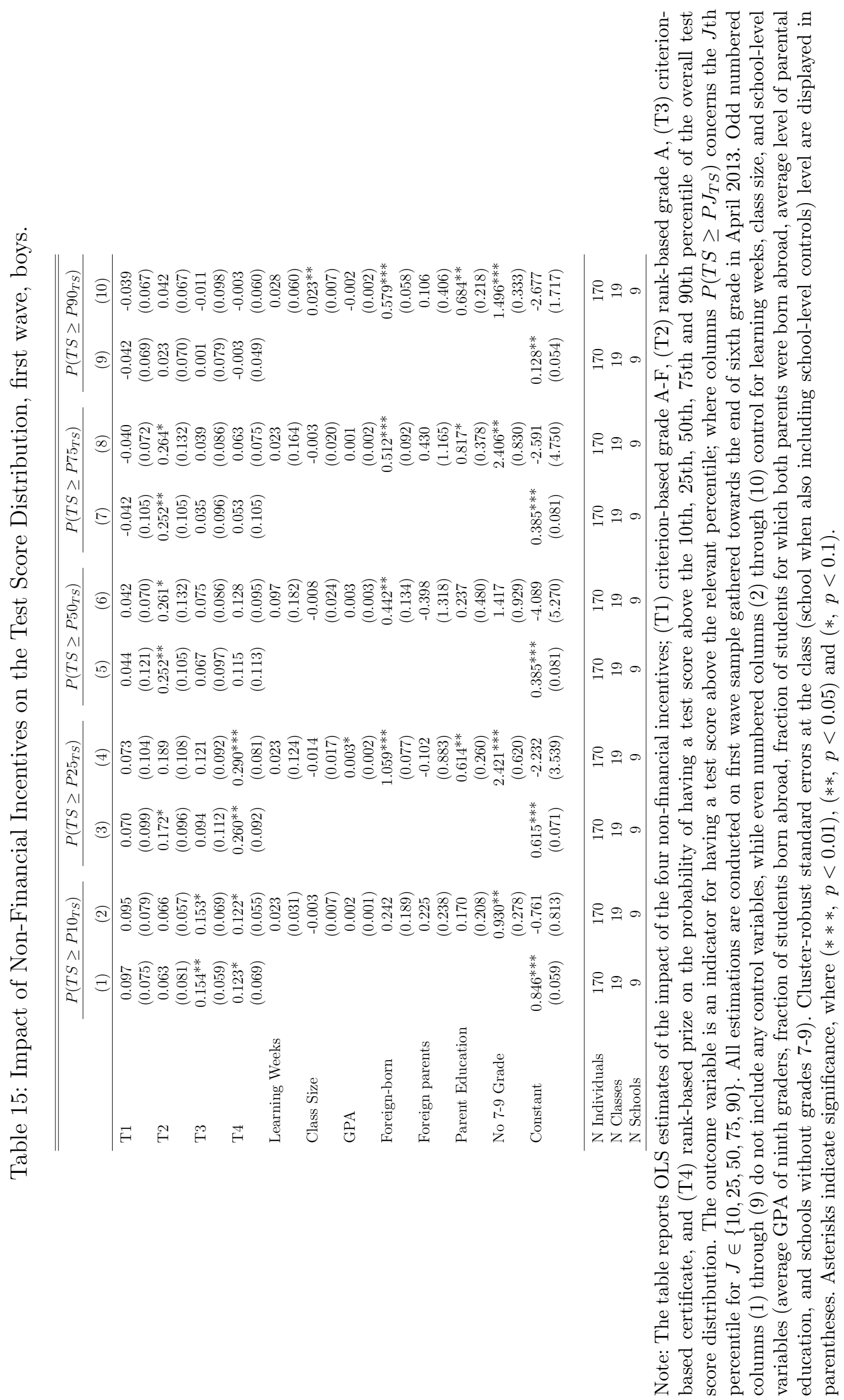




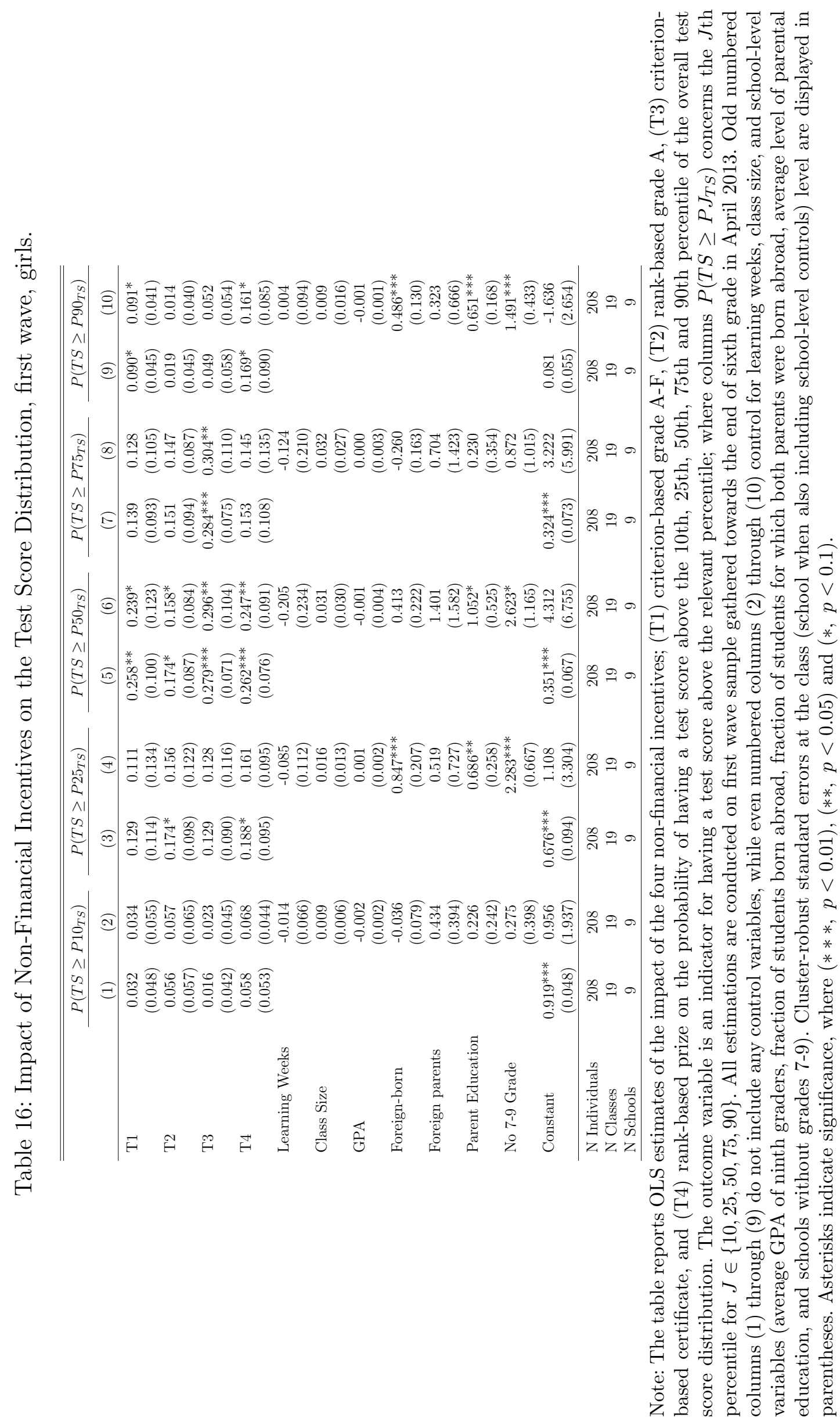




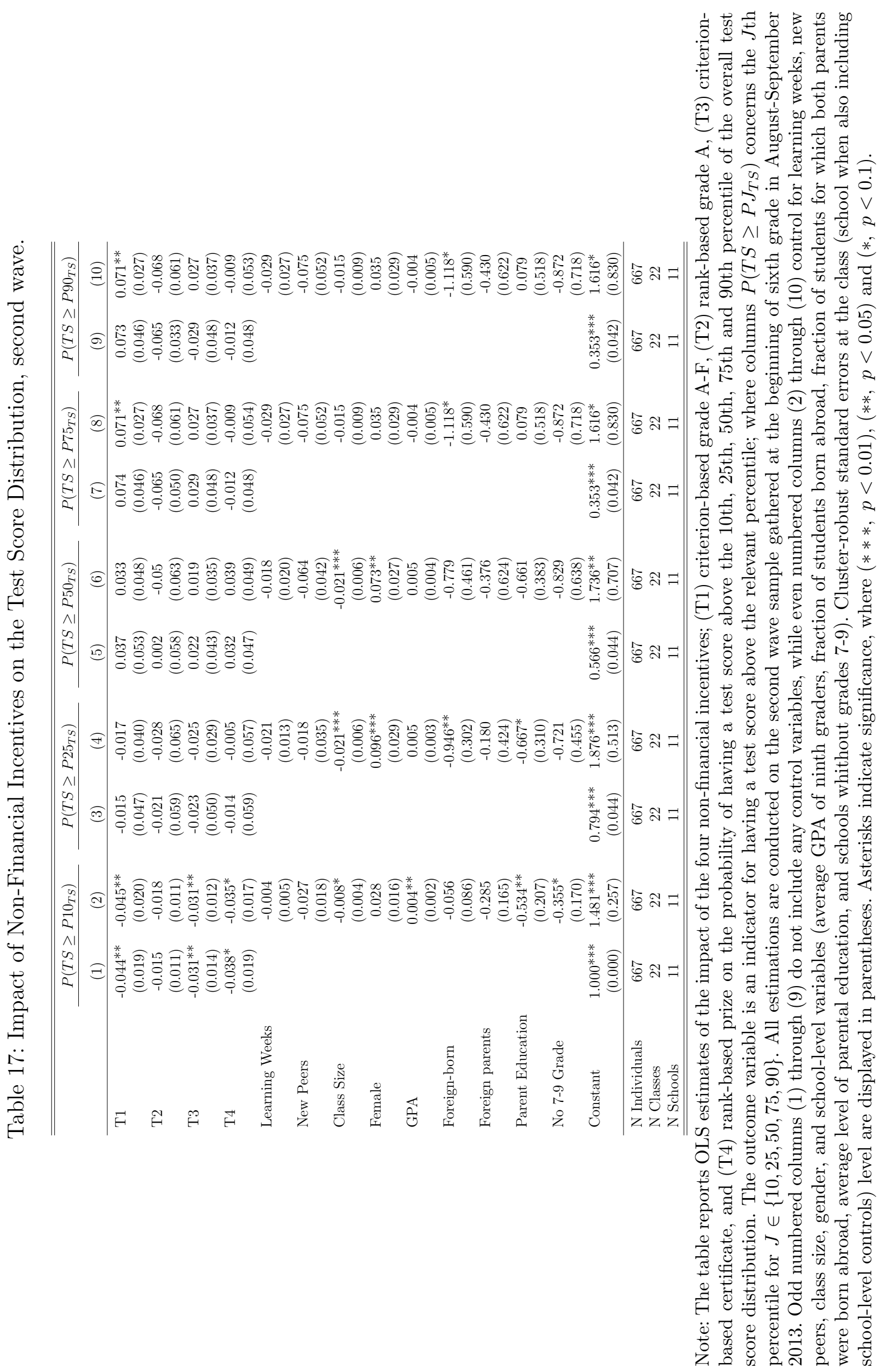


Table 18: Impact of Non-Financial Incentives on Test Scores.

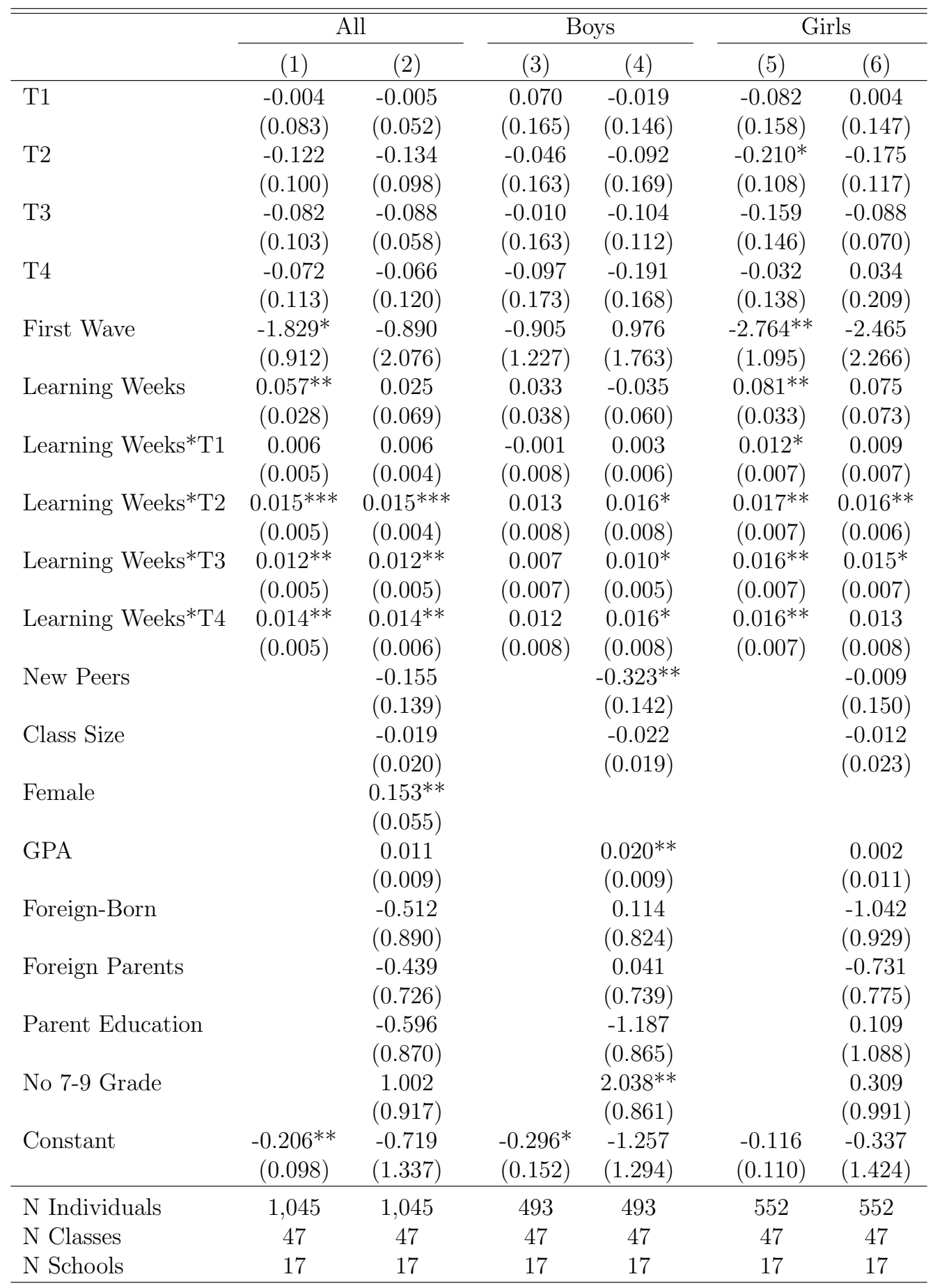

Note: The table reports OLS estimates of the ATE on test performance of four non-financial incentives; (T1) criterion-based grade A-F, (T2) rank-based grade A, (T3) criterion-based certificate, and (T4) rank-based prize. The outcome variable is test scores, standardized to mean 0 and standard deviation 1 . All estimations are conducted on the full sample; including the first wave conducted towards the end of sixth grade in April 2013 and the second wave conducted at the beginning of sixth grade in August-September 2013. ATEs are displayed for all students, and separately by gender; columns (1) and (2) show the ATEs for all students, columns (3) and (4) show the ATEs for boys, while columns (5) and (6) show the ATEs for girls. Columns (1), (3) and (5) control for wave, learning weeks, and interactions between learning weeks and T1-T4, while columns (2), (4) and (6) also control for new peers, class size, gender, and school-level variables (average GPA of ninth graders, fraction of students born abroad, fraction of students for which both parents were born abroad, average level of parental education, and schools without grades 7-9). Cluster-robust standard errors clustered at the class (school when also including school-level controls) level are displayed in parentheses. Asterisks indicate significance, where $(* * *, p<0.01)$, $(* *, p<0.05)$ and $(*, p<0.1)$. 
Table 19: Impact of Non-Financial Incentives on Test Scores.

\begin{tabular}{|c|c|c|c|c|c|c|}
\hline & \multicolumn{2}{|c|}{ All } & \multicolumn{2}{|c|}{ Boys } & \multicolumn{2}{|c|}{ Girls } \\
\hline & (1) & $(2)$ & (3) & (4) & (5) & (6) \\
\hline \multirow[t]{2}{*}{$\mathrm{T} 1$} & 0.074 & 0.078 & 0.018 & -0.006 & 0.121 & 0.150 \\
\hline & $(0.084)$ & $(0.069)$ & $(0.130)$ & $(0.105)$ & $(0.128)$ & $(0.119)$ \\
\hline \multirow[t]{2}{*}{$\mathrm{T} 2$} & 0.142 & 0.152 & 0.182 & 0.198 & 0.102 & 0.126 \\
\hline & $(0.100)$ & $(0.133)$ & $(0.141)$ & $(0.184)$ & $(0.125)$ & $(0.135)$ \\
\hline \multirow[t]{2}{*}{ T3 } & 0.140 & 0.143 & 0.126 & 0.093 & 0.143 & 0.187 \\
\hline & $(0.097)$ & $(0.100)$ & $(0.121)$ & $(0.114)$ & $(0.121)$ & $(0.122)$ \\
\hline \multirow[t]{2}{*}{$\mathrm{T} 4$} & $0.215^{* *}$ & $0.221^{* *}$ & 0.092 & 0.070 & $0.322^{* * *}$ & $0.345^{* * *}$ \\
\hline & $(0.097)$ & $(0.095)$ & $(0.131)$ & $(0.139)$ & $(0.113)$ & $(0.109)$ \\
\hline \multirow[t]{2}{*}{ First Wave } & $0.244^{*}$ & -0.978 & $0.239^{*}$ & 0.827 & 0.235 & -2.477 \\
\hline & $(0.123)$ & $(2.064)$ & $(0.126)$ & $(1.837)$ & $(0.144)$ & $(2.198)$ \\
\hline \multirow[t]{2}{*}{ New Peers } & -0.023 & 0.073 & -0.263 & -0.180 & 0.199 & 0.281 \\
\hline & $(0.143)$ & $(0.154)$ & $(0.169)$ & $(0.198)$ & $(0.203)$ & $(0.196)$ \\
\hline \multirow[t]{2}{*}{ New Peers*T1 } & 0.013 & 0.008 & 0.185 & 0.161 & -0.132 & -0.105 \\
\hline & $(0.145)$ & $(0.084)$ & $(0.329)$ & $(0.235)$ & $(0.302)$ & $(0.288)$ \\
\hline \multirow[t]{2}{*}{ New Peers*T2 } & $-0.348^{*}$ & $-0.370 * *$ & -0.321 & -0.351 & $-0.413^{* * *}$ & $-0.415^{* * *}$ \\
\hline & $(0.181)$ & $(0.158)$ & $(0.319)$ & $(0.315)$ & $(0.148)$ & $(0.135)$ \\
\hline \multirow[t]{2}{*}{ New Peers*T3 } & -0.300 & $-0.299^{*}$ & -0.227 & -0.256 & -0.339 & $-0.301^{*}$ \\
\hline & $(0.189)$ & $(0.154)$ & $(0.341)$ & $(0.239)$ & $(0.244)$ & $(0.151)$ \\
\hline \multirow[t]{2}{*}{ New Peers*T4 } & $-0.477^{* *}$ & $-0.477^{* * *}$ & -0.210 & -0.222 & $-0.696 * * *$ & $-0.678^{* *}$ \\
\hline & $(0.212)$ & $(0.144)$ & $(0.389)$ & $(0.373)$ & $(0.239)$ & $(0.254)$ \\
\hline \multirow[t]{2}{*}{ Learning Weeks } & & 0.037 & & -0.022 & & 0.086 \\
\hline & & $(0.068)$ & & $(0.061)$ & & $(0.072)$ \\
\hline \multirow[t]{2}{*}{ Class Size } & & -0.019 & & -0.022 & & -0.013 \\
\hline & & $(0.020)$ & & $(0.020)$ & & $(0.023)$ \\
\hline \multirow[t]{2}{*}{ Female } & & $0.156^{* * *}$ & & & & \\
\hline & & $(0.052)$ & & & & \\
\hline \multirow[t]{2}{*}{ GPA } & & 0.011 & & $0.019^{* *}$ & & 0.003 \\
\hline & & $(0.009)$ & & $(0.008)$ & & $(0.010)$ \\
\hline \multirow[t]{2}{*}{ Foreign-Born } & & -0.482 & & 0.034 & & -0.920 \\
\hline & & $(0.890)$ & & $(0.841)$ & & $(0.910)$ \\
\hline \multirow[t]{2}{*}{ Foreign Parents } & & -0.470 & & 0.141 & & -0.821 \\
\hline & & $(0.738)$ & & $(0.763)$ & & $(0.754)$ \\
\hline \multirow[t]{2}{*}{ Parent Education } & & -0.618 & & -1.098 & & 0.016 \\
\hline & & $(0.866)$ & & $(0.798)$ & & $(1.036)$ \\
\hline \multirow[t]{2}{*}{ No 7-9 Grade } & & 1.020 & & $2.047^{* *}$ & & 0.391 \\
\hline & & $(0.916)$ & & $(0.869)$ & & $(0.986)$ \\
\hline \multirow[t]{2}{*}{ Constant } & -0.156 & -0.908 & -0.191 & -1.428 & -0.116 & -0.598 \\
\hline & $(0.098)$ & $(1.337)$ & $(0.117)$ & $(1.287)$ & $(0.115)$ & $(1.413)$ \\
\hline N Individuals & 1,045 & 1,045 & 493 & 493 & 552 & 552 \\
\hline N Classes & 47 & 47 & 47 & 47 & 47 & 47 \\
\hline N Schools & 17 & 17 & 17 & 17 & 17 & 17 \\
\hline
\end{tabular}

Note: The table reports OLS estimates of the ATE on test performance of four non-financial incentives; (T1) criterion-based grade A-F, (T2) rank-based grade A, (T3) criterion-based certificate, and (T4) rank-based prize. The outcome variable is test scores, standardized to mean 0 and standard deviation 1 . All estimations are conducted on the full sample; including the first wave conducted towards the end of sixth grade in April 2013 and the second wave conducted at the beginning of sixth grade in August-September 2013. ATEs are displayed for all students, and separately by gender; columns (1) and (2) show the ATEs for all students, columns (3) and (4) show the ATEs for boys, while columns (5) and (6) show the ATEs for girls. Columns (1), (3) and (5) control for wave, new peers, and interactions between new peers and T1-T4, while columns (2), (4) and (6) also control for learning weeks, class size, gender, and school-level variables (average GPA of ninth graders, fraction of students born abroad, fraction of students for which both parents were born abroad, average level of parental education, and schools without grades 7-9). Cluster-robust standard errors clustered at the class (school when also including school-level controls) level are displayed in parentheses. Asterisks indicate significance, where $(* * *, p<0.01)$, $(* *, p<0.05)$ and $(*, p<0.1)$. 


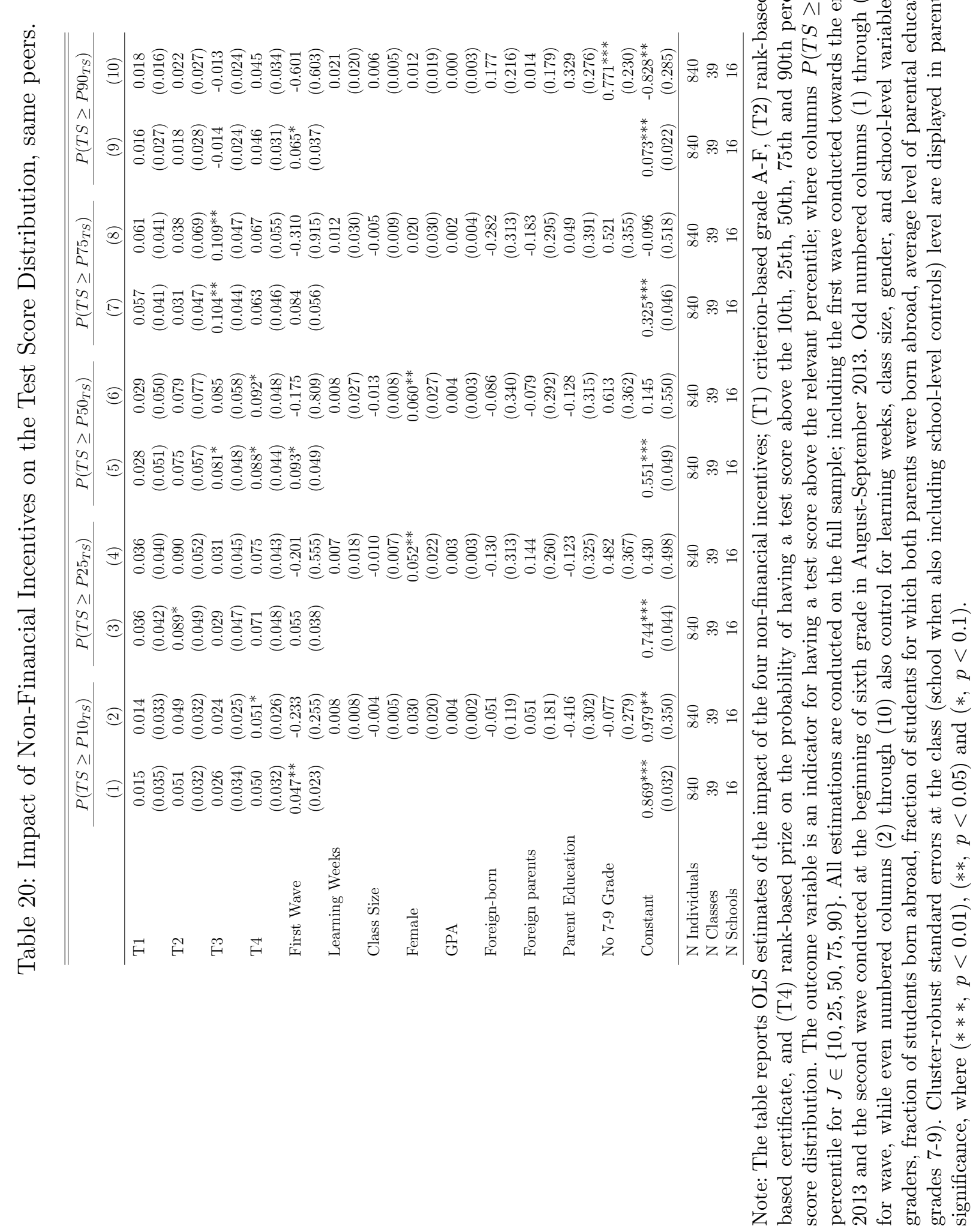




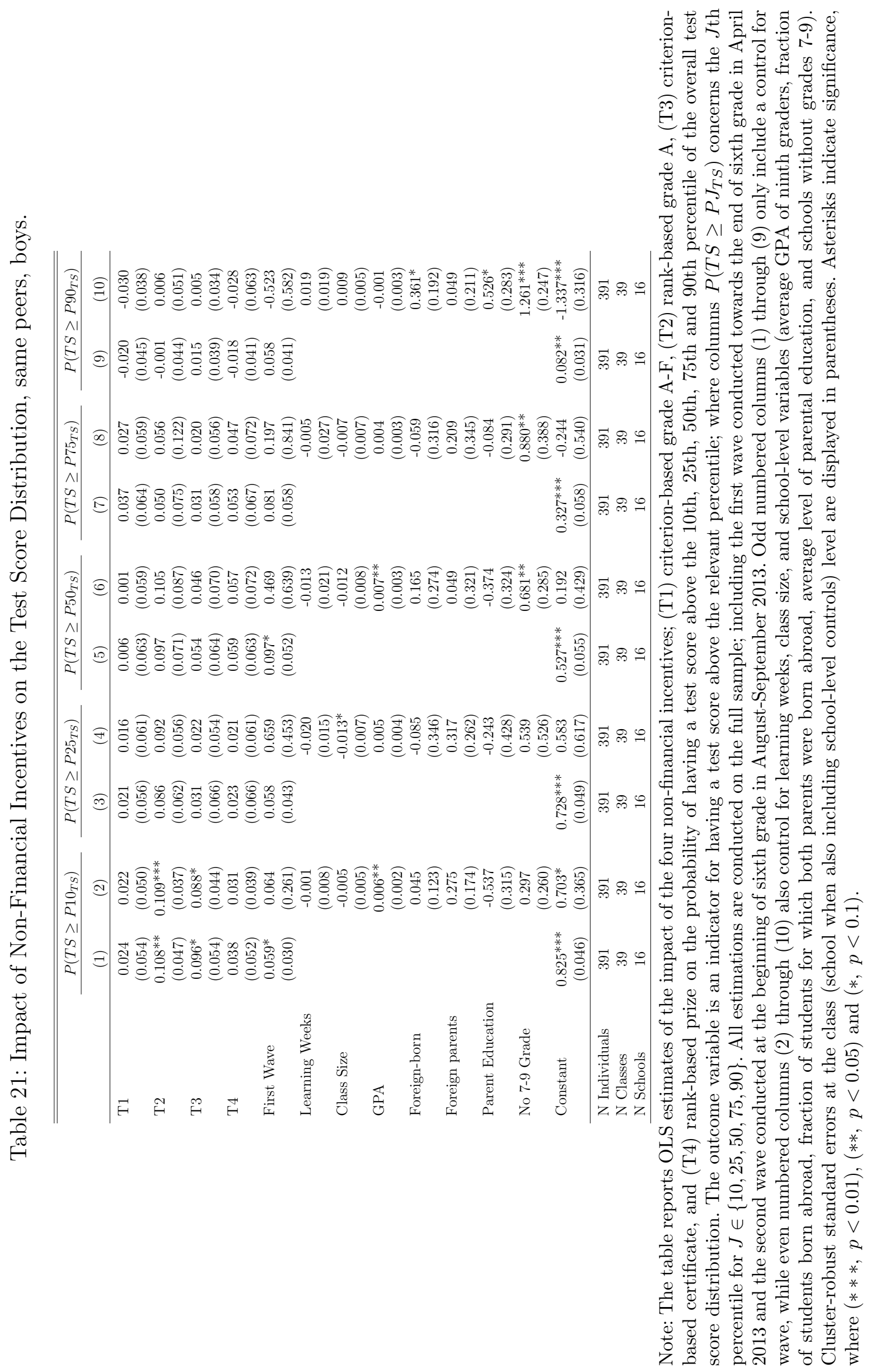




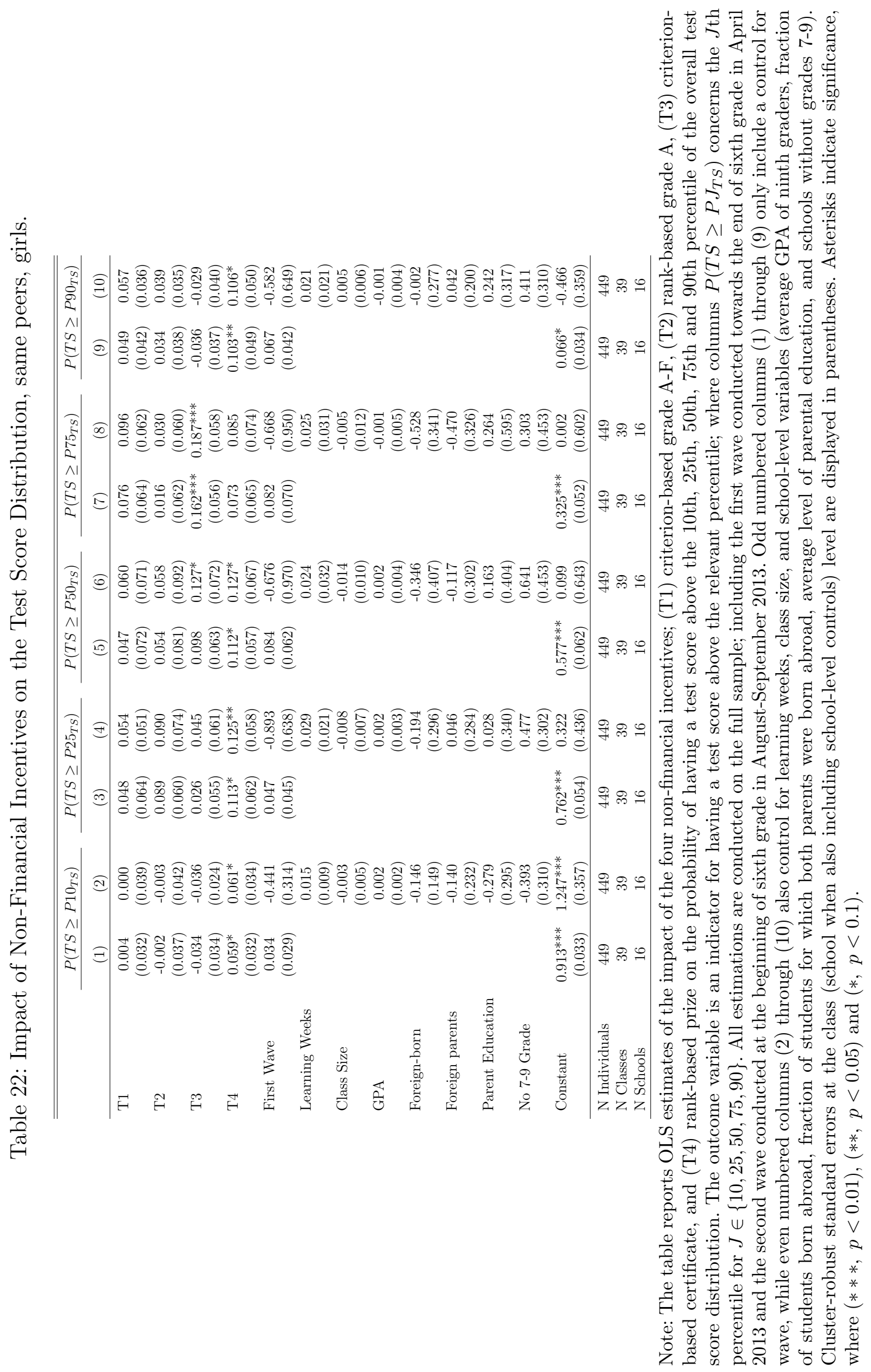

